DE92 009508

\title{
Energy Analysis Program 1990 Annual Report
}

\author{
Mark D. Levine, Program Leader
}

Applied Science Division Lawrence Berkeley Laboratory University of California

Berkeley, California 94720

(510) 486-5001 
Hashem Akbari

Feng Ant

Barbara Atkinson

Celina Atkinson

Jessie Audette

Ross Baldick

Douglas Berman

Stanley Boghosian

Betty Bratton

James Bull

John Busch

Stephen Byrne

Charles Campbell

Elizabeth Carlassaref

Peter Chan

Terry Chan

Peilin Chent

Mark Christensen

Stephen Christieł

Samuel Cohen

Deborah Connell

Caron Cooper

Christopher Craig

Paul Craig

William Davisł

Odón de Buen

Kari Dolan

Donna Doll-Nishiyama

Camille Donaldson $\ddagger$

Peter Duerr

Susan Ellis

Joseph Eto

Anthony Fisher

Ted Gartner

Gilberto Gengat

Gloria Gill

Peter Goering

Charles Goldman

Nina Goldman

Kathleen Greeley

William Hanemann

James Hanfordif

Jeffrey Harris*

Dorothy Harvey

Richard Howarth

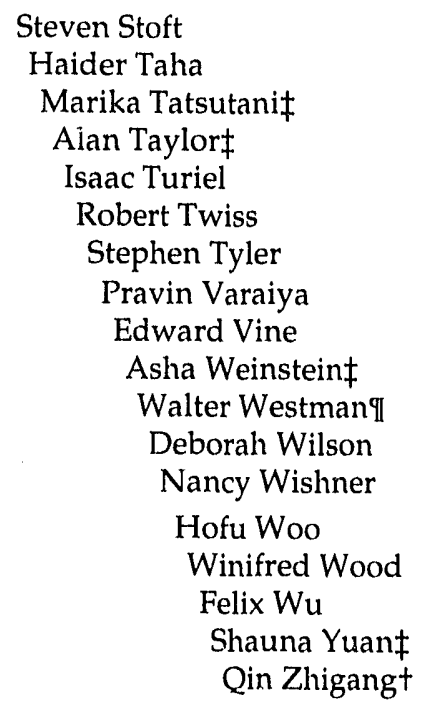

*Group Leader

'Participating Guest

‡Student Assistant

§Acting Group Leader

TIDeceased
Yu J. Huang

Hwangt

And ${ }^{*}$

onathan Koomey

Florentin Krause

Susan Krouscup

Martin Landsfeld

Benoit Lebot

ly Leef

James Lutz

Willy Makundi

Chris Marnay

Omar Masera

Andrew McAllister $\ddagger$

C. Bartlett McGuire

Elizabeth McGuire

James McMahon

Alan Meier§

Stephen Meyers

Sandra Mocco

Mithra Moezzi

Bruce Nordman

Richard Norgaard

Karen Olson

Shmuel Oren

Fredrick Patterson $\ddagger$

Mary Ann Piette

Huimin Qin

Leo Rainer

John Randolph

Robin Roecker $\ddagger$

Gregory Rosenquist

Marc Ross

David Sailor

Jayant Sathaye*

Leon Schipper*

Winardi Setiawan $\ddagger$

Agah Sezgen

Claudia Sheinbaum $†$

Jonathan Sinton $\ddagger$

Reneé Slonek

Anne Spruntf

Ruth Steiner 


\section{BUILDING ENERGY ANALYSIS}

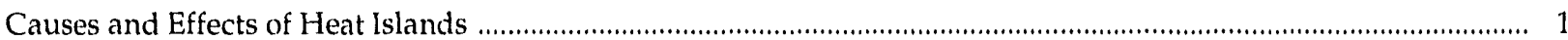

Cooling Our Communities: A Guidebook on Tree Planting and Light-Colored Surfaces ........................................ 2

Analysis of Energy Use in Building Services in California's Industrial Sector ................................................... 3

Commercial Load Shape and End-Use Intensities for College Campuses, Health Facilities,

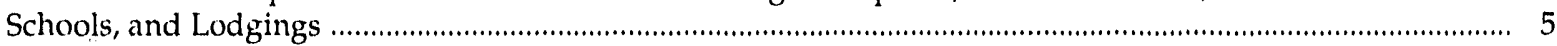

481 Prototypical Commercial Buildings for 20 Urban Market Areas ….......................................................... 6

The Energy and Comfort Performance of Evaporative Coolers for Buildings in California Climates ................... 7

Analysis of Energy Conservation Codes in Single-Family Buildings ............................................................... 8

Opportunities for Energy Efficiency Improvements in HUD-Assisted Housing ................................................ 9

\section{BUILDING ENERGY DATA}

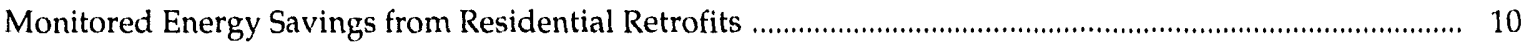

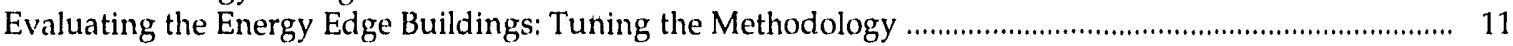

Measured Air-Conditioning Savings from Vegetative Landscaping ...................................................... 13

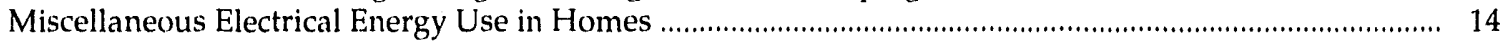

Building Code Compliance and Enforcement: San Francisco's Residential

Energy Conservation Ordinance and California's Building Standards ......................................... 15

\section{ENERGY CONSERVATION POLIC):}

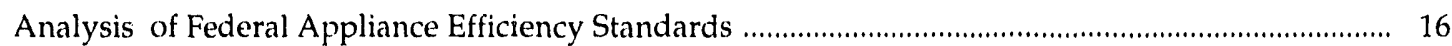

Engineering Analyses of Appliance Efficiency Improvements ................................................. 17

Assessing the Impacts of Appliance Standards on Manufacturers .............................................. 18

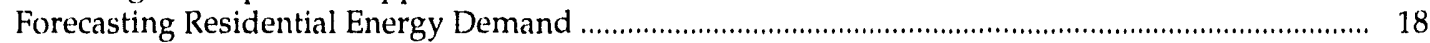

The Potential for Efficiency Improvements in Residential Buildings by the Year 2010 ..................... 19

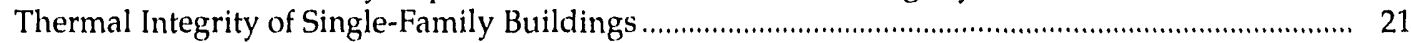

\section{GLOBAL ENERGY/ENVIRONMENTAL ISSUES}

Remote Monitoring of Effects of Climatic Change on Vegetation ......................................... 22

The Role and Impact of Energy Efficiency in Developing Countries and Eastern Europe ......... 23

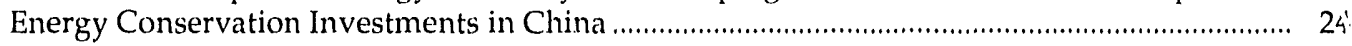

An Overview of China's Energy System .......................................................................... 25

Building Energy Use and Conservation Opportunities in Commercial Buildings in

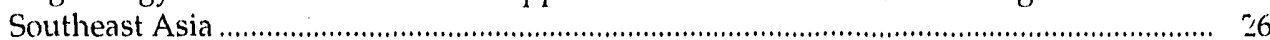

Conservation Potentials in the Building Sector in Pakistan ............................................. 27

\section{INTERNATIONAL ENERGY STUDIES}

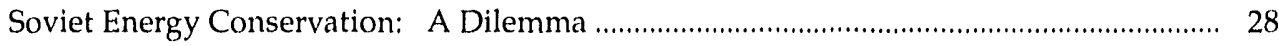

Energy Efficiency in Japan: Myths and Reality ......................................................... 29

Changes in Energy Use for Passenger Travel in Major Industrialized

Countries, 1970-1987.

Energy Savings in Industrialized Countries Since 1973:

Achievements and Prospects ................................................................. 31

Changes in Energy Use, 1973-1987: An Overview for Three Countries ....................... 33

Improving Appliance Efficiency in Indonesia ..................................................... 34

Energy Efficiency and Household Electric Appliances in Developing Countries ....... 35 
Oil Use in the Developing Countries: Statistical Analysis and Long-Term Scenarios 36

Urban Energy Use: Saturation and Fuel Transition in the Developing Countries .....

Long-Term Energy Scenarios for the Developing Countries

Residential Energy Use and Conservation in Venezuela

Tropical Forestry and Global Climate Change

Electricity Consumption and Structural Change in the Manufacturing Sector in Developing Countries

\section{UTILITY PLANNING AND POLICY}

Integrated Resource Planning 43

Auctions for Dispatchable Power

Incentives for Utility Demand-Side Management

Integrating Environmental Externalities in Utility Resource Planning.

Demand-Side Bidding: Assessing Current Experience 


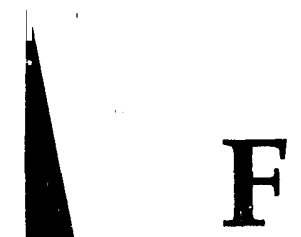

or most of the 1980s in the United States, energy and environmental issues were considered less important than a wide range of other public policy issues. This perception has changed as the nation enters the 1990s. Energy and the environment are at the forefront of many agendas: at the national level, Congress and the Department of Energy have discussed comprehensive energy legislation for the first time in more than ten years; at the state level, state government programs actively encourage energy efficiency, many more active public utility regulatory commissions have emerged; utilities are promoting demand-side programs to increase profits in several key states on both the East and West Coasts; and other local agencies have also become involved. For the first time, energy issues are an important element of the international agenda as well: a framework convention on greenhouse gas emissions is currently being negotiated.

The Energy Analysis Program has played an active role in the analysis and discussion of energy and environmental issues at several levels:

- at the international level, the Program has been serving as the key analytic team developing scenarios for long-term energy demand in developing countries (for the U.S. Environmental Protection Agency);

- also at the international level, the Program organized and led an analytic effort, "Energy Efficiency, Developing Countries, and Eastern Europe," part of a major effort to increase support for energy efficiency programs worldwide;

- at the national level, the Program has been responsible for assessing energy forecasts and policies affecting energy use (e.g., appliance standards, National Energy Strategy scenarios);

- at the state and utility levels, the Program has been a leader in promoting integrated resource utility planning; the collaborative process has led to agreement on a new generation of utility demand-side programs in California, providing an opportunity to use knowledge and analytic techniques of the I'rogram's researchers.

The past year has seen a continuation of our research emphases as well as some important new initiatives. We continue to place highest emphasis on analyzing energy efficiency, with particular attention given to energy use in buildings. The Program continues its active analysis of international energy issues in Asia (including China), the Soviet Union, South America, and Western Europe. Analyzing the costs and benefits of different levels of standards for residential appliances continues to be the largest single area of research within the Program, although increases in federal support for integrated utility resource planning may in time cause the analysis of utility issues to become our largest analytic activity.

One new initiative has come to fruition during the past year: the development and application of techniques for forecasting energy demand (or constructing scenarios) for the United States. We have built a new model of industrial energy demand, are in the process of making major changes in our tools for forecasting residential energy demand, have built an extensive and documented energy conservation supply curve of residential energy use, and are beginning an analysis of energy-demand forecasting for commercial buildings. 'Two new initiatives are on the agenda for future years: energy assistance for-and collaboration with-developing countries and the establishment of a comprehensive research program on environmental aspects of energy development and use.

Overall, 1990 has been a year of increasing Program activity and expansion. We anticipate continued expansion over the next several years. 


\section{- Building Energy Analysis}

\section{Causes and Effects of Heat Islands}

\section{H. Taha, H. Akbari, D. Sailor, and R. Ritschard}

Cities are typically warmer than their suburban rural areas, a phenomenon known as the heat island. Mid- and low-latitude urban heat islands can significantly increase city-wide summer cooling loads. In most warm/hot U.S. cities, an increase of $1^{\circ} \mathrm{C}$ in urban temperature causes an increase of $2-3 \%$ on electric utility system load. Our findings indicate that about $10 \%$ of the cooling load in these cities is caused solely by the heat island effect.

We study the causal elements of heat islands, their interactions, and the sensitivity of urban temperatures to variations in each parameter. These elements include the effective values of urban albedo, vegetative cover, emissivity, anthropogenic (man-made) heat, roughness, mixing height, building density, soil moisture, and atmospheric humidity. Anthropogenic heat, an element often ignored in previous work, is investigated in terms of ground transportation, building operation, and power plant sources.

We use boundary layer models to simulate the climate

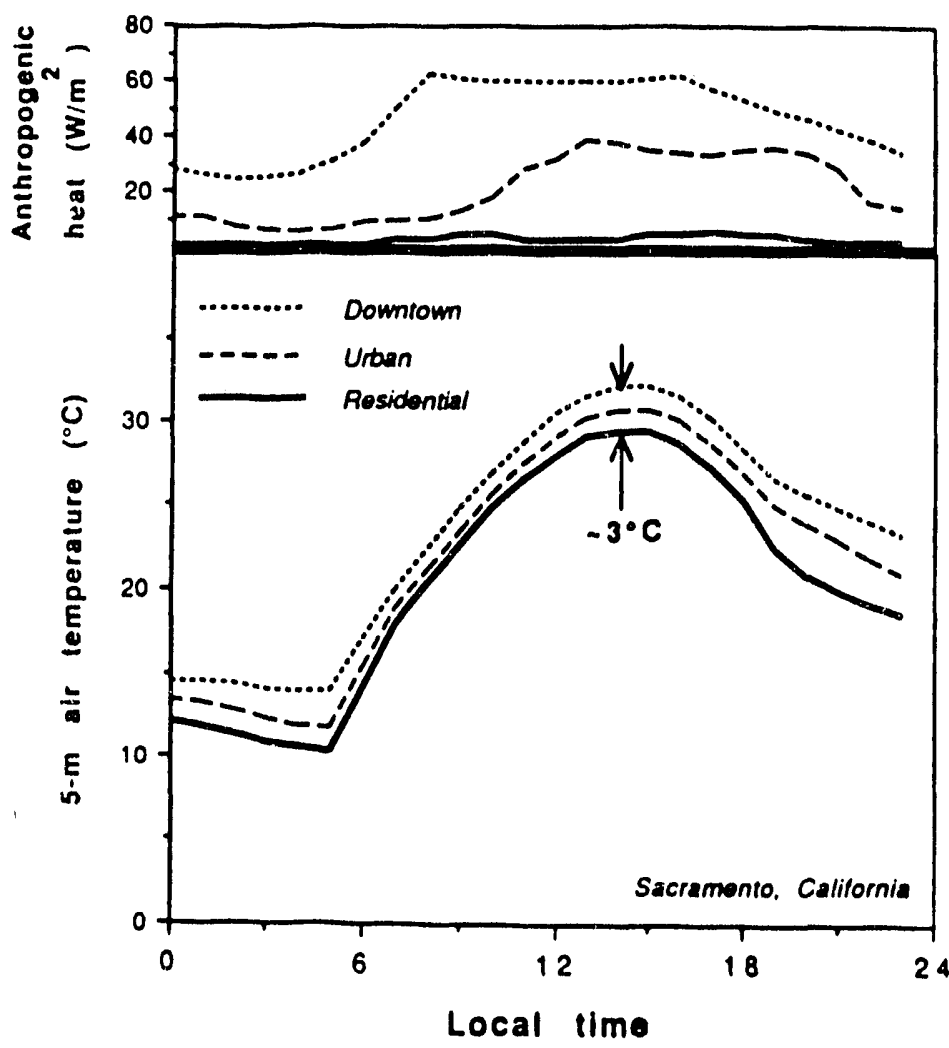

modifications and to estimate the sensitivity of urban temperature to variations in the physical characteristics of the urban surface and changes in the rate of anthropogenic heat rejection. We complement our climate predictions with DOE2.1D building energy simulations to analyze the associated changes in building energy use.

Our simulations indicate that urban temperatures are strongly dependent on urban albedo, on evapotranspiration from vegetated surfaces, and on winds, but not on anthropogenic heat and building density. We quantify the effects of each of these variables on microclimate and show that they have a significant impact on building energy use. Our preliminary results for Sacramento indicate that the effects of anthropogenic heat on heating and cooling energies are negligible in residential neighborhoods. In denser urban areas, however, the effects of anthropogenic heat on residential energy use amount to a $22 \%$ savings in heating gas and a $36 \%$ increase in cooling electricity. In downtown areas, the savings in heating become $40 \%$ and the penalty in cooling amounts to $76 \%$.

We plan to integrate climate models of different domains, i.e., canopy and urban boundary layers, to produce more comprehensive results. The models will also be modified to incorporate the processes we are interested in.

\section{References}

Taha H, Akbari H, Sailor D, Ritschard R. Causes and Effects of Heat Islands: The Sensitivity of Urban Microclimates to Surface Parameters and Anthropogenic Heat. Lawrence Berkeley Laboratory Report LBL-29864, 1990.

Taha H. An Urban Microclimate Model for Site-Specific Building Energy Simulation: Boundary Layers, Urban Camyon, and Building Conditions. Lawrence Berkeley Laboratory Report LBL-29630, 1990.
Figure. Hypothetical rates of anthropogenic heat release and their corresponding simulated impacts on urban air temperature at $5 \mathrm{~m}$ above street level. Simulations are for Sacramento, California, on August 1. 


\section{Cooling Our Communities:}

A Guidebook on Tree Planting and Light-Colored Surfaces

\author{
Y.J. Hunng, S.E. Daris, H. Akbari, and H. Taha
}

Most cities throughout the world reside in heat islands with noticeably higher temperatures than their surrounding countrysides (Figure). This phenomenon is a moderate asset during the winter but in the summer heat islands increase airconditioning usage, exacerbate pollution and smog, and add to human discomfort.

The summer heat island is caused primarily by manmade alterations to the urban landscape that have changed its thermal response to solar radiation. Urban landscapes have high thermal mass, increased surface roughness, reduced evapotranspiration from the replacement of vegetation by hard impermeable surfaces, and lowered albedo the ability to reflect incoming radiation through the use of darkcolored building materials. These properties combine to make urban temperatures hotter by 2 and $9^{\circ} \mathrm{F}$ depending on the time of day. City planners and developers have not considered the negative effects of summer heat islands on a city's energy use and environment even though analysis shows that the added cooling demand in a city such as Los Angeles costs roughly $\$ 150,000$ an hour on hot summer afternoons.

LBL's Heat Island Project has written a guidebook for the control of summer heat islands which describes their causes and societal costs and explains how the use of trees and light-colored surfaces can mitigate their effects. The guidebook also describes the experiences of various existing city-wide tree-planting programs and gives tips on how to implement a successful program.

The guidebook is written in non-technical language and is targeted to government officials, utility planners, and others interested in addressing this community-wide energy and environmental issue. The book is scheduled for completion in mid-1991 and will be available from the U.S. Environmental Protection Agency and the California Electric Power Research Institut?.

\section{Reference}

Akbari H, Huang YJ, Davis SE, Eds. Cooling Our Conmmunities: Tree Planting and Light-Colored Surfaces Guidebook. Office of Policy, Planning, and Evaluation, U.S. Environmental Protection A.gency, 1991.

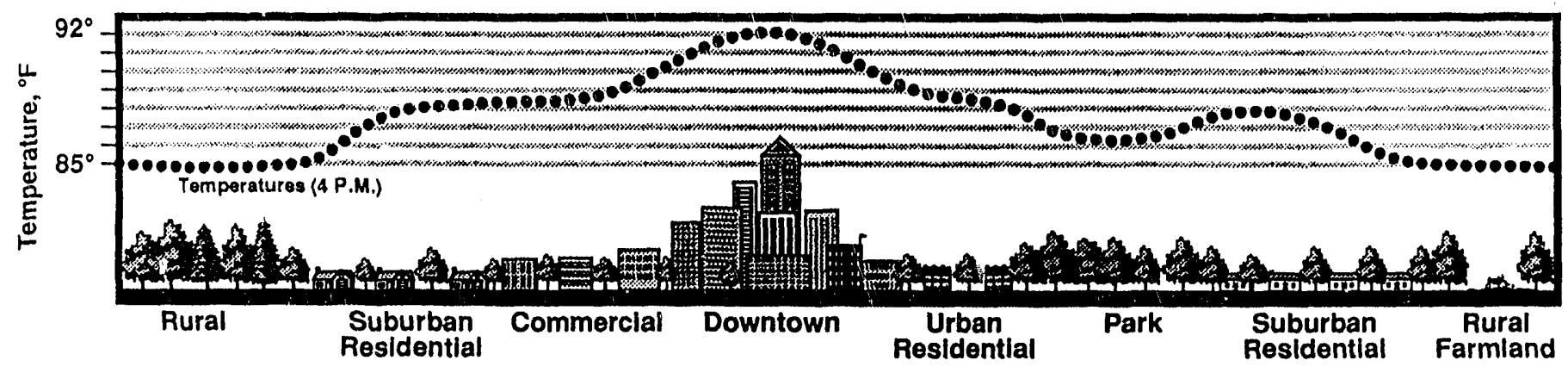

Figure. The heat island: Graph shows temperature changes in ${ }^{\circ} \mathrm{F}$ as the density of development and trees changes. (Source: Bruce Presentations, Washington, DC, 1990.) 


\title{
Analysis of Energy Use in Building Services in California's Industrial Sector
}

\author{
H. Akbari and O.A. Sezgen
}

Energy use patterns in many of California's fastest-growing industries are not typical of the existing mix of industries elsewhere in the United States. Many California firms operate small- and medium-sized facilities, often in buildings used simultaneously or interchangeably over time for commercial (office, retail, warehouse) and industrial activities. In these industrial subsectors, the energy required for "building services" to provide occupant necessities and comfort (lighting, HVAC, office equipment, computers, etc.) may be at least as important as the more familiar process energy requirements especially for electricity and on-peak demand.

In a recent study, we compiled and analyzed published and unpublished information on energy use for the building services in the industry sector. Seven different sources of information and data relevant to California have been identified. Most of these are studies and / or projects sponsored by the U.S. Department of Energy, the California Energy Commission (CEC), or local utilities. The objectives of these studies were diverse; most aimed at industrial energy use in general and in one case the objective was to analyze energy use in commercial buildings. Only one of these studies focused directly on non-process energy use in industrial buildings.

Comparison of the findings of these studies was difficult because of the varying objectives of the studies; the reported data format; the way data were aggregated; the different time periods covered by the data; and the varying coverage of the industries. The most relevant information for California came from two studies, one using data from the U.S. Census Bureau's Census of Manufacturers and the other using on-site survey information collected by the Pacific Gas and Electric Company (PG\&E) in Northern and Central California during 1981-1984. Despite the variety of objectives, all of the studies pointed to the importance of non-process energy use in industry as an area of potential conservation. The situation is even more promising for California where there is a concentration of industries such as instrument and computer manufacturing where most of the energy consumed is for air-conditioning and lighting.

One study approximated the building non-process energy use to be $15 \%$ of total industrial energy use for the United States, of which $84 \%$ was used for space heating, $8 \%$ for air-conditioning, and $8 \%$ for lighting. Another study estimated similar overall percentage $(15.5 \%)$ for industrial non-process energy use, but $17 \%$ of that went for lighting, $31 \%$ for airconditioning, ard $52 \%$ for space heating. Also, a national study for the manufacturing sector estimated that 17\% (in 1972) of purchased energy used in that sector went for space conditioning and lighting.

We further investigated these databases for California-specific data. Based on our analysis of the Northern California data for five selected industries, the contribution of total electricity consumption for lighting ranged from $9.5 \%$ in the frozen fruit industry to $29.1 \%$ in instruments. Airconditioning ranged from nonexistent in frozen fruits to $35 \%$ in instrument manufacturing. None of the five industries selected had significant electri . cal space heating. Gas space heating ranged from $5 \%$ in the motor vehicles facilities to more than $58 \%$ in the instrument manufacturing industry. 
We compared the data available from three California sources (Figure). Two of these sources provide end-use data only as percentages of total energy use, without specifying the total energy use. We therefore estimated the end-use energy intensities by proportionating the total consumption intensities obtained from the analysis of the PG\&E on-site survey by the percentage end-use figures provided by the other two stindies.

The findings of this research on the potential for energy efficiancy, conservation, and load-shaping opportunities in industry justifies a collaborative research program between the California utilities, CEC, the California Institute for Energy Efficiency, and DOE.

\section{Reference}

Akbari H, Borgers T, Gadgil A, Sezgen OA. Annlysis of Energy Use in Building Services of the Industrial Sector in Californin: A Literature Revicus and a Preliminary Characterization, Lawrence Berkeley Laboratory Report LBL-29749, 1990.

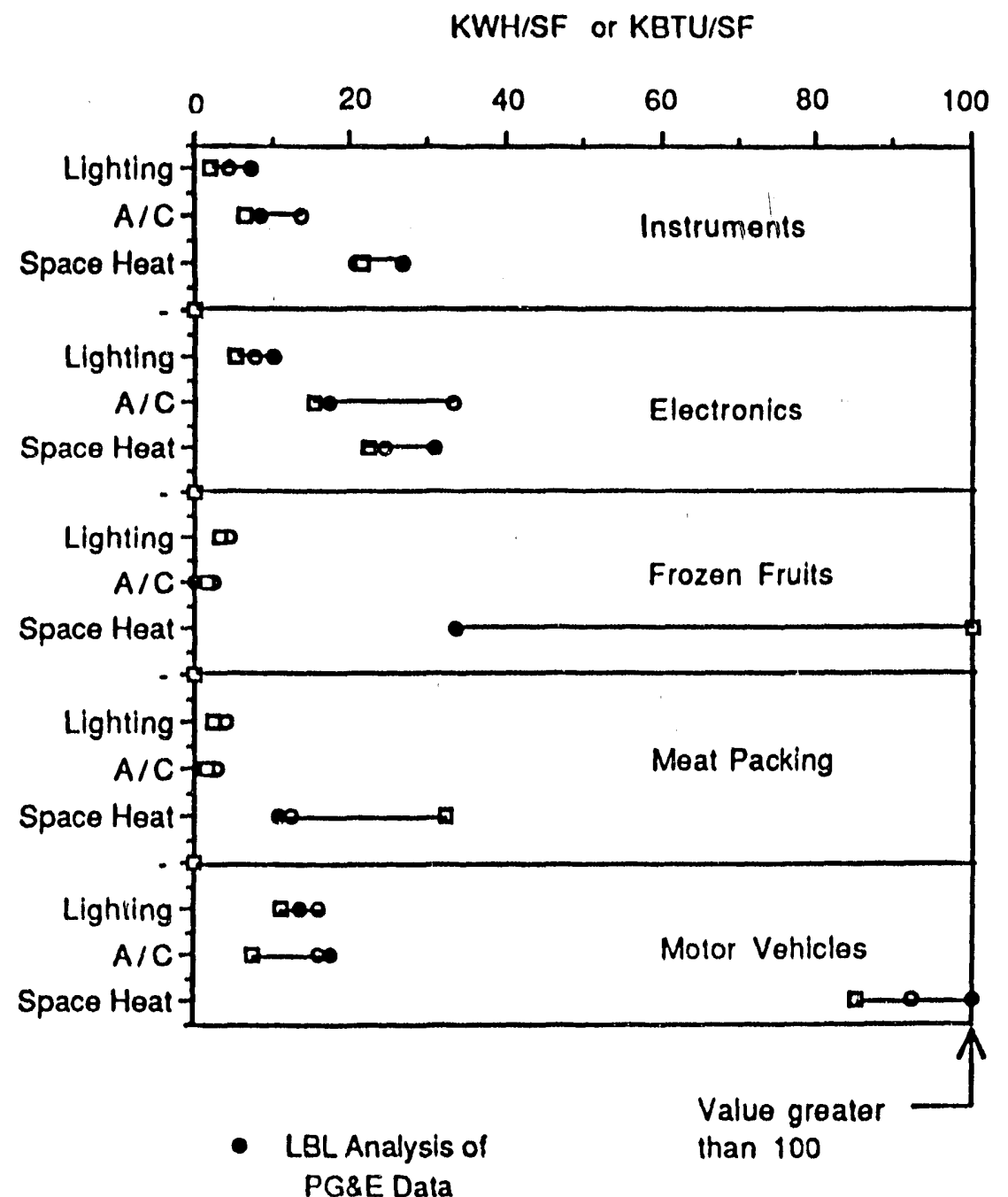

Figure. A comparison of the electricity and gas use intensities for building services in five selected industries in California. The electricity intensities are inkWh $/ \mathrm{ft}^{2} \mathrm{yr}$ and gas intensities are in $\mathrm{kBtu} / \mathrm{ft}^{2} \cdot \mathrm{yr}$.

\section{- Siudy A}

a Study B 


\section{Commercial Load Shape and End-Use Intensities for College Campuses, Health Facilities, Schools, and Lodging}

\author{
H. Akbari, J. Eto, and L. Rainer
}

This study, sponsored by the California Energy Commission (CEC), focused on the application of a new end-use load shape estimation technique and the development of a database of commercial sector end-use load shapes and enduse intensities (EUIs). The database will be used by CEC's commercial energy and peak load forecasting models. The technique relied on a unique reconciliation of whole-building hourly electricity load data to energy simulations, which were developed from detailed survey data. The outcome of the project was a set of reconciled load shapes for eight end uses in four building types that were then indexed for three building vintage and technology combinations. The building types studied were schools, college campuses, health facilities, and lodging. We focused primarily on electrical end uses including cooling, ventilation, lighting, cooking, refrigeration, water heating, hospital equipment, and miscellaneous equipment. The hourly load shapes were aggregated to produce twelve monthly load shapes for three day types (peak, standard, and non-standard) and integrated to produce annual EUIs.

The Table summarizes the initial and reconciled EUIs for the four building types. The cooling and ventilation EUIs are averages for four Southern California climate zones; the study generated individual EUIs for each of four climate zones-coastal, inland, desert, and valley.

\section{References}

Akbari H, Eto J, Turiel I, Heinemeier K, Lebot B, Nordman B, Rainer L. Integrated Estimation of Commercial Sector End-Ulse Load Shapes and Energy Lise Intensities. Lawrence Berkeley Laboratory Report LBL-27512 Rev., 1989.

Akbari H, Rainer L, Eto J. Integrated Estimation of Commercial Sector End-Use Load Shapes and Energy Use Intensities, Phase II. Lawrence Berkeley Laboratory Report LBL-30401, 1991.

Table. Initial and Reconciled EUIs (kWh/ $\left.\mathrm{ft}^{2} \cdot \mathrm{yr}\right)$

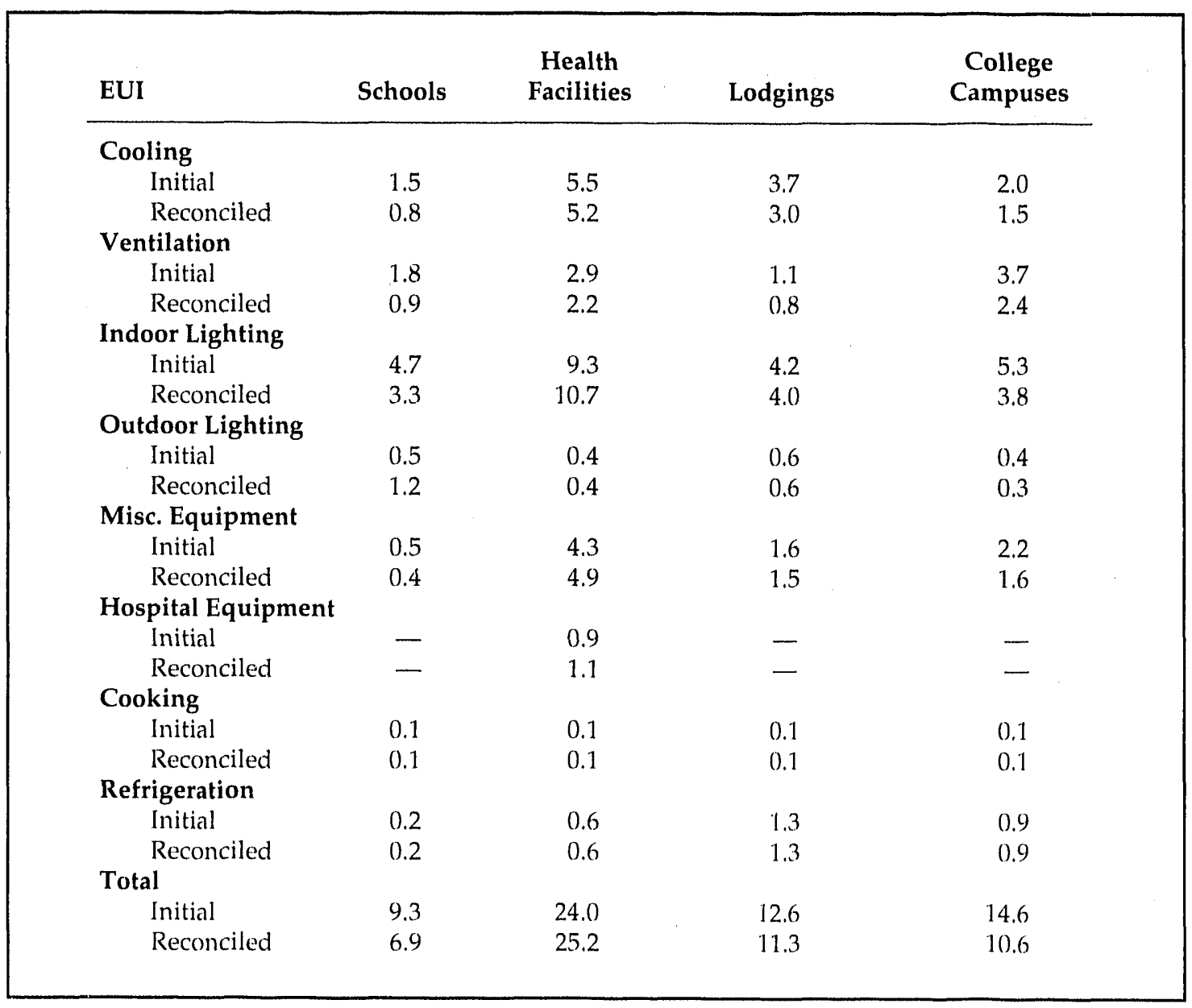




\section{Prototypical Commercial Buildings for 20 Urban Market Areas}

\section{Y.J. Huang, H. Akbari, L. Rainer, and R.L. Ritschard}

LBL has developed building load shapes and energy use intensities of commercial and multifamily buildings as part of a Gas Research Institute (GRI) project to assess the cogeneration potential for these types of buildings in 20 city markets. LBL's role in the project was to characterize the building stock in the cities by 1) estimating the number and sizes of buildings by class type, location, vintage, and equipment, 2) developing prototypical buildings for each category, and 3 ) performing DOE-2 computer simulations for these buildings.

The first task required extensive analysis of building stock data such as those from F.W. Dodge, DOE's Energy Information Administration Agency, as well as sectorspecific data for hospitals and schools. The second task required further analysis of the same data sources to determine average building and energy use characteristics and was combined with a review of 20 engineering studies from across the nation. The final building descriptions included physical dimensions, shell construction, zoning, equipment configuration, and hourly energy use profiles disaggregated by major end-uses, e.g., lighting, hot water. An iterative procedure was used to calibrate the energy uses of these prototypes against the measured energy use data for each of the building sectors.

The total number of prototypical buildings simulated was 481 and included hospitals, schools, prisons, hotels, restaurants, offices, supermarkets, apartments, and retail stores. The completed database is available from GRI in electronic format and consists of: 1) DOE-2 input files, 2) output files with the hourly building

Figure. Thermal/electric ratios binned against thermal loads for a prototypical existing hospital in Chicago. loads (heating, total and latent cooling), electricity use (airconditioning and non-air-conditioning), outdoor temperatures and humidities, and 3) a Fortran computer program that permits users to extract monthly totals, peak loads, and loads binned by hour-of-day or outdoor conditions. The Figure shows the hourly data for a prototypical old hospital in Chicago separated into two-dimensional bins. The bar heights indicate the number of hours within each bin.

\section{Reference}

Huang YJ, Akbari H, Rainer L, Ritschard RL. 481 Prototypical Commercial Buildings for 20 Urban Market Arens (Technical documentation of building loads database developed for the GRI Cogeneration Market Assessment Model). Lawrence Berkeley Laboratory Report LBL29798, 1990.

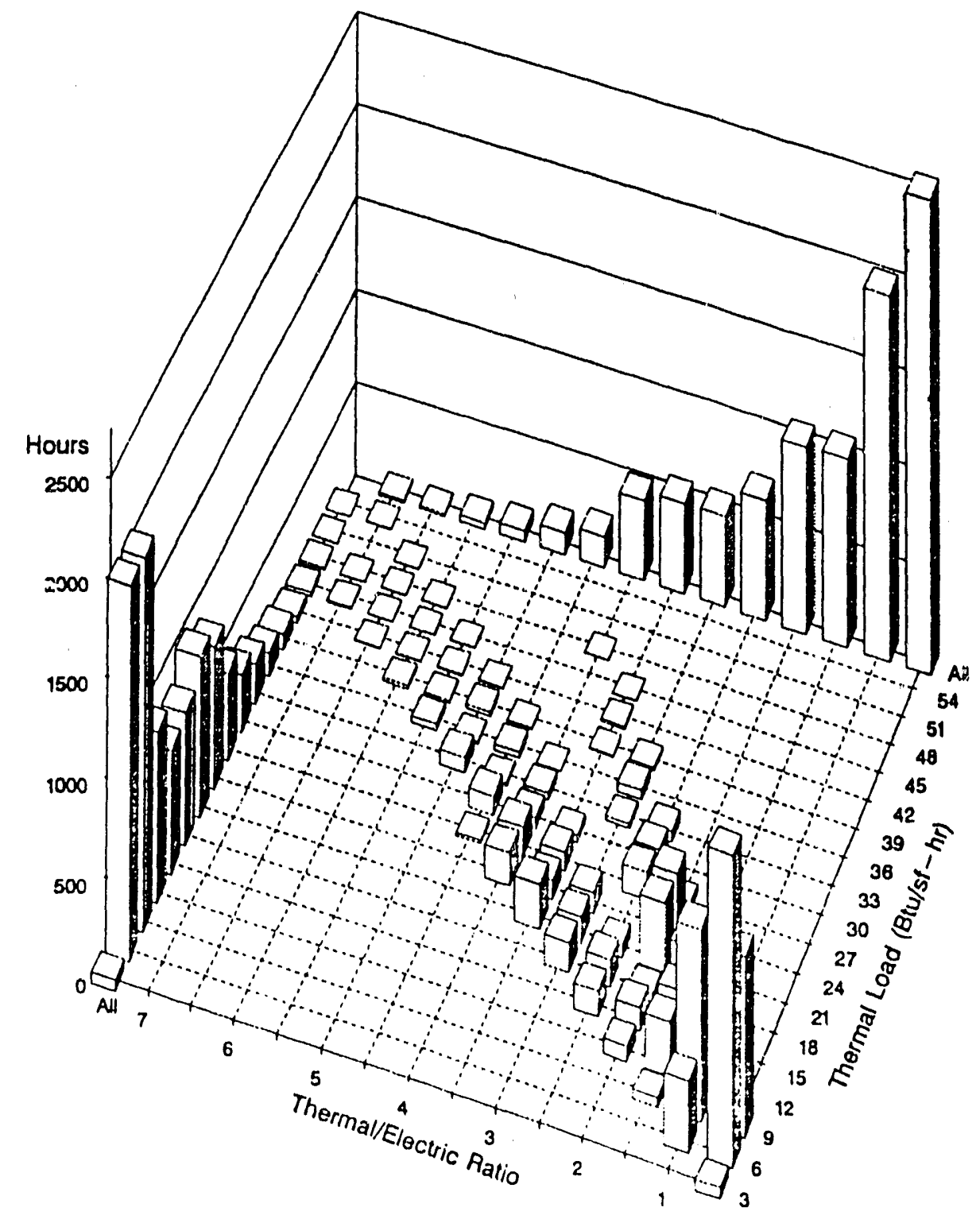




\section{The Energy and Comfort Performance of Evaporative Coolers for Buildings in California Climates}

\author{
Y.J. Huang, H.F. Wu, P.L.Chen, H.M. Qin, and \\ J.W. Hanford
}

The use of evaporative coolers is an energy-conserving alternative to air-conditioning that is particularly suited to the semi-arid climates of California. Because evaporative coolers require power only to drive fans and pumps, they consume far less electricity than do air conditioners, but water consumption could be a concern in arid locations. Evaporative coolers also reduce indoor air quality problems since they use $100 \%$ outside air at high ventilation rites. In addition, evaporative coolers are environmentally benign since they do not use chlorofluorocarbons known to damage the ozone layer.

This project has been investigating the applicability of evaporative coolers in residences and small commercial
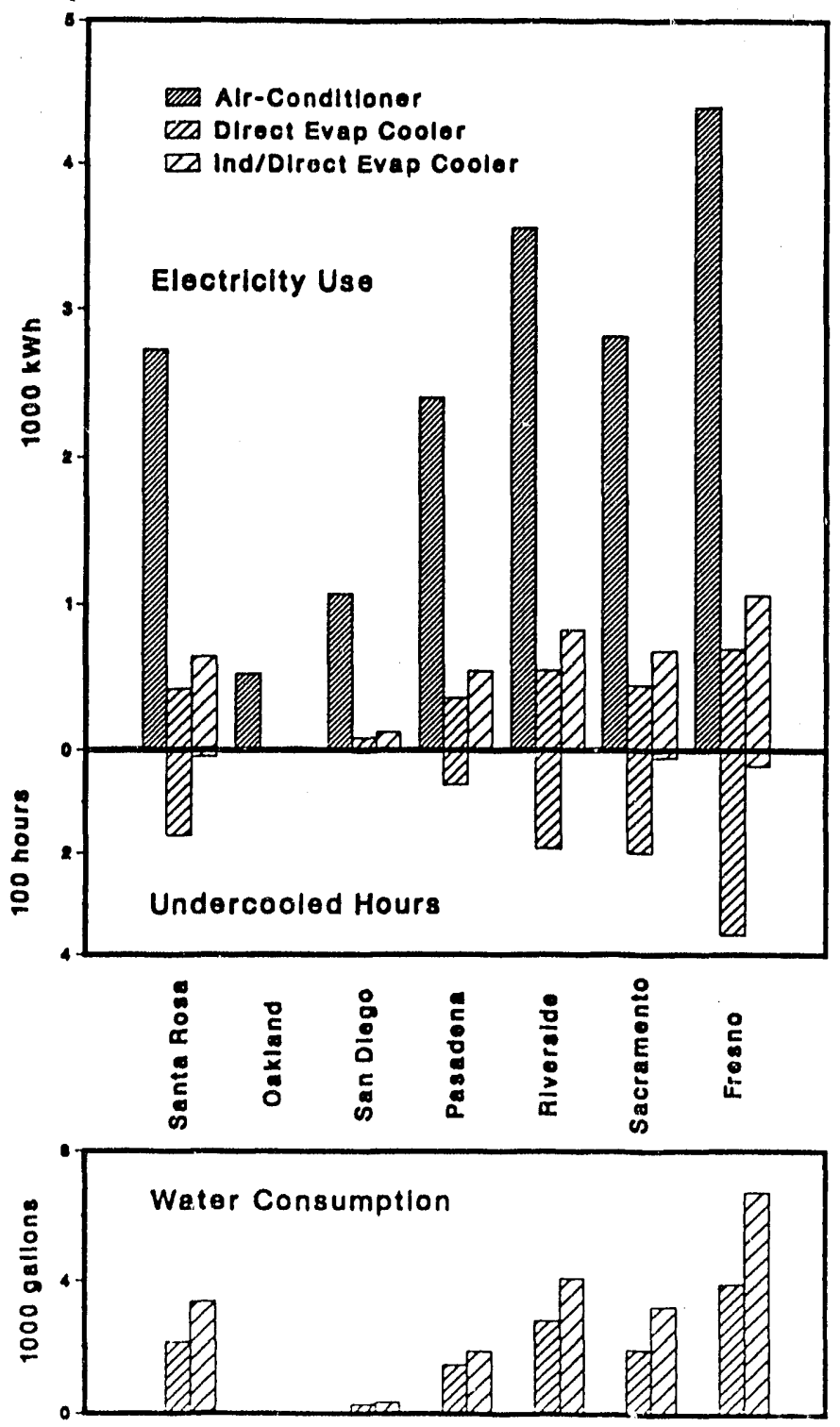

buildings in California. The engineering analysis was done by linking detailed numerical models for different evaporative cooler designs to the DOE-2 building energy simulation program, which was then used to calculate the energy and water consumption of, and the indoor conditions produced by, evaporative coolers in typical houses in various California climates. The analysis shows that direct evaporative coolers use less than $20 \%$ of the electricity of a standard air conditioner, but cannot provide adequate comfort during the hottest months in Sacramento or Fresno. More advanced two-stage indirect/direct coolers, however, are capable of maintaining indoor comfort while still consuming only $25 \%$ of the electricity of an air conditioner (Figure). The analysis also quantifies the amount of water needed for evaporative coolers, an issue which may be of concern in drought-plagued locations. Another objective of the engineering effort is to evaluate innovative configurations and control strategies that would either improve the effectiveness of evaporative coolers or extend their use to other climates, buildings, or HVAC systems.

In parallel with the engineering effort, the project is also conducting a survey of engineers, contractors, and manufacturers to determine the institutional and non-energy related engineering barriers that impede the proliferation of this old and yet newly revived cooling technology.

\section{References}

Chen PL, Qin HM, Huang YJ, Wu HF. A Heat and Mass Transfer Model for Thermal and Hydraulic Calculations of Indirect Evaporative Cooler Performance. Lawrence Berkeley Laboratory Report LBL-28201, 1991.

Huang YJ, Wu HF, Hanford JW, Chen PL, Qin HM. The Energy and Comfort Performance of Evaporatioc Coolers for Residentinl Buildings in Californin Climates. Lawrence Berkeley Laboratory Report LBL-29799, 1991.

Chen PL, Qin HM, Huang YJ, Wu HF, Blumstein C. Intproving the Performance of Indirect Evaporatine Coolcrs. Lawrence Berkeley Laboratory Report LBL29796, 1991.

Chen PL, Qin HM, Huang YJ, Wu HF, Blumstein C. The Encrgy Savings of Pre-Cooling Incoming Outdoor Air by Indirect Evaporative Cooling. Lawrence Berkeley Laboratory Report LBL-29797, 1991.
Figure. Comparison of evaporative cooler to air conditioner performance in severa! California climates. 


\section{Analysis of Energy Conservation Codes in Single-Family Buildings}

\section{R.L. Ritschard, J.W. Hanford, and O.A. Sezgen}

Within all 50 states, some form of code or standard for energy conservation in new building construction has been implemented. As part of a study for the Gas Research Institute, the impacts of two building codes, the Model Energy Code (MEC) of 1990 and the proposed ASHRAE 90.2 Standard were evaluated using DOE-2.1D model simulations of the 1990 single-family construction. In addition, appliance and equipment energy-related improvements mandated by the National Appliance Energy Conservation Act (NAECA) were also modeled and analyzed.

The study approach consisted of modeling 1990s prototypical houses in 16 U.S. locations without the code or standard requirements and then comparing these "base case" conditions to simulation results with improved insulation levels (thermal codes) under MEC or 1 SHRAE 90.2 and appliance or equipment efficiency changes as required by the NAECA. Comparisons to the MEC were made at seven locations. The simulations considered both heating and cooling energy consumption, includirig the effects of gas furnaces and electric air-conditioners with and without the code requirements.
The major conclusions for gas usage are that the ASHRAE 90.2 Standard is more effective in reducing space- and waterheating energy demand than the MEC in all but one location (Figure). In cold climates such as Minneapolis, Boston, New York, and Chicago, the ASHRAE Standard "'ii. reduce annual natural gas usage by about $25 \%$. The effects o appliance and equipment improvements, as designated in the NAECA, on gas heating are less than those of the thermal codes. The combination of the ASHRAE Standard and NAECA requirements provide the greatest annual heating savings (up to $36 \%)$.

The impacts of these codes on electricity usage are different from the gas results. The appliance and equipment improvements causes greater savings in cooling energy use $(11-18 \%)$ than those of the thermal codes $(1-10 \%)$. The ASHRAE Standard and MEC alone may increase electricity usage for cooling (by 5-11\%) in climates with little cooling demand (e.g., Minneapolis, Chicago, Boston). As with the heating energy use, the ASHRAF Standard plus requirements of the NAECA show the greatest savings (4-22\%) in cooling energy consumption. Similar savings (but lower, on average) are also found in three colder climates Minneapolis, Chicago, Boston.

\section{Leference}

Ritschard RL, Hanford JW, Sezgen OA. Analysis of Energy Conservation Codes in Single-Family Buildings.

Lawrence Berkeley Laboratory Report LBL-30376, 1991.

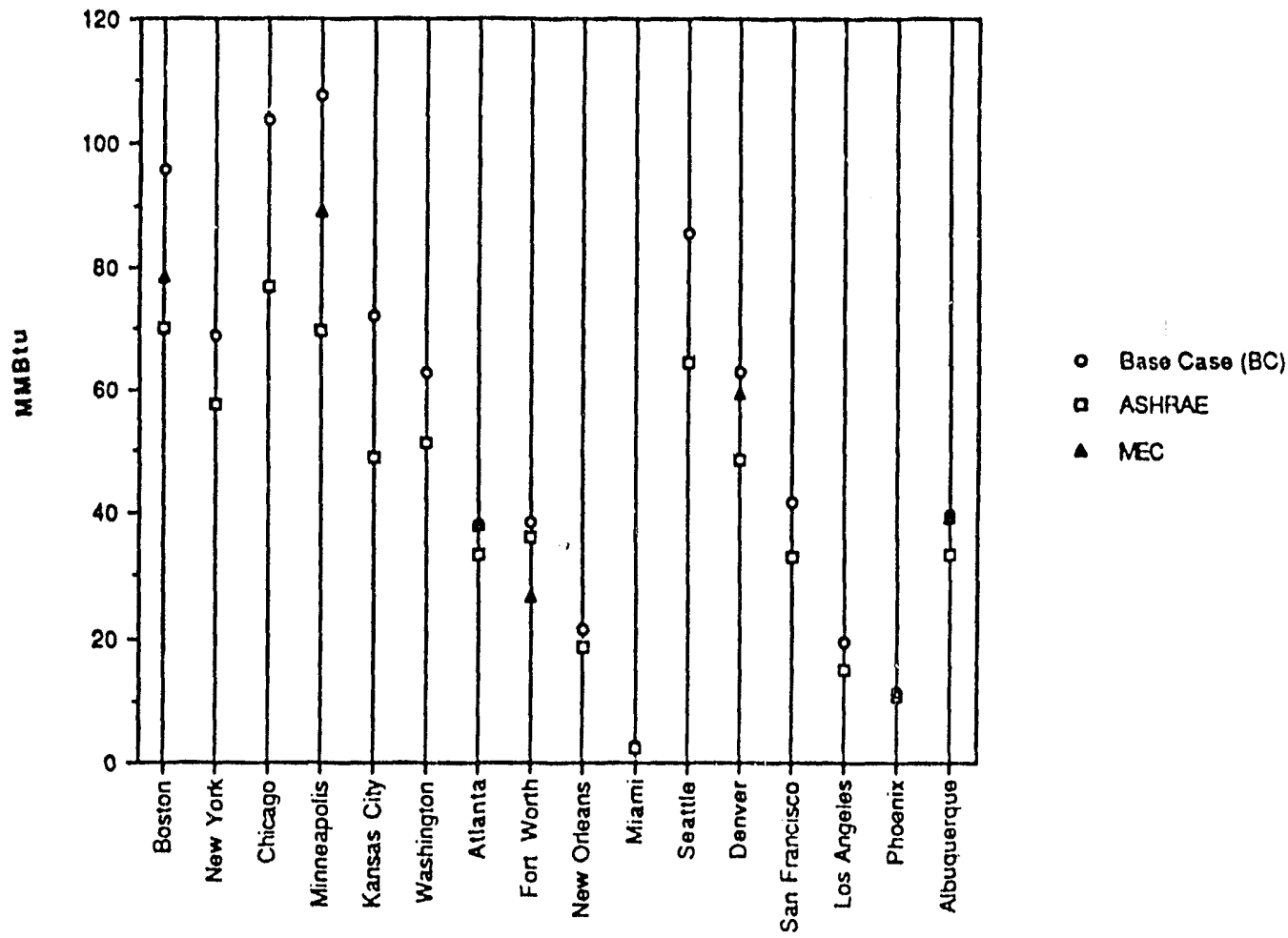

Figure. Gas heating energy recpuirement of two thermal coctes. 


\section{Opportunities for Energy Efficiency Improvements in HUD-Assisted Housing}

\section{R.L. Ritschard, R. Diamond, and J.A. McAllister}

One of the primary goals of the U.S. Department of Housing and Urban Development (HUD) is the expansion of home ownership and affordable housing opportunities. Recognizing that energy efficiency can play a significant role in an affordable housing strategy, HUD and DOE have recently established a DOE-HUD Initiative on Energy Efficiency. The goals of this multiyear program are to improve the energy efficiency of HUD-assisted housing in order to make it more affordable by applying existing technical information on energy efficiency, developed at DOE and other federal, state, and local public and private organizations, to HUD-assisted housing construction and retrofit activities. It is expected that the DOE-HUD initiative will lead to annual savings of 0.75 to 1.0 quad (quadrillion Btus) within the buildings sector after a 10-year implementation period.
The DOE-HUD initiative follows four strategic steps:

- prioritization of te rgeted HUD programs;

- development of technical linkages between DOE, HUD, and other private and public sector organizations;

- dissemination of information to personnel responsible for implementing HUD-funded programs; and

- revision of energy-related guidelines for certain HUD programs.

LBBL has been involved in studies of HUD's public housing since 1984 and has published 12 technical papers on this subject. A key research area identified in those studies was the effectiveness and persistence of energy savings from conservation measures installed in public housing. For example, in some cases energy savings decreased after the first post-retrofit year (Figure). As part of the DOE-HUD initiative, an extensive literature search on the persistence of energy savings was completed and a long-term research plan was prepared for implementation during the next few years. Other HUD programs that provide federal assistance to private investors, property owners, nonprofit corporations, and other organizations for low-income multifamily housingare also being studied. The multifamily work conducted during FY90 include the development of guidelines and handbooks on energy-related audits and retrofits of HUD-owned and HUD-insured multifamily buildings, provision of technical assistance on utility-sponsored retrofits to owners of Section 202 housing for elderly and handicapped tenants in the Northeastern United States, and preparation of an action plan that describes how the HUDassisted housing programs can be linked to state and local public and private sector energy conservation activities.
Figure. Persistence of savings for projects with multiple years of post-rctrofit data. Energy use increases after the first postretrofit year at the Trenton projects; energy savings are sustained through both postretrofit years at two of the three San Francisco projects. Other low-cost measures, including caulking and weather stripping, low-flow showerheads, and domestic hot water blankets, were also installed at the San Francisco projects. 


\section{- Building Energy Data}

\section{Monitored Energy Savings from Residential Retrofits}

\author{
S. Cohen, C. Goldman, and ). Harris
}

The Buildirg Energy Use Compilation and Analysis (BECA) project compares measured data on the energy savings and economics of retrofitting existing single-family homes. The compilation now includes 275 data points and represents more than 75,000 retrofitted houses. The first phase focused on individual retrofit measures. The following measures were found to be cost-effective: attic insulation, high-density cellulose wall insulation, flame retention burners, condensing furnaces, infiltration reduction guided by blower-doors, and low-cost water-heating conservation devices.

The second phase of the analysis focused on the effectiveness of energy conservation programs. The state-of-theart in weatherizing homes has improved dramatically in the last 15 years, in large part due to continued monitoring and program evaluation in a few cold-climate states. A national evaluation of the 1981 DOE Weatherization Assistance Pro. gram showed average savings of $14 \mathrm{MBtu}$ / year or $10 \%$ of the normalized annual consumption (NAC) (Table). The investments were not cost-effective because they had a cost of conserved energy (CCE) of $\$ 11 / \mathrm{MBtu}$ (compared to the average residential price of gas, $\$ 6 / \mathrm{MBtu}$ ).

More recent programs have been more successful. Twelve post-1980, state low-income weatherization programs showed median NAC savings of $12 \%$ and a median CCE of $\$ 6.80$ / MBtu. Moreover, these programs offer well-documented approaches for significant improvements in energy savings and cost-effectiveness of low-income weatherization. Recent demonstration programs in Michigan and Minnesota achieved $18 \%$ NAC savings with CCEs of $\$ 3.60 / \mathrm{MBtu}$ and $\$ 5.90 / \mathrm{MBtu}$, respectively, despite low levels of pre-retrofit consumption.

A Virginia pilot program demonstrated that mild-climate weatherization can also be cost-effective; it cut energy

Table. Savings and economics of low-income and utility weatherization programs.

\begin{tabular}{|c|c|c|c|c|c|}
\hline & \multirow{2}{*}{$\begin{array}{l}\text { No. of Retrofit } \\
\text { Programs } \\
\text { (No. of Homes) }\end{array}$} & \multicolumn{2}{|c|}{$\begin{array}{c}\text { Average } \\
\text { Energy Savings } \\
\text { of Space-Heat Fuel } \\
\text { (MBtu/yr) }\end{array}$} & \multirow{2}{*}{$\begin{array}{l}\text { Average } \\
\text { Cost } \\
(1989 \$)\end{array}$} & \multirow{2}{*}{$\begin{array}{c}\text { Average } \\
\text { CCE } \\
\text { (1989 \$/MBtu) }\end{array}$} \\
\hline & & MBtu/yr & $\%$ & & \\
\hline \multicolumn{6}{|l|}{ Low Income Weatherization } \\
\hline 1981 National & $1(965)$ & 14 & 10 & 1380 & 11.00 \\
\hline Post-1980 State Evaluations & $12(3,800))$ & & & & \\
\hline Median Value & & 19 & 12 & 1080 & 6.80 \\
\hline Range & & $7-23$ & $7-14$ & $810-2220$ & $5.30-16.00$ \\
\hline Optimal Weatherization Demo's & $4(490)$ & $24-45$ & - & $980-2560$ & $3.60-6.30$ \\
\hline Targeted High Users & $4(240)$ & $21-95$ & $9-25$ & $670-4040$ & $4.0(0-5.70$ \\
\hline \multicolumn{6}{|l|}{ Utility Weatherization } \\
\hline \multicolumn{6}{|l|}{ Gas Utilities } \\
\hline Pre-1980 Programs & $5(33,200)$ & $12-33$ & $6-21$ & $500-700$ & 1.8()$-4.40$ \\
\hline Post-1980 Programs & $5(16,800)$ & $5-33$ & $8-19$ & $570-38(0)$ & $5 .(0)-11.00)$ \\
\hline \multicolumn{6}{|l|}{ Electric (Pacific NW) } \\
\hline Median Value & $21(12,700)$ & $4020 \mathrm{kWh}$ & 16 & 2150 & $5.44 / \mathrm{kWh}$ \\
\hline Range & $20(12,400)$ & $2000-8600 \mathrm{kWh}$ & $8-26$ & 64()$-2800$ & $1-15 \mathrm{c} / \mathrm{kWh}$ \\
\hline
\end{tabular}


use $24 \mathrm{MBtu} /$ year ( $16 \%$ of $\mathrm{NAC}$ ) with a CCE of $\$ 4.50 / \mathrm{MBtu}$. This program emphasized wall and ceiling insulation and blower-foor guided sealing of the foundation area and attic bypasses. Most programs that weatherize manufactured homes typically attempt to use the same retrofits as for sitebuilt homes in spite of difterent construction materials and designs. Consequently, average savings are mucin lower than for site-built homes, while retrofit costs are comparable.

Over the last decade, an increasing number of electric and gas utilities have provided financial incentives and other services to their single-family residential customers. The first generation of gas conservation programs promoted attic insulation retrofits. More recent gas utility programs with measured data focused on low-income households. Retrofit costs are higher in these low-income programs because of an expansion in the list of measures, which include major equipment retrofits or replacements in cold-climate areas. For these programs, CCEs are typically $\$ 9-12 / \mathrm{MBtu}$. For 21 electric utility conservation programs in the Pacific Northwest which installed shell measures, median NAC savings were $16 \%$.
About $20 \%$ of the single-family data points in the BECA compilation include data on predicted as well as actual energy savings. The actual reductions in the electricity consumption of groups of participating homes were typically $63 \%$ of predicted estimates in eight weatherization programs sponsored by electric utilities, although the variance between predicted and actual savings was quite large among individual homes as well as for various weatherization programs.

\section{Reference}

Cohen S, Goldman C, Harris J. Mensured Energy Sorrings and Economics of Retrofitting Existing Single-Fanily Homes: An Lutatc of the BECA-B Dataluse'. Lawrence Berkeley Laboratory Report No. L.BL-28147 (1-2), February 1991.

\title{
Evaluating the Energy Edge Buildings: Tuning the Methodology
}

\author{
O. de Buen, R. Diamont, J. Harris, A. Meier, B. Nordman, and \\ M.A. Pictte
}

LBL is currently evaluating the performance of 28 new, energyefficient commercial buildings in the Pacific Northwest. These buildings, as part of the Bonneville Power Administration's Energy Edge Program, were built to reduce energy use by $30 \%$ beyond the proposed building standards. Our work focuses on evaluating the energy performance of the buildings and the cost and savings of individual measures.

Monitored performance data are being compared to the design-stage predictions and revised simulations calibrated to the recent energy use data. A pilot study was conducted to evaluate the process of calibrating (tuning) DOE-2 computer simulated end-use profiles with the monitored hourly data. This fine-tuning was found to be extremely time-consuming, so an alternative "quick-tune" strategy was developed to calibrate the simulation to the monitored monthly end-use totals (e.g., interior lighting, heating, ventilation). The difference in the energy savings from the conservation measures predicted by the two tuning methodologies was only $2 \%$ of the total energy consumption of the building. Six of the buildings have been quick-tuned, including the original pilot-study builiting (Figure) and the results look promising given the uncertainty in the assumptions in any modeling approach.

The Energy Edge Project has provided us with new insights into several aspects of commercial building performance, including construction, operation, and evaluation methods. Consistent commissioning procedures are needed during building start-up, and long-lorm tracking of efficiency measures are needed to ensure persistent savings. To improve the evaluation of conservation strategies there is a need for "standard costs" for individual measures, and alternatives to expensive end-use metering, such as short-term monitoring and diagnostic tests. Results from this work will be used in revising building codes and utility programs for the Pacific Northwest region. 


\section{References}

Diamond RC, Harris JP, de Buen O, Nordman B, Cody B. Evaluating Actual Performance of New Commercial Buildings: The Energy Edge Demonstration Program. In: Procedings of the ACEEE 1990 Summer Study on Encrgy Efficincy in Buildings, Alngust 26-Sept. 1, 1990). Washington, DC: American Council for an Energy Efficient Economy, 1990, pp. 3.77-3.89.
Harris JP, Diamond RC, de Buen O, Hatcher A, Nordman B, Piette MA. Energy Edge Impact Evnluntion: Findings and Recommendations from the Phase One Eunluation. Lawrence Berkeley Laboratory Report No. LBL-30358, 1990.

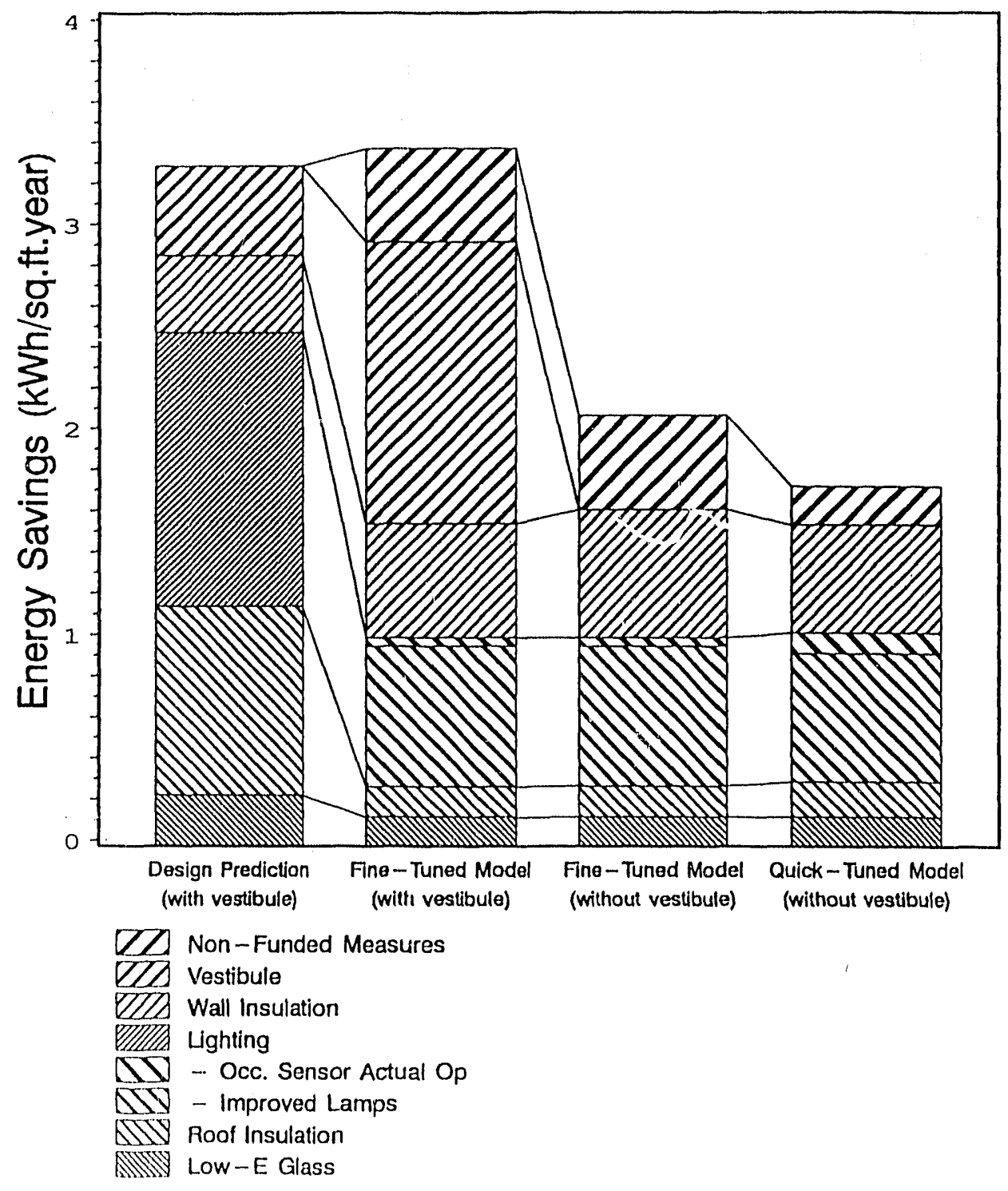

Figure. Savings from individual measures: Comparison between design-predicted model, fine-tuned, and quick-tuned model for the pilot building. The "with" and "without" vestibule cases are shown because of uncertainty in the infiltration assumptions. The "Design Prediction" combines savings from using occupancy sensors and improved lamps. 


\section{Measured Air-Conditioning Savings from Vegetative Landscaping}

\section{A. Meier}

The placing of trees and shrubs around buildings has long been recognized as an important technique for reducing heat gain into a building and, thereby, use of air-conditioning. The value of plantings as a technique to reduce airconditioning loads has not been well documented nor incorporated into analytical procedures. Architects and engineers thus favor technologically complex measures to reduce cooling loads over simpler, cheaper, designs based on the use of trees and other plants. In this project, measurements of airconditioning savings from vegetative landscaping were compiled and evaluated.

Trees, shrubs, and vines affect air-conditioning electricity use in four physically different paths:

- direct gain through windows

- conduction gain through opaque surfaces

- latent heat from infiltrating air

- sensible heat from infiltrating air.

The relative importance of these paths depends on type and amount of vegetation used, climate, building structure, orientation, and type of air-conditioning system installed.

Seven projects with energy data were identified in the
United States and Japan. The experiments took place in humid, dry, and temperate climates. The landscape treatments varied: some buildings were surrounded by grass, whereas others were surrounded by complex combinations of trees and shrubs.

The compilation demonstrates that the careful application of shrubs, trees, and vines could reduce cooling electricity use by 25 to $50 \%$ (Figure). These savings were achieved in a variety of climates and using greatly different landscape treatments. Reductions in air-conditioning energy were obtained even in humid climates. Large savings were also obtained in a dry climate simply by planting grass around the building. These results suggest that vegetation interacts with heat gain through many physically different processes, and that several combinations of vegetation and siting may yield similar savings.

\section{Reference}

Meier A. Measured Cooling Savings from Vegetative Landscaping. In: Proceedings of the ACEEE 1990 Summer Study on Energy Efficiency in Buildings, Pacific Grove, CA, Alrgust 26-September 1, 1990. Washington, DC: American Council for an Energy Efficient Economy, 1990, pp. 4.133-4.143.

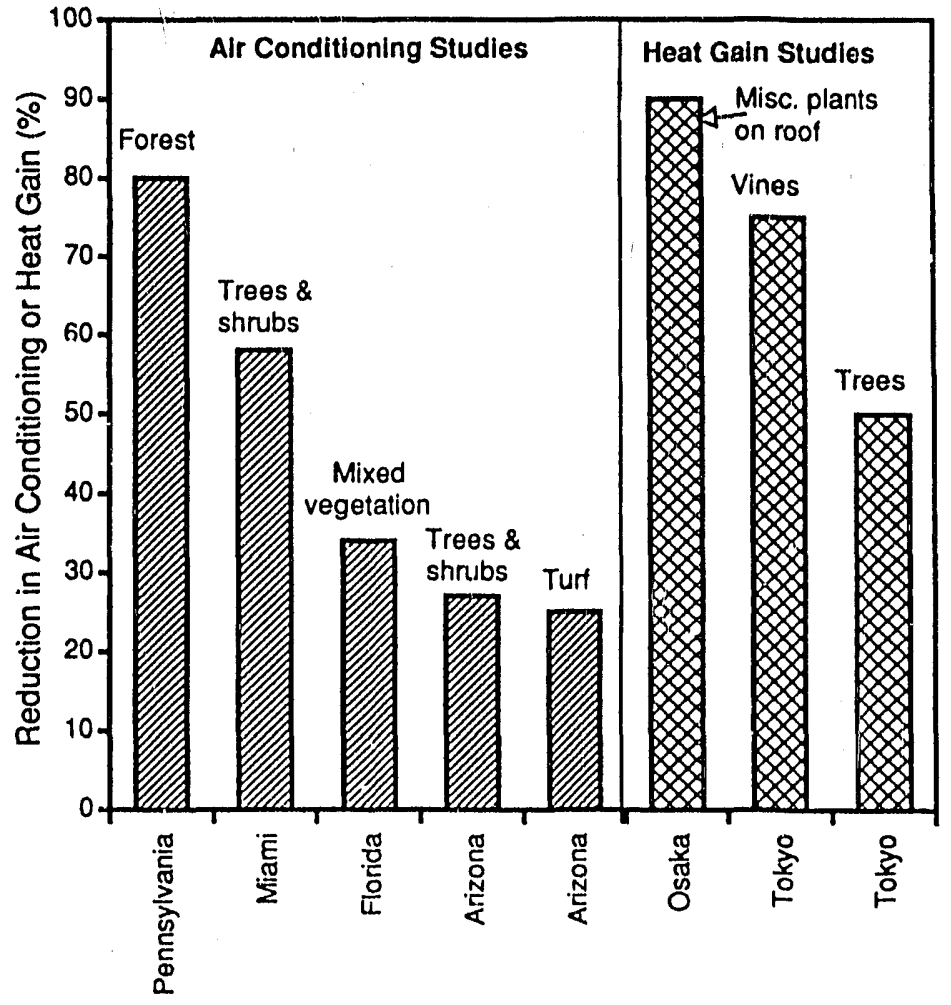

Figure. Reductions in heat gain and air-conditioning electricity use due to vegetative landscaping at various locations. 


\section{Miscellaneous Electrical Energy Use in Homes}

\author{
A. Meier, L. Rniner, and S. Greenberg
}

The "miscellaneous" use of electricity in homes has not been well measured or even defined. The saturations and unit electricity consumptions (UECs) were estimated for 35 appliances within the miscellaneous category of residential electricity use in the United States. Based on these estimates, the total national electricity consumption of these same appliances was calculated (Table).

On a nationwide basis, no single appliance within the miscellaneous end use category consumes as much electricity as a "standard" end use. In specific homes, however, miscellaneous uses can easily exceed the electricity used by a water heater or refrigerator. Some of these appliances, such as waterbed heaters, aquariums, and pool equipment, are already present in up to $15 \%$ of American homes. Encrgy audits of homes must become increasingly sophisticated because failure to identify the miscellaneous uses will cause unrealistically high estimates of energy use for the standard end uses, leading to overestimates of savings from standard conservation measures.

The linkage between an end-use and a specific appliance is weakening. This is most evident in the cooking end use, where once cooking was almost exclusively performed with the stove but is now shared among the stove, microwave, toaster oven, coffee maker, and a host of other specialized appliances. The cooling end use is undergoing a similar decoupling as the de-humidifier and ventilation equipment (particularly ceiling fans) are providing an increasing share of the service. The decoupling trend has important implications for energy efficiency investments and programs. Efficiency investments in a specific appliance will be harder to justify when the savings accrue to an appliance that is only providing, about $40 \%$ of the service.

\section{Reference}

Rainer L, Greenberg S, Meier A. The Miscellaneous Electrical Use in Homes. In: Procedings of the ACEEE 1990 Summer Study on Energy Efficiency in Buildings, Pacific Grove, CA, August 26-September 1, 1990. Washington, DC: American Council for an Energy Efficient Economy, 1990, pp, 9.263-9.271.

Table. Estimated stocks and unit electricity consumptions (UECs) of miscellaneous appliances.

\begin{tabular}{|c|c|c|c|c|}
\hline \multirow[b]{2}{*}{ End Use } & \multirow{2}{*}{$\begin{array}{c}\text { Stock } \\
\text { (millions) }\end{array}$} & \multirow{2}{*}{$\begin{array}{c}\text { UEC } \\
\text { (kWh/year) }\end{array}$} & \multicolumn{2}{|c|}{ National Consumption } \\
\hline & & & (TWh/year) & (\% of Total) \\
\hline Furnace Fan & 45 & 500 & 22.5 & 2.78 \\
\hline Color TV & 87 & 250 & 21.8 & 2.69 \\
\hline Waterbed Heater & 14 & 900 & 12.6 & 1.56 \\
\hline Microwave Oven & 72 & 120 & 8.6 & 1.07 \\
\hline Dishwasher & 36 & 200 & 7.2 & 0.89 \\
\hline Pool Pump & 4 & 1500 & 6.0 & 0.74 \\
\hline Aquarium/Terrarium & 10 & 548 & 5.5 & 0.68 \\
\hline Crankcase Heater & 27 & 200 & 5.4 & 0.67 \\
\hline Spa/Hot Tub & 2 & 2300 & 4.6 & 0.57 \\
\hline Clock & 180 & 25 & 4.5 & 0.56 \\
\hline Well Pump & 11 & 400 & 4.4 & 0.54 \\
\hline Dehumidifier & 11 & 400 & 4.4 & 0.54 \\
\hline Toaster/Toaster Oven & 86 & 50 & 4.3 & 0.53 \\
\hline Audio System & 81 & 50 & 4.1 & 0.50 \\
\hline Hair Dryer & 85 & 40 & 3.4 & 0.42 \\
\hline Electric Blanket & 27 & 120 & 3.2 & 0.40 \\
\hline Vacuum Cleaner & 90 & 30 & 2.7 & 0.33 \\
\hline Ceiling Fan & 54 & 50 & 2.7 & 0.33 \\
\hline Grow-Lights \& Accessories & 3 & 800 & 2.4 & 0.30 \\
\hline VCR & 59 & 40 & 2.4 & 0.29 \\
\hline Coffee Maker & 36 & 50 & 1.8 & 0.22 \\
\hline Black \& White TV & 45 & 40 & 1.8 & 0.22 \\
\hline Computer & 13 & 130 & 1.7 & 0.21 \\
\hline
\end{tabular}




\begin{tabular}{|lrccc|}
\hline Table (cont'd) & & & & \\
\hline Iron & 32 & 50 & 1.6 & 0.20 \\
Humidifier & 11 & 100 & 1.1 & 0.14 \\
Engine Heater & 4 & 250 & 1.0 & 0.12 \\
Exhaust Fan & 54 & 15 & 0.8 & 0.10 \\
Whole House Fan & 8 & 80 & 0.6 & 0.08 \\
Sump/Sewage Pump & 13 & 40 & 0.5 & 0.06 \\
\hline Garbage Disposer & 40 & 10 & 0.4 & 0.05 \\
Heat Tape & 3 & 100 & 0.3 & 0.04 \\
Bottled Water Dispensor & 1 & 300 & 0.3 & 0.04 \\
Window Fan & 9 & 10 & 0.2 & 0.02 \\
Electric Mower & 5 & 160 & 0.1 & 0.01 \\
Instant Hot Water & 0.5 & $\mathbf{1 6 1 0 *}$ & 0.1 & 0.01 \\
\hline Total Miscellaneous Use & - & $\mathbf{8 9 7 8 *}$ & $\mathbf{1 4 5}$ & $\mathbf{1 8}$ \\
Total Household Use & - & & $\mathbf{8 0 8}$ & $\mathbf{1 0 0}$ \\
\hline
\end{tabular}

Total household stock in 1990 was 90 million homes.

"per household

\section{Building Code Compliance and Enforcement: San Francisco's Residential Energy Conservation Ordinance and California's Building Standards}

\section{E. Vine}

As part of LBL's technical assistance to the Sustainable City Project (a collaborative effort by the cities of Portland, San Francisco, and San Jose), compliance and enforcement activities related to local and state building codes for existing and new construction were evaluated in two case studies. In the first year of the project, each city worked with key individuals in local government and the community to identify policy options that would contribute to solving local problems in selected priority areas (e.g., economic development and transportation) while also improving overall energy efficiency. As part of its planning process, the City of San Francisco asked LBL to examine how well the city's Residential Energy Conservation Ordinance (RECO) is being complied with and enforced and to examine similar issues related to California's building standards for new construction.

The analysis of RECO showed that a limited, prescriptive energy conservation ordinance for retrofit of existing residential buildings can be enforced relatively easily with little administrative costs, and that compliance with such ordinances can be quite high. Compliance with the code was facilitated by extensive publicity, an informed public concerned with the cost of energy and knowledgeable about energy efficiency, the threat of punishment (Order of Abate. ment), the use of private inspectors, and training workshops for city and private inspectors.

The analysis of California's Title 24 Standards for new residential and commercial construction showed that enforcement of this type of code for many climate zones is more complex and requires extensive administrative support for education and training of inspectors, architects, engineers, and builders. Under this code, prescriptive and performance approaches for compliance are permitted, resulting in the demand for a variety of methods of enforcement: technical assistance, plan review, field inspection, and computer analysis. In contrast to retrofit of existing stock, building design, new materials, and construction practices are of critical importance in new construction, creating a need for expanded technical assistance and extensive interaction between enforcement personnel and the building community.

Compliance problems associated with building design and installation did occur in both residential and nonresidential buildings. Because statewide codes are enforced by local officials, these problems may increase over time as energy standards change and become more complex and as other standards (e.g., health and safety codes) remain a higher priority. The Califorria Energy Commission realizes that code enforcement by itself is insufficient and expects that additional educational and technical assistance efforts (e.g., manuals, training programs, and toll-free telephone lines) will ameliorate these problems.

\section{Reference}

Vine E. Building Code Compliance and Enforcement: The Experiences of San Francisco's Residential Energy Conserontion Ordinance and California's Building Stondards for Neze Construction. Lawrence Berkeley Laboratory Report LBL29748, 1990. 


\section{- Energy Conservation Policy -}

\section{Analysis of Federal Appliance Efficiency Standards}
J.E. McMahon, B. Atkinson, D.B. Berman,
S. Boghosian, P. Chan, T. Chan, J. Koomey,
B. Lebot, M.D. Levine, J. Lutz, G. Rosenquist,
S. Stoft, I. Turiel, and C. Wodley

The Energy Policy and Conservation Act (P.L. 94-163), as amended by the National Energy Conservation Policy Act (P.L. 95-619) and by the National Appliance Energy Conservation Act of 1987 (P.L. 100-12) and by the National Appliance Energy Conservation Amendments of 1988 (P.L. 100$357)$, provides energy conservation standards for 12 of 13 types of consumer products" and authorizes the Secretary of Energy to prescribe amended or new energy standards.

\footnotetext{
"Products covered: 1) refrigerators, refrigerator-freezers, and freezers; 2) room air conditioners; 3) central air conditioners and heat pumps; 4) water heaters; 5) furnaces; 6) dishwashers; 7) clothes washers; 8) clothes dryers; 9) direct heating equipment; 10) hitchen ranges and ovens; 11) pool heaters; 12) television sets; and 13) fluorescent-lamp ballasts.
}

Initiated in 1979, LBL's assessment of the standards is designed to evaluate their economic impacts according to the legislated criteria (Figure).

The economic impact analysis is performed in five major areas:

- Engineering Analysis, which establishes the technical feasibility and product attributes including costs of design options to improve appliance efficiency.

- Consumer Analysis at two levels: national aggregate impacts and impacts on individuals. The national aggregate impacts include LBL-REM forecasts of appliance sales, efticiencies, energy use, and consumer expenditures. The individual impacts are analyzed by life-cycle cost, payback pe riods, and cost of conserved energy, which evaluate the savings in operating expenses relative to increases in purchase price.

- Manufacturer Analysis, which provides an estimate of manufacturers' response to the proposed standards. Their response is quantified by changes in several measures of financial performance.

- Utility Analysis that measures the impacts of the altered energy-consumption patterns on electric utilities.

- Environmental Effects Analysis that estimates changes in emissions of carbon dioxide, sulfur oxides, and nitrogen oxides, due to reduced energy consumption in the home and at the power plant.

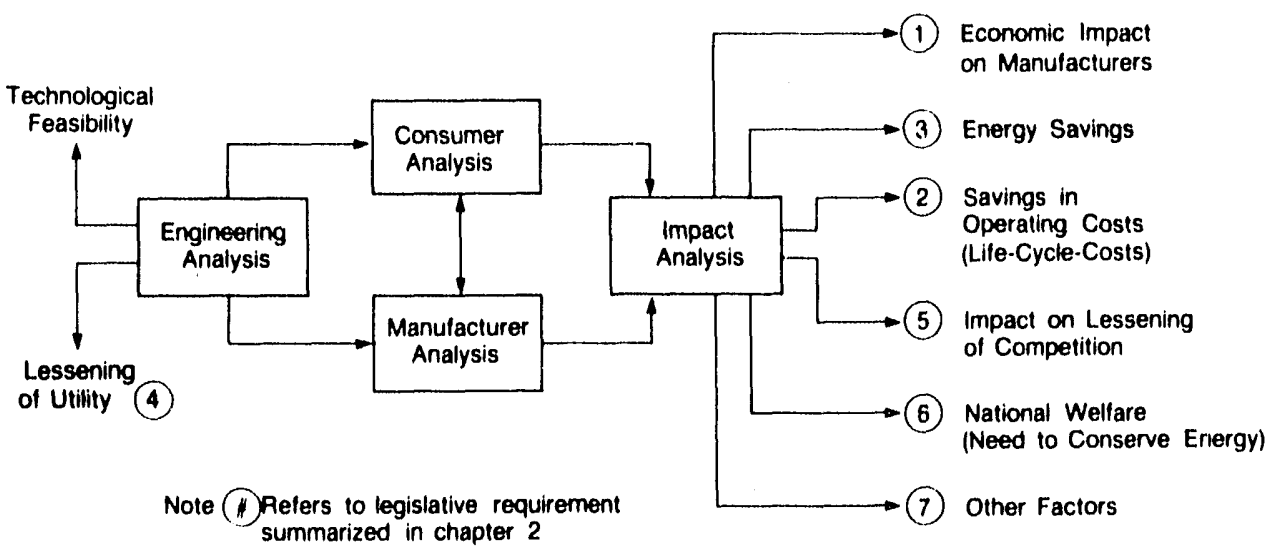

Figure. Analytic framework for the appliance standards analysis. (XBI 856-8918) 
- Regulatory Impact Annlysis collects the results of all the above analyses into the net benefits and costs from a national perspective.

This year we analyzed the impacts of proposed updates to standards for dishwashers, clothes washers, and clothes dryers. Potential energy savings were demonstrated for these products, and standard levels were identified which are projected to save energy, and to save money for consumers, without undermining the financial health of the appliance industry. Data collection began for analysis of nine products (room air conditioners, water heaters, furnaces, clothes washers, direct heating equipment, kitchen ranges and ovens, pool heaters, televisions, and fluorescent light ballasts).

We also began data collection and modelling to study alternative policies for improving energy efficiency of lighting equipment in buildings, including residential and commercial applications.

In the next year, we will analyze proposed energy efficiency standards for the nine products listed above. We will also complete the engineering analysis and projections of potential energy savings from more efficient lighting equipment in buildings.

\section{References}

U.S. Department of Energy, Assistant Secretary, Conservation and Renewable Energy, Building Equipment Division. Energy Conservation Standards for Consumer Products: Refrigerators and Furnnces. U.S. Department of En- ergy Technical Support Document DOE/CE-(1277, November, 1989.

McMahon JE, et al. Impacts of U.S. Appliance Performance Standards on Consumers, Manufacturers, Electric Utilities, and the Environment. In: Procidings of the ACEIE 1990 Summer Study on Energy Efficinncy in Buildings, Allgust 26-September 1, 1990). Washington, DC: American Council for an Energy-Efficient Economy, 1990, pp. 7.107-7.116.

Turiel l, et al. U.S. Residential Appliance Energy Efficiency: Present Status and Future Policy Directions. In: Proceedings of the ACEEE 1990 Summer Study on Energy Efficiency in Buildings, August 26-September 1, 1990. Vol. 1. Washington, DC: American Council for an Energy-Efficient Economy, 1990, pp. 1.314-1.234.

McMahon JE. National Appliance Efficiency Regulations and Their Impacts. In: MIT Conference on Energy and the Enviromment in the 21 st Century, March 26-28, 1990. Cambridge, MA: MIT Press, 1990.

Carlsmith RS, Chandler WU, McMahon JE, Santini DJ. Encrgy Efficiency: How Far Can Wo Go? Publication No. ORNL/TM-11441, January 1990.

U.S. Department of Energy, Assistant Secretary, Conservation and Renewable Energy, Building Equipment Division. Energy Conservation Standards for Consumer Prodncts: Dishonashers, Clothes Washers, and Clothes Dryers. U.S. Department of Energy Technical Support Document DOE/CE-0299P, December 1990.

\section{Engineering Analyses of Appliance Efficiency Improvements}

\author{
I. Turiel, B. Atkinson, S. Boghosian, \\ J. Lutz, and $G$. Rosenquist
}

The economic impacts of appliance efficiency standards depend largely on the relation between cost and energy consumption of a consumer product. Our engineering analysis seeks primarily to identify this cost-consumption relationship for selected appliances. In 1990, we reanalyzed dishwashers, clothes washers, and clothes dryers, based on public comments received on a previous notice of proposed rulemaking (NOPR). A final rulemaking is expected to be published by DOE early in 1991.

In addition, we have initiated analyses for eight products: water heaters, pool heaters, direct heating equipment, mobile home heaters, fluorescent ballasts, room air conditioners, ranges/ovens, and televisions. A new initiative for lighting products was also begun late in 1990. The pros and cons of lighting standards and other lighting energy conservation programs will be addressed.
The engineering analysis consists of the following steps: select appliance classes, select baseline units for each class, select design options for each class, determine maximum technologically feasible design and the efficiency improvement for each option for each class, and the cost of each design option. Data are obtained through contacts with trade organizations and manufacturers, from suppliers of purchased parts and materials, and from computer simulations.

In 1991, we plan to complete the engineering analysis of eight products. We will take into account the public comments received from the Advanced NOPR. Clothes washers will also be reanalyzed in 1991, based on additional data for horizontal axis designs expected to be received from manufacturers. We will also complete our report on the results of our analysis of existing lighting programs and potential lighting standards approachs.

\section{Reference}

Federal Register, September 28, 1990; 55:189:39624-39634. 


\section{Assessing the Impacts of Appliance Standards on Manufacturers}

\author{
S. Stoft and T. Chan
}

The Manufacturer Analysis assesses the impact of appliance standards on the profitability and competitiveness of the various appliance-manufacturing industries to be affected by mandatory energy efficiency standards. The primary tool used by this evaluation is the Manufacturer Impact Model (LBL-MIM). LBL-MIM uses engineering cost and efficiency estimates as well as collected economic and financial data for this analysis. Outputs include price, rate of profit, shipments, revenues, net incomes, and the standard errors of these estimates. LBL-MIM also provides estimates of retail prices used by the Residential Energy Model (LBLREM) and the life-cycle cost analysis.

This year, we have used LBL-MIM to prepare a final analysis of dishwashers, clothes washers, and clothes dryers as well as to prepare a Technical Support Document. In addition to the standard analysis, a regulatory impact analysis was done. Our results continue to indicate that federal energy efficiency standards are not likely to have drastic impact on profitability because of the industry's ability to pass on variable costs with a markup.

A step toward compatibility between LBL-MIM and LBL-REM was taken by revising LBL-MIM to accept discount rotes as input. This allows LBL-MIM to use empirical data reflecting market behavior from LBL-REM. Next year will bring further integration of the demand functions of $L B L$ MIM and LBL-REM. An external review panel consisting of industry, academic, and Environmental Protection Agency representatives reviewed LBL-MIM's modeling approach and economic assumptions to identify strengths and areas for improvement. The panel's findings were submitted to DOE and LBL has evaluated and proposed new work to address suggested areas of improvement.

Data collection efforts for the next round of product analyses (kitchen ranges and ovens, room air conditioners, direct heating equipment, water heaters, pool heaters, television sets, fluorescent lamp ballasts, and mobile home furnaces) were initiated and included a combination of questionnaires submitted to industry trade associations and individual firms, and plant visits.

In 1991, we expect to complete the integration of the LBLMIM and LBL-REM demand functions, collect data and complete the preliminary analysis for the eight products in the next round of products, and evaluate the feasibility of developing standards for lighting products.

\section{Reference}

U.S. Department of Energy, Assistant Secretary, Conservation and Renewable Energy, Building Equipment Division. Energy Conservation Standards for Consumer Products: Dishwashers, Clothes Washers, and Clothes Dryers, U.S. Department of Energy Technical Support Document DOE/CE-0299P, December 1990.

\section{Forecasting Residential Energy Demand}

\section{J.E. McMahon, D.B. Berman, and P. Chan}

The LBL. Residential Energy Model (LBL-REM) provides estimates of the impacts on consumers of federal policies affecting anergy consumption by home appliances including furnaces and air conditioners. LBL-REM combines engineering estimates of possible appliance designs with a simulation of market behavior for the purchase of appliances, including fuel choice, efficiency choice, and usage behavior.

The LBL-REM has been improved this year by: incorporating into REM new data from public comments on the proposed rules for dishwashers, clothes washers, and clothes dryers; updating the demographic and housing projection for the nation, by region; and enhancing the capability to analyze uncertainty.

The model was used to perform several analyses of impacts of federal policies on consumers and on national energy consumption, including: supporting DOE's promulgation of new standards for dishwashers, clothes washers, and clothes dryers; estimating the remaining potential for improving energy efficiency in buildings for the National Energy Strategy; and calculating potential reductions in carbon dioxide emissions resulting from alternative energy efficiency policies, including energy taxes and improving the economic efficiency of the marketplace.

In addition, LBL-REM results were used to analyze impacts of proposed efficiency standards on manufacturers, electric utilities, and the environment.

We plan to continue to model impacts of any proposed federal conservation standards, including incorporating into REM any new data from public comments on the advanced notice of proposed rulemaking for nine products. An analysis of potential standards for room air conditioners, water heaters, direct heating equipment, and pool heaters will be performed on a regional basis. We will develop new projections of energy consumption for televisions, mobile home furnaces, fluorescent lamp ballasts, and ranges and ovens. We will continue improving the consumer market analysis and forecasting capabilities of REM and enhancing the capability to analyze uncertainty. We will develop an improved method for estimating elasticities for REM.

\section{Reference}

McMahon JE, Berman D, Chan P, Chan T, Koomey J, Levine

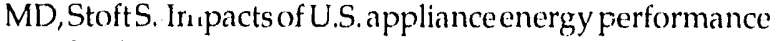
standards on consumers, manufacturers, electric utilities, and the environment. In: Proceedings of the ACEEE 1990) Summer Study on Energy Efficiency in Buildings, August 26 September 1, 1990. Washington, DC: American Council for an Energy-Efficiency Economy, 1990), pp. 7.1(17-7.116. 


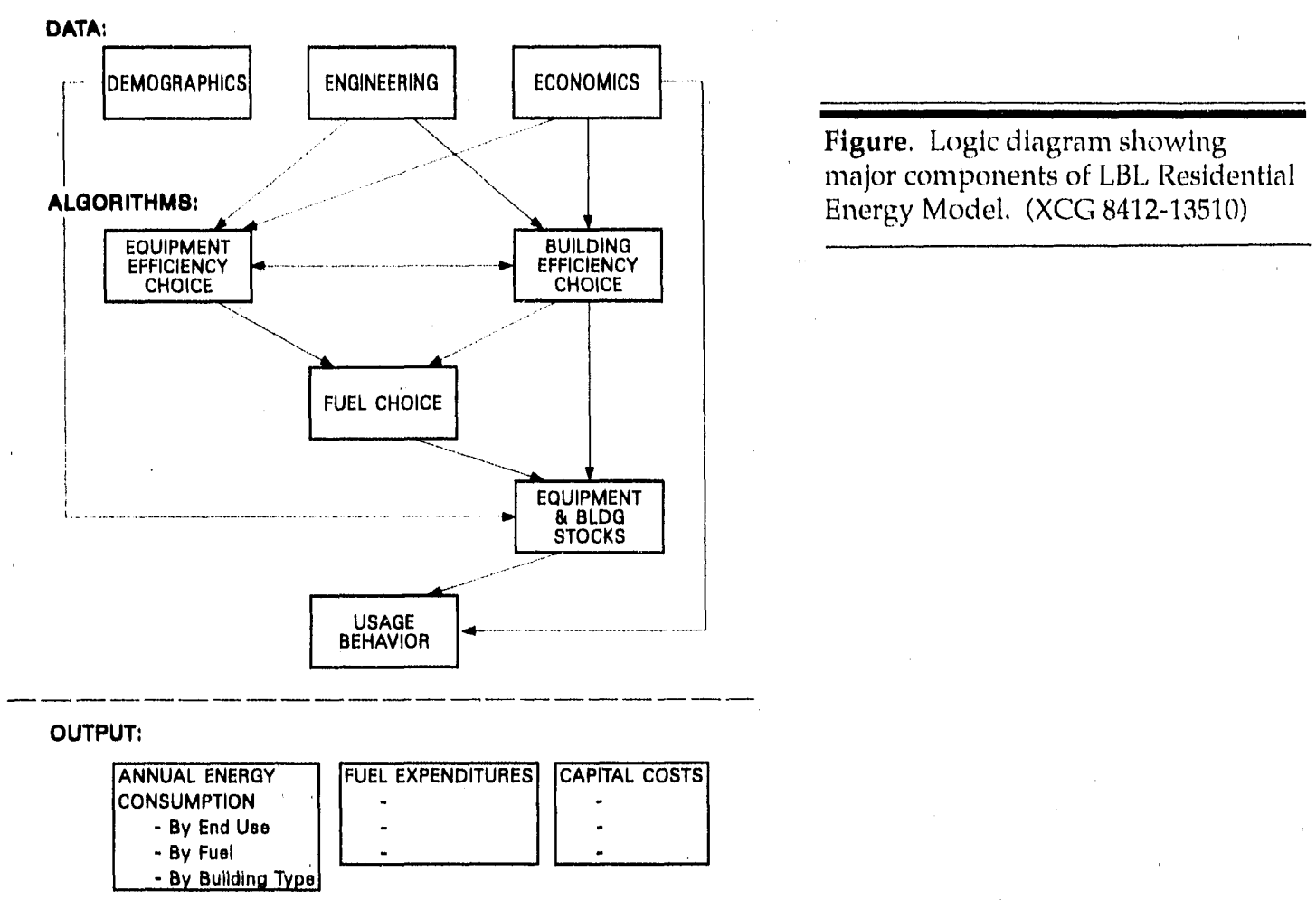

\section{The Potential for Efficiency Improvements in Residential Buildings by the Year 2010}
A. Meier, C. Atkinson, J. Koomey, B. Atkinson, S. Boghosian, J. McMahon, and M.D. Levine

A database of residential electricity conservation measures was established. For each measure, key engineering and economic data were collected. These data, plus estimates of the stock of physically eligible homes and appliances, permit the calculation of the national potential for electricity conservation. The results are presented as supply curves of conserved electricity (Figure 1, next page).

The supply curve of conserved electricity consists of almost 200 cost-effective measures; i.e., measures whose cost of conserved energy (CCE) are less than the price of electricity. The curve describes a combination of four kinds of efficiency activities:

- retrofitting existing buildings and equipment

- raising efficiency of appliances as they are replaced

- improving the thermal performance of new buildings,

- switching from electricity to gas.
The reduction in energy use by the year 2010 is best seen in Figure 2 (see next page). The cost-effective technical potential is about $400 \mathrm{TWh} /$ year below the frozen efficiency projection.

The conservation potential is distributed among water heating, space conditioning, lighting, and "other." Potential savings of about $100 \mathrm{TWh} /$ year were identified in both the water-heating and space-conditioning end uses, whereas lighting and refrigeration each contribute about 60 TWh/ year. The greatest potential end-use savings lie in water heating $(60 \%)$, lighting $(50 \%)$, refrigerators $(39 \%)$, and space conditioning $(31 \%)$. The measure with the largest savings is a package of hot water conservation measures (low flow showers, aerators, and water-efficient washing machines and dishwashers). Three large measures cost less than $24 /$ $\mathrm{kWh}$ : retrofits for water-heater tanks, refrigerator improvements, and measures to conserve hot water.

\section{Reference}

Meier A, Atkinson C, Atkinson B, Boghosian S, McMahon JE, Koomey J. A Database of Electricity Conserernation Mensure's for the Resitential Sector. Lawrence Berkeley Laboratory Report No. L.BL-30477, 1991. 


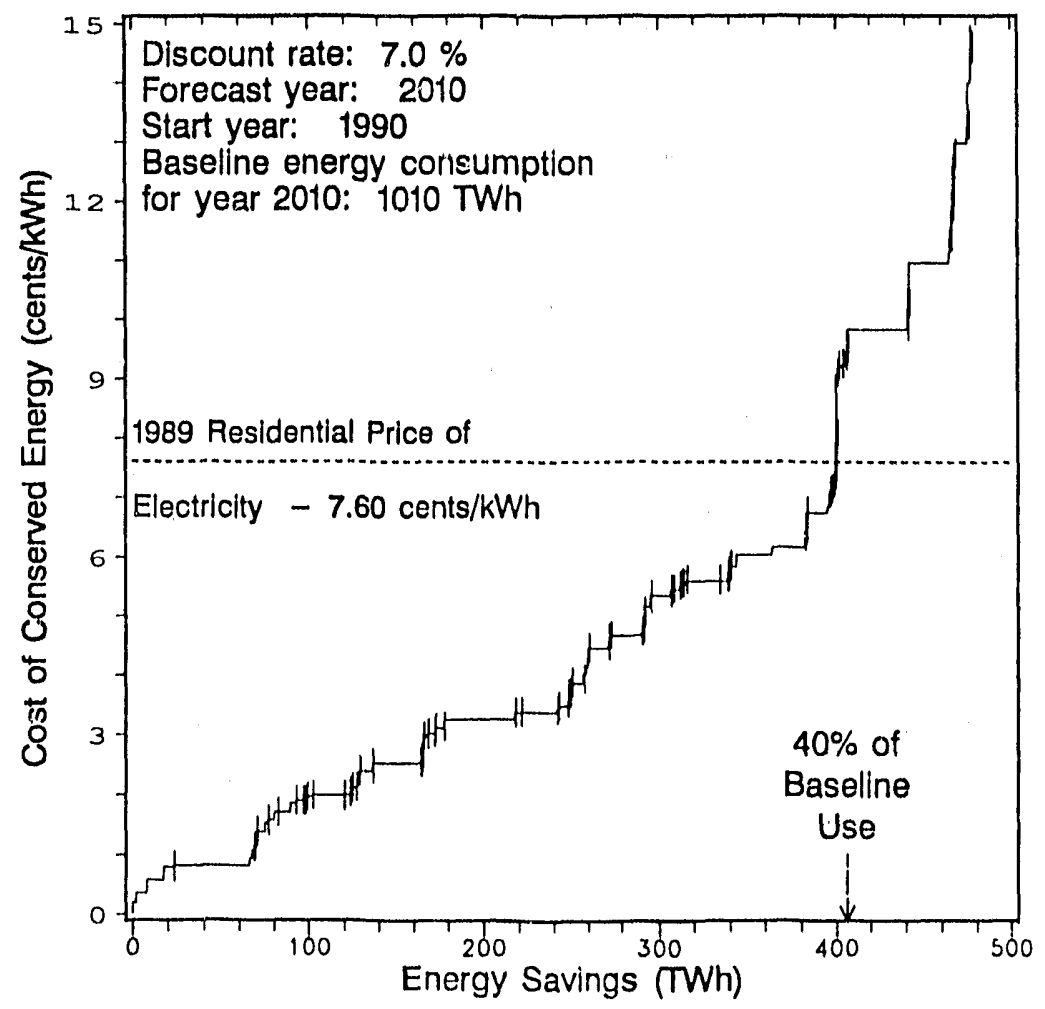

Figure 1. A supply curve of conserved electricity. Each step represents a conservation measure. Its height is the measure's CCE and its width is the estimated savings in the year 2010.

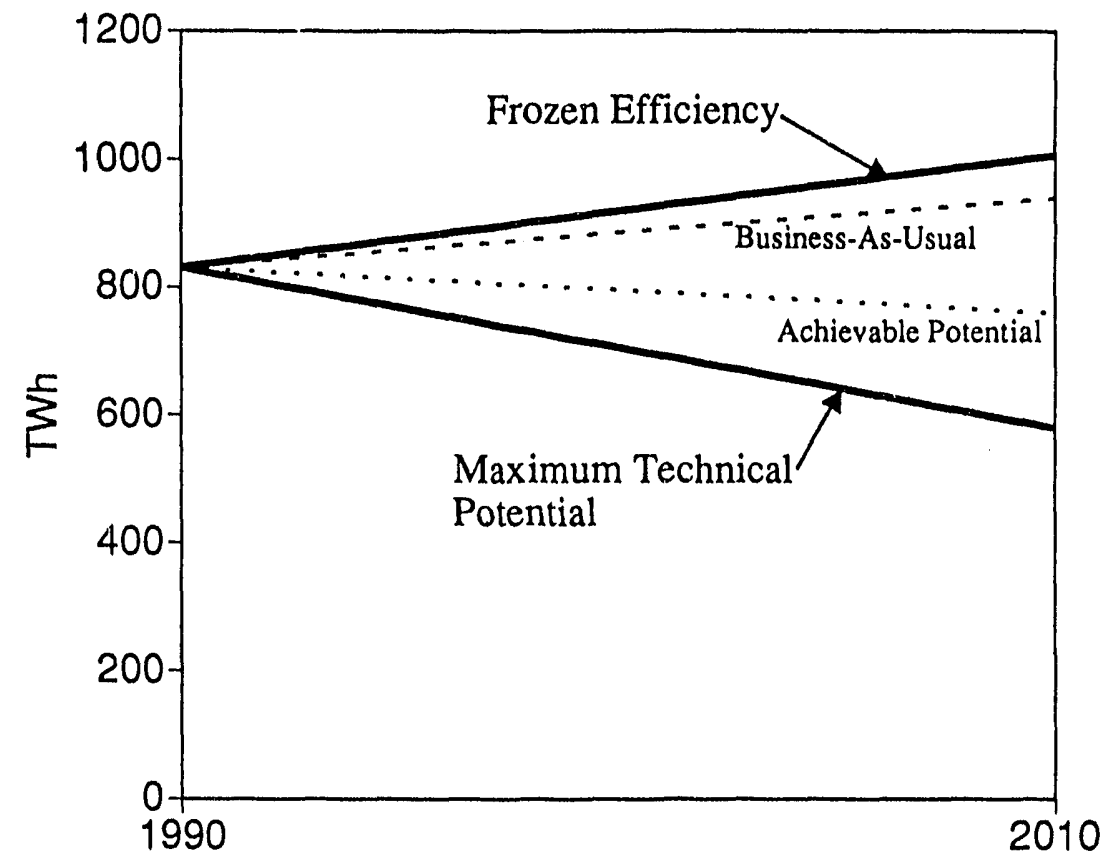

Figure 2. Electricity use over time for the baseline ("frozen efficiency") forecast, an LBL "business-as-usual" forecast, the achievable conservation potential, and the technical potential. 


\section{Thermal Integrity of Single-Family Buildings}

\author{
J. Koomey, S.Boghosian, and J. McMahon
}

The purpose of this ongoing research is to estimate the costs and potential for energy conservation in new and existing single-family dwellings in different regions of the United States. This research involves the following steps:

1) establishing baseline characteristics of houses, such as the amount of insulation in the building shell, the type of glazing, the rate of air infiltration, and the foundation type (e.g., basement, slab, or crawl space). These characteristics are based on surveys conducted by the National Association of Home Builders (NAHB) and the U.S. Department of Energy, and are summarized in building prototypes that vary by region and house vintage;

2) determining the population-weighted average weather for each region of the country, based on a climateaveraging program developed at Lawrence Berkeley Laboratory;

3) calculating the energy use of the prototypical houses (and more efficient versions of this prototype) using the appropriate average weather and a building simulation program (the Program for the Energy Analysis of Residences-PEAR);
4) summarizing regional data on costs of adding insulation, changing glazings, and reducing infiltration, both in new and retrofit applications. These data are from $\mathrm{NAHB}$ and from utility conservation programs throughout the United States;

5) estimating the cost-effectiveness of making buildings more efficient or of using different heating fuels.

The table shows the average heating and cooling energy use for new single-family homes using heat pumps in the ten Federal regions of the United States in 1987. This table was created using the methodology outlined in steps 1-3 above. It shows that Region 5 (the upper midwest) has the highest space-heating energy intensity per square foot, and Region 6 (Texas and surrounding states) has the highest space-cooling energy intensity per square foot. These results for average building prototypes are then recalculated for buildings with more insulation, better glazing, and lower infiltration rates, and capital costs are assigned to each level of improved building shell efficiency.

Cost and energy savings information is being incorporated into Lawrence Berkeley Laboratory's Residential Energy Forecasting Model (LBL-REM) and into a companion model that calculates total conservation potential in U.S. residential buildings (ACCESS). The data are being updated to include more advanced window and insulation technologies that promise to reduce costs substantially in the years ahead.

Table. Heating and Cooling Site Energy Use of New Single-Family Homes with Heat Pumps, 1987

\begin{tabular}{|c|c|c|c|c|c|c|c|}
\hline $\begin{array}{l}\text { Federal } \\
\text { Region }\end{array}$ & $\begin{array}{l}\text { Floor } \\
\text { Area } \\
\left(\mathrm{ft}^{2}\right)\end{array}$ & MMBtu/yr & $\begin{array}{c}\text { Heating } \\
\text { Energy } \\
\left(\mathrm{kBtu} / \mathrm{ft}^{2} / \mathrm{yr}\right)\end{array}$ & Index & MMBtu/yr & $\begin{array}{c}\text { Cooling } \\
\text { Energy } \\
\left(\mathrm{kBtu} / \mathrm{ft}^{2} / \mathrm{yr}\right)\end{array}$ & Index \\
\hline 1 & 2013 & 19.61 & 9.74 & 1.14 & 2.09 & 1.04 & 0.33 \\
\hline 2 & 2887 & 24.64 & 8.54 & 1.00 & 4.90 & 1.70 & 0.55 \\
\hline 3 & 2242 & 23.10 & 10.30 & 1.20 & 4.77 & 2.13 & 0.68 \\
\hline 4 & 1852 & 11.72 & 6.33 & 0.74 & 11.83 & 6.39 & 2.(0).5 \\
\hline 5 & 2008 & 24.44 & 12.17 & 1.42 & 2.38 & 1.18 & 0.38 \\
\hline 6 & 1800 & 9.57 & 5.32 & 0.62 & 13.56 & 7.53 & 2.42 \\
\hline 7 & 2411 & 21.20 & 8.79 & 1.03 & 7.52 & 3.12 & $1 .(1)$ \\
\hline 8 & 2013 & 21.81 & 10.84 & 1.27 & 1.61 & 0.80 & 0.26 \\
\hline 9 & 1783 & 3.61 & 2.02 & 0.24 & 0.40 & (0.23 & 0.07 \\
\hline 10 & 1805 & 17.69 & 9.80 & 1.15 & 0.47 & 0.26 & 0.08 \\
\hline National & 2013 & 17.23 & 8.56 & 1.00 & 6.26 & 3.11 & 1.00 \\
\hline
\end{tabular}

Index is relative to National average heating or cooling site energy $\left(\mathrm{kBtu} / \mathrm{ft}^{2}\right)$ :

Heat pump seasunal performance factor $=7.32\left(\mathrm{COP}^{2}=2.15\right)$; heat pump seasonal energy efficiency ratio $=10.1$ $(\mathrm{COP}=2.96)$.

Electric site energy can be converted to $\mathrm{kWh}$ using $3412 \mathrm{Btu} / \mathrm{kWh}$.

Federal regions: $1=$ New England; $2=$ New York/New Jersey; $3=$ Mid.Atlantic; $4=$ South Atlantic; $5=$ Midwest; $6=$ Southwest $7=$ Central; $8=$ North Central; $9=$ West $10=$ Northwest 


\section{Global Energy/Environmental Issues}

\section{Remote Monitoring of Effects of Climatic Change on Vegetation}

\section{R.L. Ritschard, W.E. Westman, and M.F. Lantsfeld}

Canopies of natural yegetation can respond to climatic variation by exhibiting a range of changes in leat anatomy, biochemistry, morphology, and canopy structures. Each of these changes will alter the reflectance of radiation from canopies in broadly predictable ways, making optical remote sensing a potentially powerful tool for tracking changes in vegetative conditions due to climatic influence. This study attempts to determine the feasibility of using satellite data to monitor interannual changes in vegetation canopy conditions based on changes in climate (i.e., temperature and precipitation).

Three vegetation types, northern coastal scrub, coastal sage scrub, and grassland, in the San Bruno Mountain State and County Park, just south of San Francisco, were selected for this study. Fourteen sites were selected for the estimation of foliar cover of dominant species of plants and percent of exposed ground. In addition, daily weather data were obtained and used to compute the various climatic variables. Potential evapotranspiration was computed from temperature, relativ. humidity, and latitude data. Monthly water surplus or deficit values were computed as the difference hetween monthly total precipitation and total potential evapotranspiration. These vegetation types and climate data were then compared to satellite images from three cloud-free time poriods at the end of the summer dry season (September $1984,1986,1989$ ).

Because its spatial resolution $(30 \mathrm{~m})$ allows one to distinguish distinct vegetation types, LANDSAT Thematic Mapper (TM) satellite data were used for this study. Previous laboratory studies have elucidated the relationship between reflectance from drought-stressed leaves and TM spectral bands. TM Band 3 (red region, $6.30 \mathrm{~mm}$ ), which can be used to identify leaf chlorophyll content, increases as chlorophyll breaks down because of drought-related conditions. TM Band 4 (near infrared region, $760-900 \mathrm{~nm}$ ) is sensitive to leaf water content and its radiance increases as leaves dry out. TM Band 5 (middle infrared region, 1550-1750 nm) increases as fall leaf moisture decreases. After registering LANDSAT TM scenes to topographic maps of the study area, the satellite data are overlain the study sites using ERDAS software and a geographic information system.

Preliminary results (Figure) show that as the drought of the late 1980s progressed (indicated by winter and summer water deficits, i.e., precipitation minus potential evapotranspiration), spectral reflectance (especially TM Bands 3, 4, and the ratio $4 / 3$ ) increases. Band 5 and the $5 / 4$ ratio are less sensitive to climatic variation. Sensitivity of response to climate is greatest in the northern coastal scrub and least in grassland, with coastal sage scrub being intermediate. These results can only be regarded as preliminary; a larger sample size (i.e., more years of satellite data) is required for definitive confirmation or rejection. The present study has provided some strong indication, however, that canopy changes in northern coastal scrub may have adequate sensitivity to serve as a useful indicator ecosystem for monitoring climatic change.

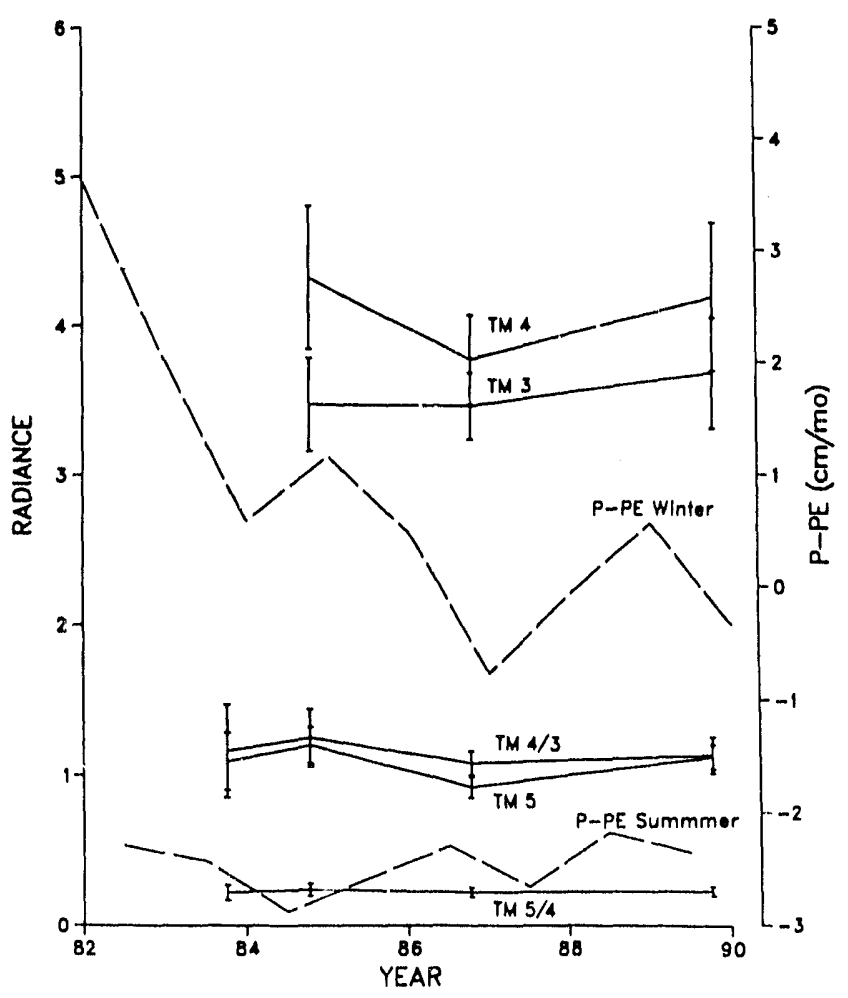

Figure. Satellite and climate data for coastal sage scrub, San Bruno Mountain State and County Park, CA. 


\section{The Role and Impact of Energy} Efficiency in Developing Countries andEastern Europe

M.D. Levine, A. Gadgil, S. Meyers, J. Sathaye, J. Stafurick, and T. Wilbankst

The objective of this project has been to explore efficiency improvements as an energy strategy for developing countries and Eastern Europe. The final report will be distributed widely to technical and public policy audiences to promote the creation of significant new energy efficiency programs in these countries, with assistance from the United States and other modern industrialized nations. The report describes the evolving energy patterns in these countries and outline's the role that energy efficiency can play in the near and mid-range future. It summarizes the main issues that must be confronted in improving energy efficiency, together with the growing record of success in this regard. Finally, it suggests what needs to be done to accelerate energy efficiency improvement in the developing world and Eastern Europe, as a fundmental contribution to economic and social development. clude:

Some key observations resulting from the research in-

- Most of the developing world currently faces a growing need for energy services in order to support economic and social development, but inadequate resources to meet that need.

- On a per capita basis, developing countries in 1987 consumed an average of 18 million Btu in commercial fuels and an additional 8 million Btu in

*RCG/Hagler, Bailly, Inc.

'Energy Division. Oak Ridge National Laboratory. biofuels, compared with more than 130 million Btu in Western Europe and 305 million Btu in the United States.

- Although per capita and total energy consumption in the developing world remains less than half that of the developed world, the rate of growth in energy consumption has been far higher in the developing countries for the last two decades (Figure).

- Reasons for the rapid increase in primary energy consumption in the developing economies include: 1) rapid population growth; 2) faster economic growth than in the modern industrialized countries, particularly in the 1970s; 3) migration from rural areas, where energy needs are met primarily with biomass, to urban areas where commercial fuels predominate; 4) penetration of energy-intensive technologies (e.g., increasing use of fertilizers, personal vehicles, and electric appliances); 5) limited capability and resources to improve energy efficiency; and 6) expansion of energy-intensive industries.

- Overall, commercial energy consumption in the developing world grew around 20\% faster than gross domestic product (GDP) between 1973 and 1987. The relationship between energy consumption and GDP has varied between regions and over time.

- Generally, developing countries and Eastern Europe require substantially greater quantities of energy resources to deliver one unit of useful energy than do modern industrialized countries. It is likely that the energy intensity (measured as commercial and non-commercial energy per unit GDP) of developing and Eastern European countries is approximately $60 \%$ greater than that of industrialized countries.

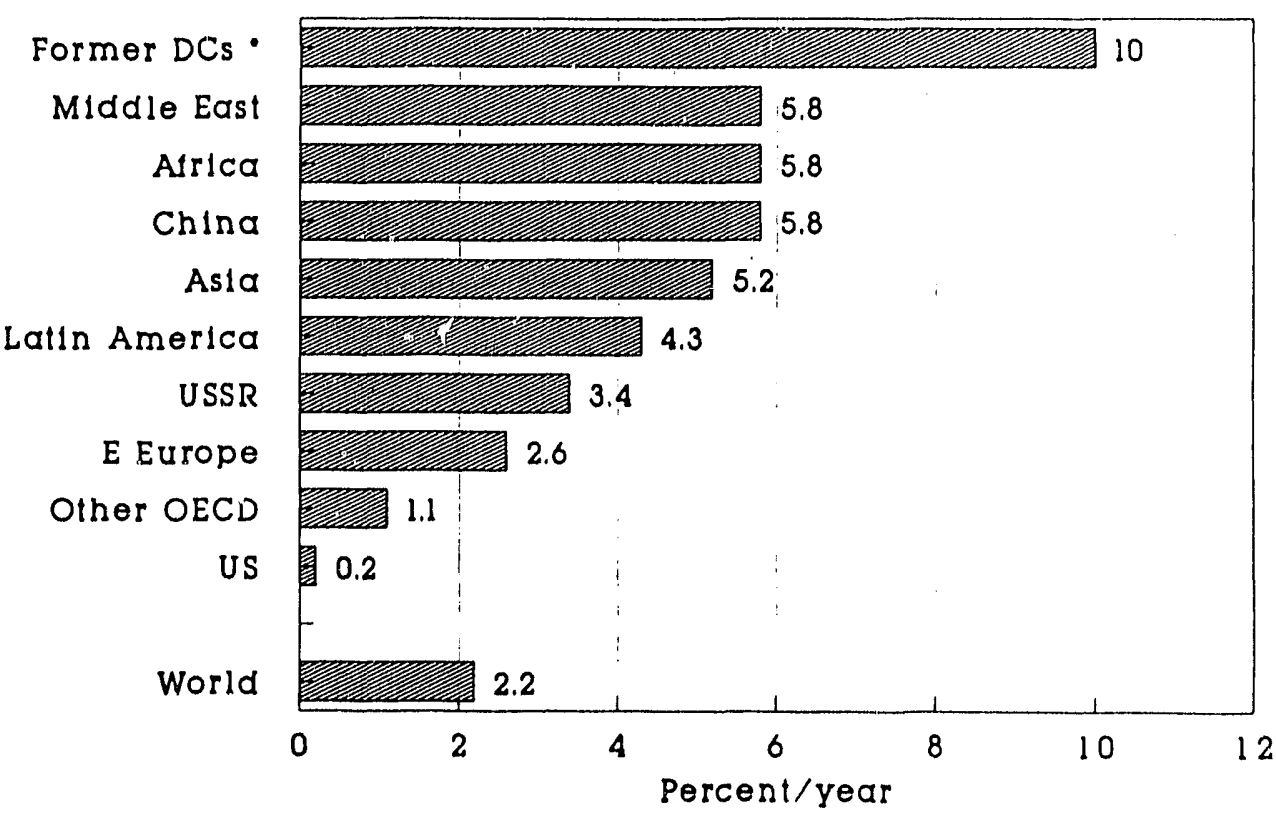

Figure. Average growth rates of primary energy consumption, 1973-1987. (DCs $=$ developing couritries) 
Although there are major barriers to successful implementation of energy efficiency programs in developing countries and Eastern Europe (and such activities are only in early stages), there have been important successes. Brazil, China and Tunisia have all mounted large, successful programs.

Even though supply projects are nceded, a new balance between supply and energy efficiency investments must be established. An annual investment of $\$ 20$ to $\$ 30$ billion in energy efficiency projects can be justified. Between $\$ 1$ billion and $\$ 2$ billion per year of assistance is needed in order for developing countries and Eastern Europe to create and administer energy efficiency policies and programs.

\section{References}

Levine MD, Gadgil A, Meyers S, Sathaye I, Stafurick I, Wilbanks T. Energy Efficioncy, Developing Nations, and Eastern Europe: An Analysis of Ke'y lssues. Report to the U.S. Working Group On Global Energy Efficiency, March 1991.

Levine MD, Meyers S, Wilbanks T. Energy efficiency and developing countries. Enzironmental Scicnce and Technology 1991; 25(4):585-589.

\section{Energy Conservation Investments in China}

M.D. Levine and L. Xuey ${ }^{*}$

Until 1978, energy production and use in China grew very rapidly, during most years at a rate of one and one-half to two times that of the economy. This is not surprising, considering the emphasis placed in China on the development of heavy industry, the lack of adequate price signals and other mechanisms to balance energy supply and demand, and the general inattention given to efficient resource allocation by leading Chinese planners.

The considerable reductions in energy growth since 1978 are surprising when compared to the experiences of other developing countries. During the last decade, energy demand in China has grown only $50 \%$ as rapidly as an admittedly overheated economy. Growth of energy demand substantially below economic growth is unusual in the developing world.

This project explores the factors that have motivated energy planners in China to pay more attention to energy conservation. It summarizes information never before made available outside of China about types of programs under-

*Energy Research Institute, l'eoples Republic of China. taken, the criteria used to evaluate energy efficiency investments, and the performance of these investments. It focuses on the period 1981 to 1985 when the Sixth Five-Year Plan was implemented. This period is of great interest because it represents a radical shift in energy policy in China. A massive and ambitious plan for investing in energy savings programs was initiated along with other measures by which the government supported energy conservation.

The most important finding of the study is that the Chinese have made very large investments in energy efficiency: 8 billion yuan (or more than $\$ 3$ billion) from 1981 to 1985. This investment was highly cost-effective. We estimate that it reduced energy growth by more than 25 million tons of coal equivalent, thereby reducing annual growth from $7 \%$ to $4 \%$ by 1985 . This result is significant and important. The conservation supply curve, applied only to those programs carried out during the Sixth Five-Year Plan, illustrates the impacts of these programs (Figure).

Continuing work explores more recent progress in energy efficiency investments and begins to evaluate the overall energy conservation potential in China and the costs of efficiency improvements.

\section{Reference}

Levine MD, Xueyi L. Energy Conserontion Programs in the Pcoples Republic of Chinn. Lawrence Berkeley Laboratory Report No. LBL-29211, 1990.

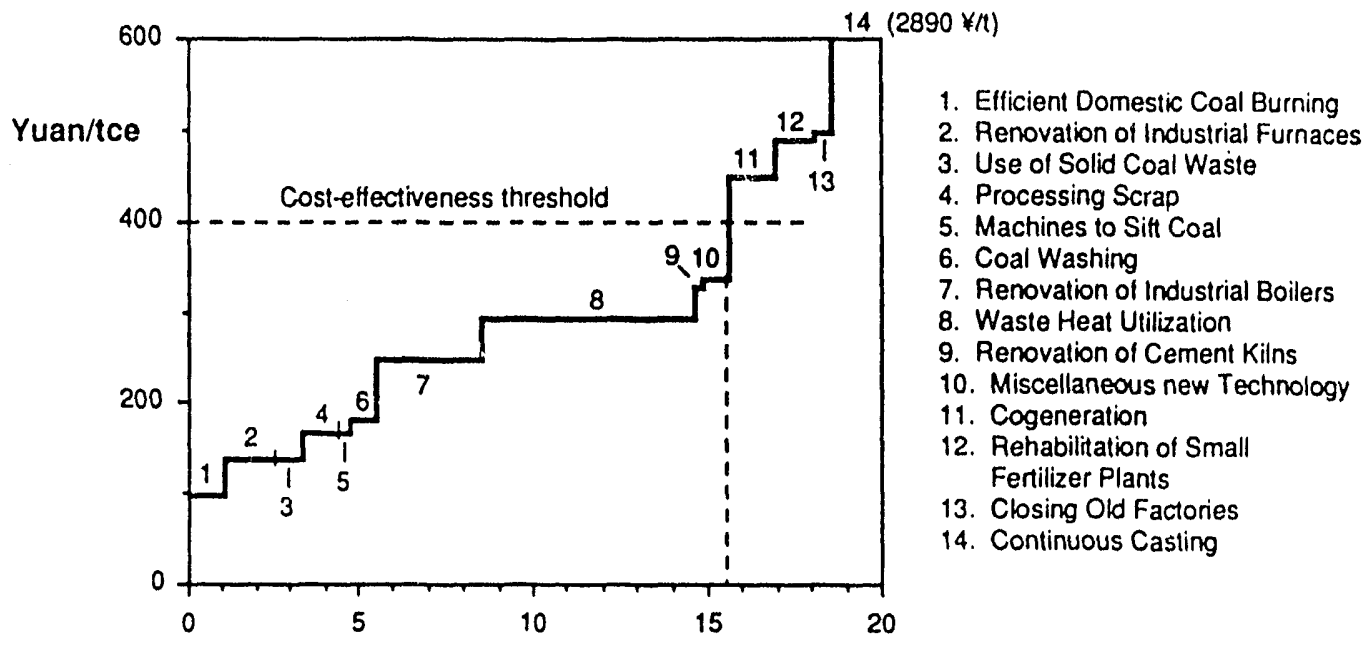

Figure. Cost of conserved energy in China's Sixth Five-Year Plan. (Mtce $=$ one million tons coal equivalent)

Annual Energy Savings (Mtce/y) 


\section{An Overview of China's Energy System}

\section{M.D. Levine, J. Audette, W.B. Davis, R.J. Hzang,} F. Lill, and J. Sinton

The objective of this project has been to study energy issues in the People's Republic of China related to global climate change. The rapid historical growth of energy in China, combined with the high proportion of coal use in the energy economy and the immense population of China, has made China a major contributor to global release of greenhouse gases.

This project involves close collaboration with Chinese researchers, particularly at the Energy Research Institute of the State Planning Commission.Work has concentrated on four topics:

- compilation of statistical data describing the evolution of the Chinese energy system;

- review and analysis of energy conservation programs in China;

- analysis of factors contributing to overall reductions in energy intensity in China over the past decade; and

- assessment of alternatives to coal-on both the demand and supply sides-to reduce growth of greenhouse gas emissions over the next 20 to 30 years.
Some key findings of the research to date:

- Extremely rapid economic growth in China has led to rapid increase in encrgy consumption.

- Despite the rapid growth in energy supply, China has persistent shortages of energy, particularly electricity and, more recently, coal.

- China has devoted considerable effort to improving the efficiency of energy use; as a result, energy has grown only half as rapidly as gross domestic product (GDP) over the past decade (Figure).

- Nevertheless, energy use remains very inefficient in China. However, care must be taken in making comparisons between China and industrialized countries. In the steel industry, for example, raw data suggest that the energy required to produce a ton of steel in China is twice that required in the U.S. A more careful analysis, in which corrections are made for accounting differences, differing products, and the like, reveals that the average intensity of Chinese steel plants is about $40 \%$ greater that U.S. plants.

Continuing work includes research in all four areas of the project as well as preparation of a monograph on critical energy issues facing China.

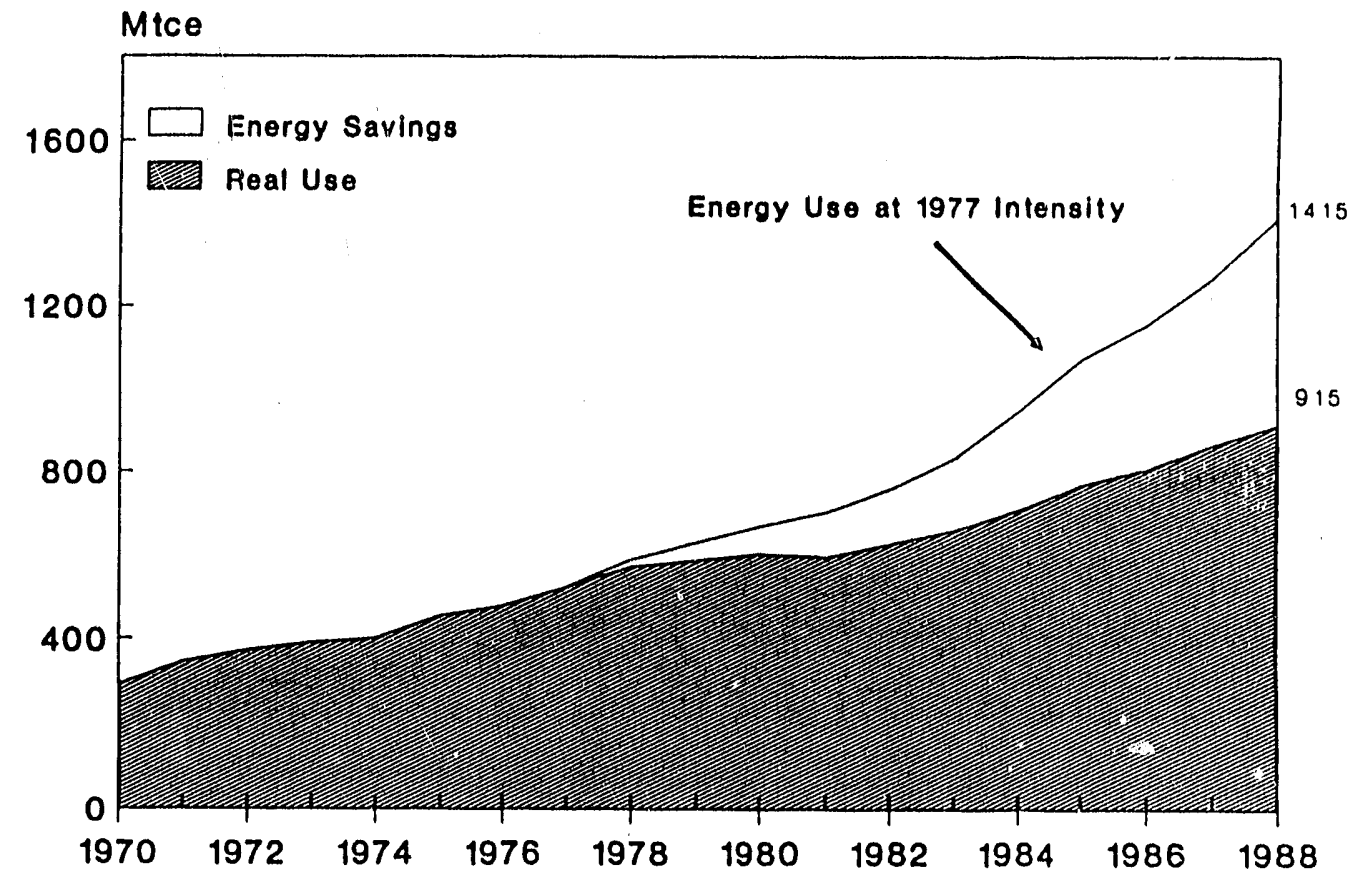

Figure. Energy/GDP growth in China Here GDP is national income and is at 1980) constant prices. (Mtce $=$ one million tons coal equivalent) 


\section{Building Energy Use and Conservation Opportunities in Commercial Build- ings in Southeast Asia}

\author{
M.D. Levine, J.F. Busch, and J.J. Deringer.
}

This research gathered and analyzed measured data on the energy performance of air-conditioned commercial buildings in Indonesia, Malaysia, the Philippines, Singapore, and Thailand. The results showed a significant difference between the most and least energy-intensive office buildings (Figure). In addition, average energy intensity among different building types varied considerably. Hospitals displayed the highest average annual energy intensity $\left(382 \mathrm{kWh} / \mathrm{m}^{2}\right)$, followed by shopping complexes $\left(332 \mathrm{kWh} / \mathrm{m}^{2}\right)$, hotels $(307$ $\left.\mathrm{kWh} / \mathrm{m}^{2}\right)$, and office buildings $\left(246 \mathrm{kWh} / \mathrm{m}^{2}\right)$. Substantial cost-effective energy savings are possible: $30 \%$ to $40 \%$ for new buildings using existing technology and 10\% to 20\% for existing buildings. An overall 20\% savings in energy use in commercial buildings in these countries would yield benefits of $\$ 400$ million a year. A new project related to this one involves

- expanding the database to include more buildings in more developing countries;

- performing analysis on the data (e.g., weather normalization) to permit comparisons among countries;

- working with other developing countries to establish model codes and other approaches to improve the energy efficiency of their buildings.

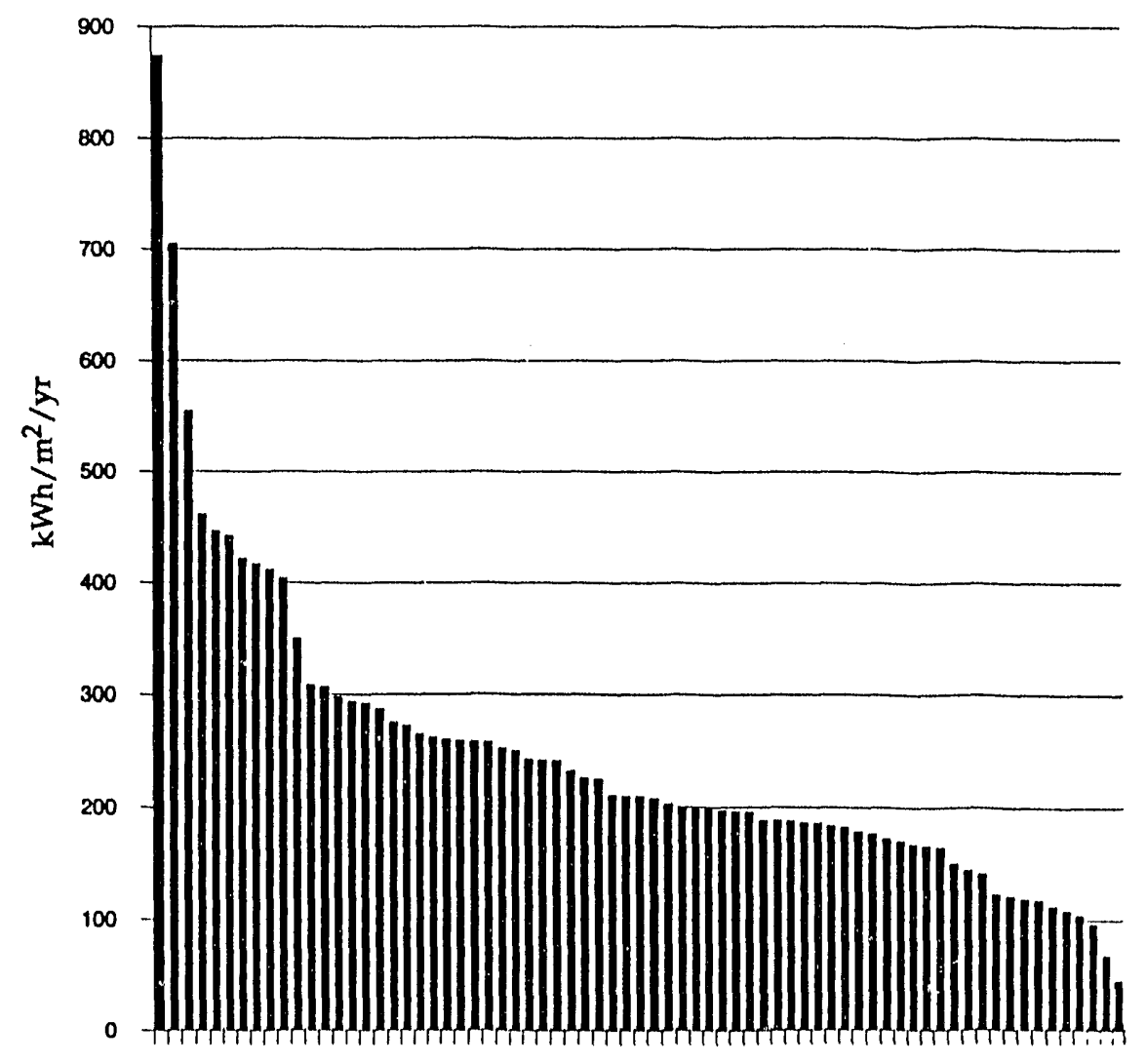

135791113151719212325272931333537394143454749515355575961636567697

Average $=246 \mathrm{kWh} / \mathrm{m}^{2} / \mathrm{yr}$

Figure. Annual energy use in Southeast Asian office buildings. 


\section{Conservation Potentials in the Building Sector in Pakistan}

\author{
H. Akburi, Y.J. Huang, R.L. Ritschard, and \\ O.A. Sezgen
}

In a study sponsored by $\mathrm{RCB} /$ Hagler, Bailly, Inc., we analyzed the conservation potential in residential and commercial office buildings in Pakistan. The elements of the study included:

- preparation of survey forms for residential and commercial buildings, and compilation of data to determine the characteristics of Pakistani buildings;

- analysis of the weather data to be used for the simulations;

- development of prototypical models for residential buildings, office buildings converted from residential buildings, and office buildings;

- determination of the promising and feasible combination of energy conservation measures;

- examination of energy performance of alternative HVAC systems for the office buildings;
- development of methods for making use of the large database generated from DOE-2 simulations of the buildings.

The study focused on the development and simulation of three prototypical buildings: a single-family detached house, an office converted from a single-family detached house, and an office building-each in five representative climate regions. For offices, prototypes have been developed for both individual office rooms with window air-conditioning units and large offices with central air-conditioning units. Typical conservation measures considered include: envelope retrofit measures to control heating and cooling loads of the building; energy-efficient lighting; energy-efficient heating and cooling system; and energy-efficient appliances (refrigerators, washers, driers, etc.). Our methodology for analyzing the impact of conservation measures included performing a systematic series of DOE-2.1D simulations, benchmarking and validating the simulation results with monthly utility bills, and performing parametric simulations of energy conservation measures.

For offices in Karachi, cooling energy use is very sensitive to air-conditioning COP, window film, roof and wall insulation, and roof color (Figure). The impact of wall color, efficient lighting systems, daylighting, and infiltration of airconditioning use is fairly low. Those measures that have the

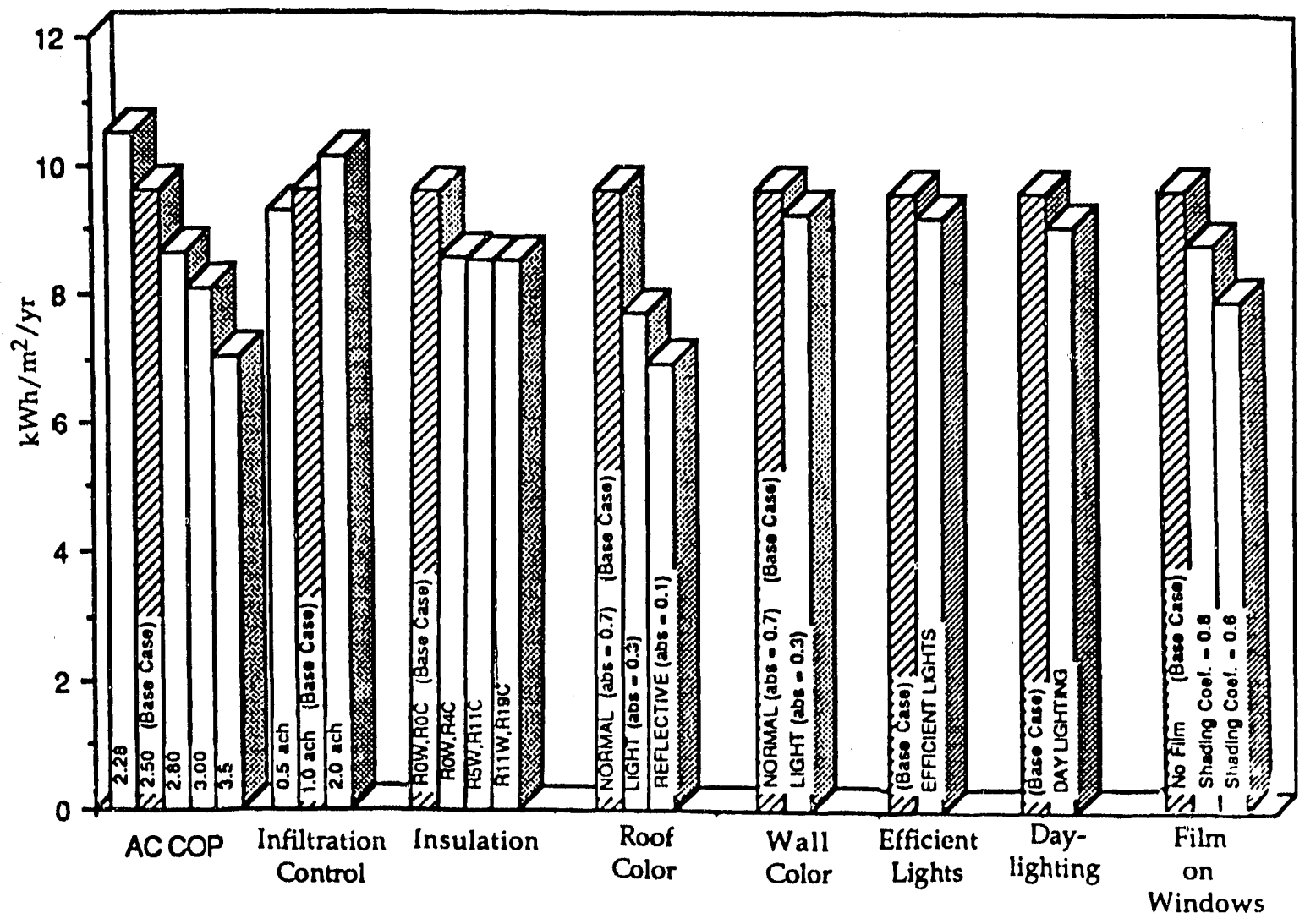

Figure. Simulated cooling energy use for a variety of conservation options in a prototypical office building in Karachi. 
greatest impact on heating energy demand are roof and wall insulation (positive impact), roof color (negative impact), and control of infiltration (positive impact). The combined parametrics for office buildings include variations in walls and roof insulation, roof color, air-conditioning COP, and air infiltration. Our simulations indicate that savings on the order or $30 \%$ to $60 \%$ in both heating and cooling energy use in Pakistani office buildings are easily achievable through use of simple and available conservation measures such as insulating roofs and walls, controlling; infiltration, use of
high-COPair-conditioning units, and coloring the roofs white. Similar potential energy savings are also possible for Pakistani houses and converted office buildings.

\section{Reference}

Akbari H, Huang YJ, Ritschard RL, Sezgen OA. Energy-Usi Characteristics of Pakistani Prototypical Office Buildings and Single-Family Houses. Lawrence Berkeley Laboratory Report No. LBL-293i8, July 1990.

\section{- International Energy Studies -}

\section{Soviet Energy Conservation:}

\section{A Dilemma}

\section{Schipper and R.C. Cooper}

We have carried out an extensive analysis of energy use in the Soviet Union. We found that the structure of energy use in the Soviet Union differs so much from that in the West that comparisons with Western countries of the ratio of total energy use to economic activity are almost meaningless. Put simply, the Soviet Union is far more materials- and freightintensive than most Western economies, while Soviet citizens have far less living space and mobility than Westerners. Moreover, most energy uses in the Soviet Union are considerably less efficient than are corresponding ones in the U.S. or Europe.

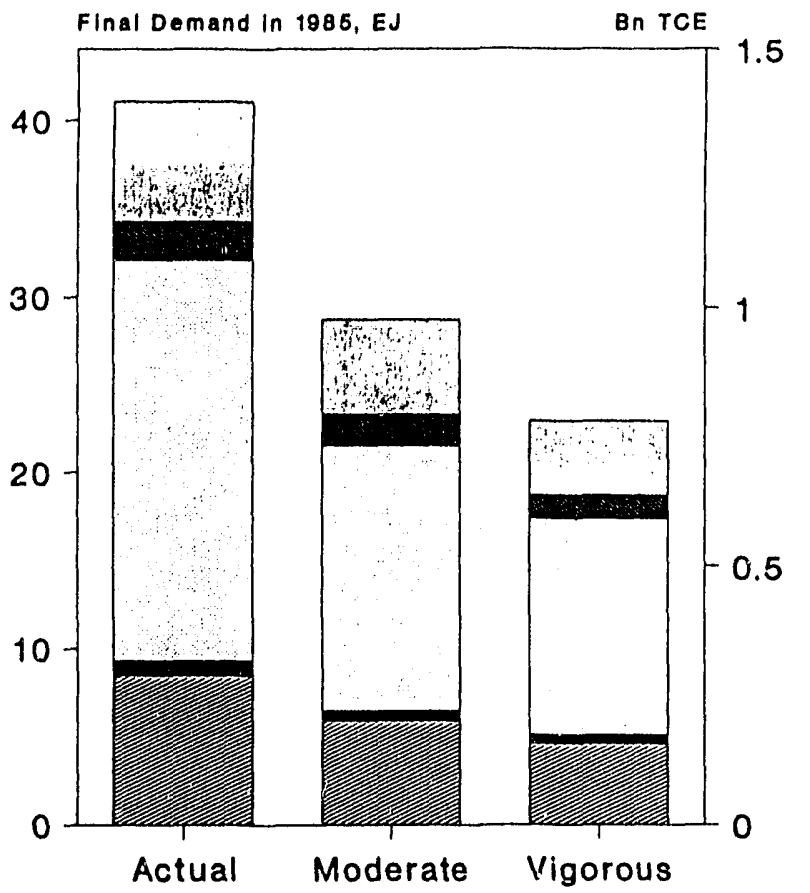

How much energy could be saved in the Soviet Union? If energy intensities fell to those of average Western practices, Soviet final energy use might fall as much as $30 \%$, as the Figure shows for the "moderate" case. If Soviet energy intensities were as low as those in new homes, factories, cars, and aircraft in the West, the reduction would be as much as $45 \%$, also showed in the Figure as the "vigorous" case. Reductions in the obvious waste of raw materials produced and shipped might allow for further reductions in energy use, but increases in comfort and mobility could require equal increases.

It has been difficult for the Soviet economy to save energy; most energy intensities have been stable, although fuel intensities of some subsectors (power production, certain materials, trucks, and railroads) have declined. What has prevented the realization of greater energy savings? The

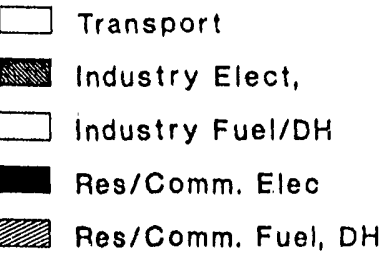

Figure. Soviet energy efficiency potential: implications for 1985 energy demand. Moderate = average Western intensities; Vigorous = lowest Western intensities; $\mathrm{DH}=$ district heating; $\mathrm{Bn}$ TCE = billion tonnes of coal equivalent. 
obvious barrier is the lack of realistic energy prices, which lie below replacement costs, as well as the lack of a mechanism that makes users pay directly for energy used. Other barriers include lack of interministerial cooperation, the shadow of secrecy over much data on how energy is actually used, and the closed nature of the Soviet economy, all of which have prevented application of many Western energy-saving techniques.

\section{References}

Schipper L, Cooper RC. Energy Llse and Comservation in the LIS.S.R: Patterns, Prospects, and Problems. Lawrence Berkeley Laboratory Report No. LBL-29831, 1991.

Cooper RC, Schipper L. The Soviet energy conservation dilemma. Energy Policy (in press, May 1991).

\section{Energy Efficiency in Japan: Myths and Reality}

\author{
L. Schipper, A. Sprunt, S. Christie, and H. Kibune*
}

Japan, with approximately the same per capita gross national product (GNP) as the United States in recent years, uses less than half as much the per capita energy as the United States. Do differences in the efficiency of energy use account for this difference in per capita energy use? To answer this question, we investigated energy use in Japan since 1970 for 25 sectors and end uses and compared these with similar end uses in the United States. We found that less than half of the difference in the energy to GDP ratio was caused by greater efficiency in Japan; the major part of the difference is caused by differences in how Americans and Japanese live.

We compared the levels of activity in Japan and the United States for manufacturing, travel, freight, residential, and the service sector. The manufacturing share of GDP in Japan is higher than the United States, but in other sectors, per

* Japan Institute of Energy Economics and Massachusetts Institute of Technology. capita activity is significantly less than in the United States. Japanese homes, for example, are less than $85 \mathrm{~m}^{2}$ in size vs. more than $140 \mathrm{~m}^{2}$ in the United States. The Japanese travel less than 10,000 km/year; Americans, more than 22,000) km/ year. If we examine the structure of activity in each manufacturing sector, Japanese output includes a larger share in energy-intensive raw materials than the United States. Japan transports far more of its domestic freight by truck, the most energy-intensive mode, than does the United States. But in consumer-oriented sectors, Japan's mix is far less energyintensive than that of the United States. Only $55 \%$ of Japan's total domestic travel is by car vs. $85 \%$ in the United States; only $5 \%$ of Japanese homes have central heating vs. over $80 \%$ in the United States, and the Japanese have virtually no clothes dryers, dishwashers, or freezers. If the United States had the same levels and mix of activities as Japan, primary energy use for the five sectors studied would be $20 \%$ less than it actually was in 1987. The Figure shows per capita energy use in the United States with the Japanese level and mix of activities assumed for the United States (but U.S. energy intensities), as well as the level of energy use that would obtain if the Japanese had the U.S. level and mix of activities (but Japanese energy intensities).
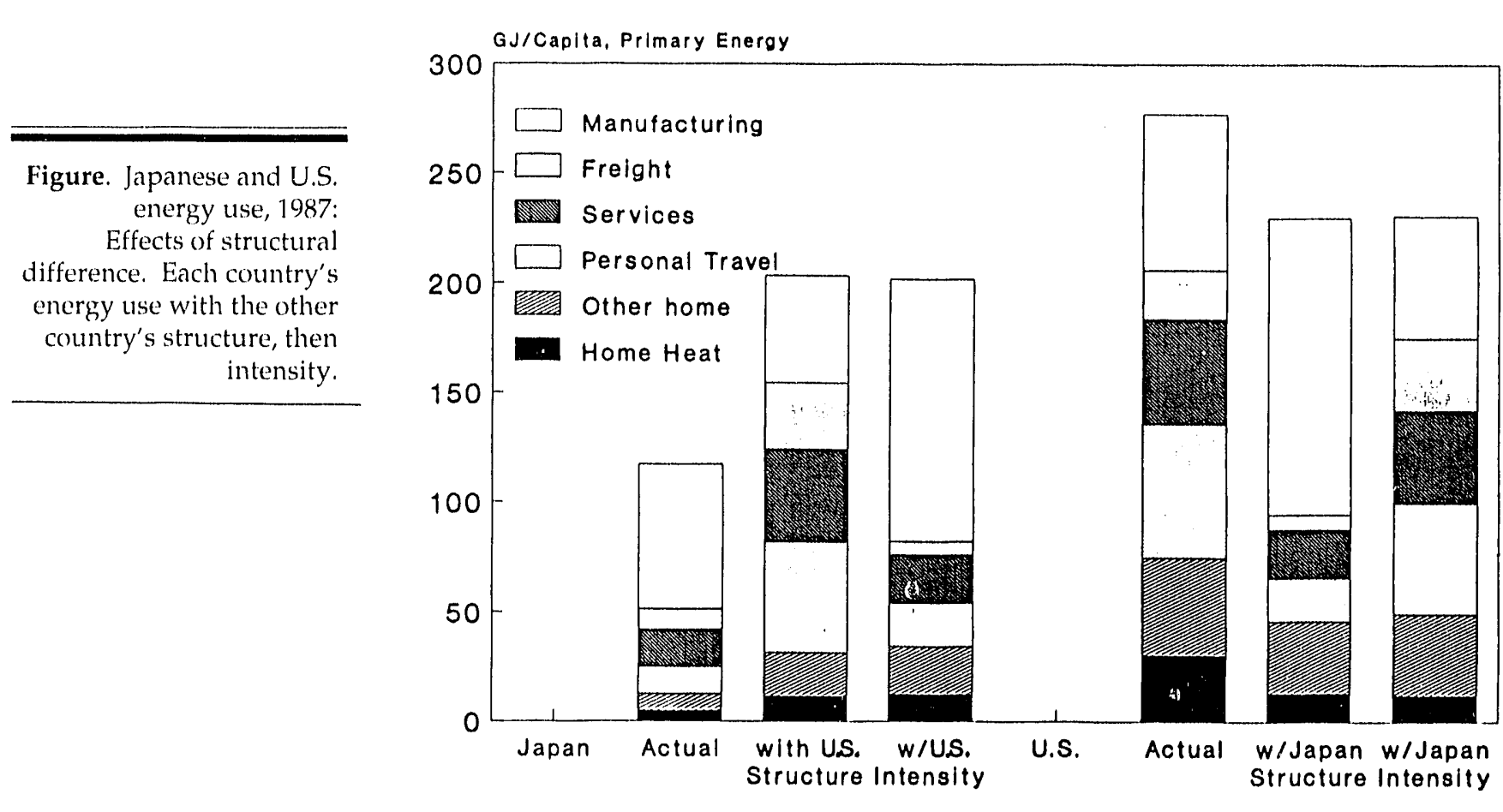
Does Japan use energy more efficiently than the United States? When allowance is made for differences in the mix of industrial output, Japan uses approximately 30\% less energy per unit of output in industry than the United States. Japanese trucks use less energy per tonne-km than American trucks. Japanese appliances refrigerators and air conditioners appear to use $25 \%$ less energy than comparable American ones, and Japan's auto fleet about $30 \%$ less energy $/ \mathrm{km}$. Japanese households use only $40 \%$ as much heat, per unit of floor area and degree-day, as American homes, but this difference is caused almost entirely by the spartan heating habits of the Japanese, who only heat occupied rooms to 14 or $15 \mathrm{C}$. In all, if Americans used energy with the same intensities as the Japanese, U.S. primary energy use in the five sectors studied would be about $20 \%$ less than it actually was in 1987, as the Figure also shows. Ignoring Japanese heating practices, U.S. energy use would only fall by $15 \%$. Thus we can state that lower energy intensities in Japan account for half (or less) of the difference in the energy/GDP ratio; differences in the mix of activities and lifestyles account for the rest.

Since 1973, the ratio of energy use to GDP fell in Japan by $31 \%$, and in the United States by $26 \%$. After we account for changes in the mix of activities in each sector, we found that energy intensities in Japan fell $20 \%$, those in the United States, by $19 \%$. Almost all of the savings in Japan occurred in the manufacturing sector, while significant savings in the United States also occurred in households, services, and transportation. We found that the savings in Japanese industry led those of all industrialized nations, but a significant slowdown occurred after oil prices fell in 1986. In sectors not engaged in world trade domestic transportation, households, and services however, little energy saving occurred in Japan, in part because standards of comfort there increased. While there is certainly a potential for further energy efficiency increases in these sectors in Japan, continued increases in comfort and mobility may offset the impact of these savings on Japanese energy use.

\section{References}

Schipper L, Howarth R, Geller H. United States energy use from 1973 to 1987: The impacts of improved efficiency. Anmual Revieze of Energy 1990);15:455-504.

Howarth R, Schipper L, Duerr P. Manufacturing Oil and Energy Use in Eight OECD Commtries. Lawrence Berkeley Laboratory Report No. LBL-27887, 1990.

\section{Changes in Energy Use for Passenger Travel in Major Industrialized Countries, 1970-1987}

\author{
L. Schipper, P. Duerr, R. Stciner, F. An, and \\ S. Strom*
}

This work analyzes some of the changes that took place in the structure of energy use for passenger travel in industrialized countries. Data are presented on energy use and travel activity for the four major modes of travel (automobile, bus, rail, and air) for eight countries: United States, Japan, the U.K., West Germany, France, Italy, Sweden, and Norway. We use the Laspeyres and Divisia ind ices to analyze the causes of the change in energy use between 1970) and 1987. The total change in energy use for travel is explained by changes in domestic passenger transport volumes, the mix of modes of travel, and the energy intensities of each mode.

We have found two important effects that since 1970 have had a fundamental impact on energy use for travel. First, shifts among modes of transport toward more energyintensive modes and toward large increases in travel volume (measured in passenger-kilometers) increased the energy used for travel in many industrialized countries, often more rapidly than the overall growth in the gross domestic product. Second, energy intensities of passenger transport (mea- sured in MJ/passenger-kilometer) fell in only a few countries between 1970 and 1987. Although individual automobiles have become more energy-efficient, efficiency improvements have been restrained - or even offset - by greater automobile size, power, and weight; by worsening traffic conditions in Japan and Europe; and by lower occupancy per car.

The Figure (see opposite page) shows the effect of changes in energy intensities on energy use for passenger travel. Holding constant both the volume of travel and the mix of modes, we calculate the change in energy use caused only by changes in the intensities of individual modes, with 1970) energy use indexed to 100 . Particularly notable are the increases in intensities in Japan and West Germany. The most important exception to this trend was the United States, but the intensities of land-based travel remain higher there than in most other countries. These findings lead to a pessimistic outlook for future energy use for travel. After all, if little or no energy was saved during the decades of high fuel prices, what can be expected in the 1990s?

\section{References}

Schipper LJ, Duerr P, Steiner R, An F. Energy Llsc in Passinger Trimsiport in OECD Countric's: Change' Betre'e'n 1970 and 1987. Lawrence Berkeley Laboratory Report No. LBL29830, 1991.

* University of Oslo, Norway 
1970 Energy Use $\cdot 100$

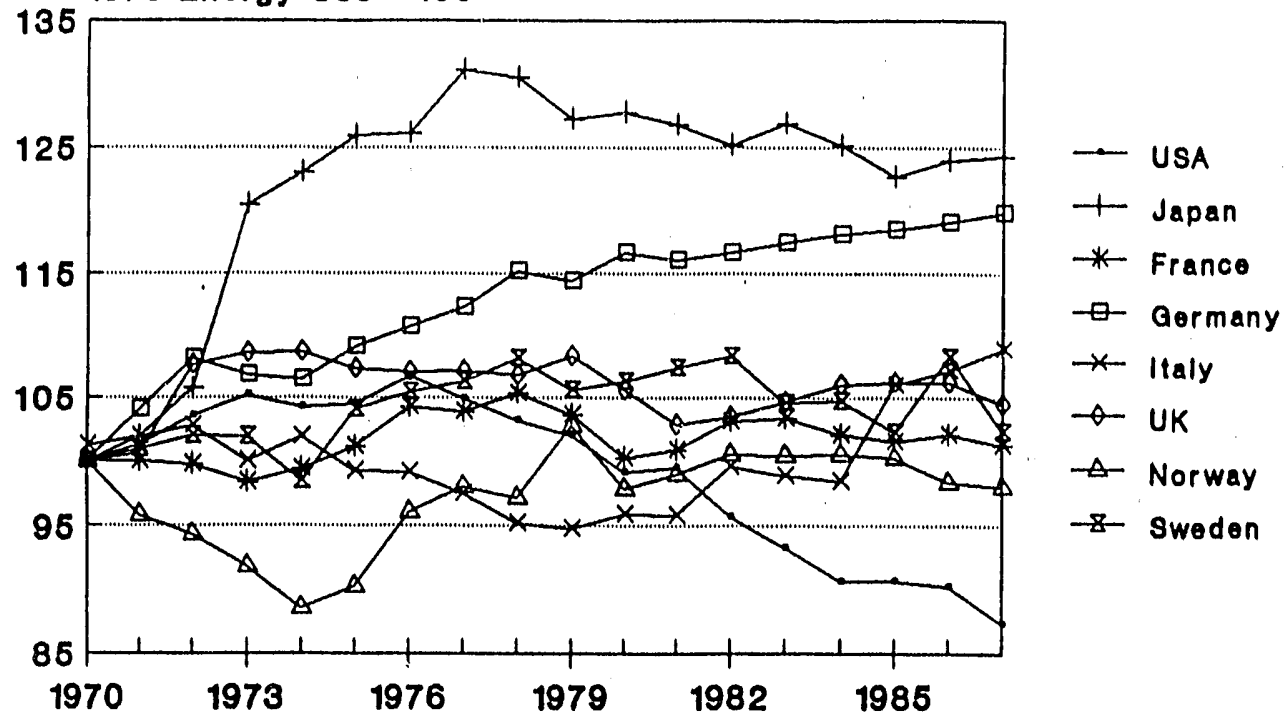

- Modal MIX and Actlvity hold constant at 1970 lovols

Figure. Travel energy use in major industrialized countries (varying energy intensity)

\section{Energy Savings in Industrialized Countries Since 1973: Achievements and Prospects}

\author{
L. Schipper, R. Howarth, P. Duerr, R. Steiner, \\ A. Sprunt, A. Ketoff, and S. Meyers
}

We have made an exhaustive study of changes in energy use in major Organization for Economic Cooperation and Development (OECD) countries. Our analysis is based on detailed sectoral studies of manufacturing, transportation, households, and services in the United States, Japan, Denmark, Sweden, Norway, the U.K., West Germany, France, and Italy. In the United States, Japan, and West Germany, reductions in energy intensities alone lowered primary energy used by about 20\% between 1973 and 1987. In the other countries studied, overall energy savings were generally comparable. We focus here on key sectoral results.

In spite of oil price shocks, transportation energy use in most OECD countries was considerably higher in 1987 than in 1973. Total travel increased, as did the share of travel occupied by energy-intensive cars and air travel. In contrast to passenger transport, growth in freight was slow. However, the share of energy-intensive truck freight increased. In all, these changes in activity and in the mix of modes increased energy use in every country studied.
Only the United States showed aggregate energy savings in transportation, although significant improvements were realized in certain modes in all countries studied. The intensity of air travel, for example, fell substantially in each country examined. The on-the-road fuel intensities of cars fell by $30 \%$ in the United States, but less than $10 \%$ in the other countries; new cars behaved similarly and little progress was achieved after 1986 (Figure, next page). For freight trucks, fuel use per kilometer decreased, but fuel use per tonnekilometer actually increased in most countries studied, including the United States.

In manufacturing, energy use declined even though output increased by nearly one-third in the countries studied. The shift away from the processing of raw materials alone reduced energy use for manufacturing between 1973 and 1987 by an average of $3 \%$ in six European countries, by $12 \%$ in Japan, and by $15 \%$ in the United States. Reductions in energy intensities in the major sub-sectors reduced manufacturing energy use by $33 \%$ in the United States, by $37 \%$ in Japan, and an average of $29 \%$ in six European countries betw'sen 1973 and 1987.

Energy intensity in the residential sector fell in almost every country, but important increases in comfort offset much of the savings. The energy requirements of household appliances behaved similarly, falling an average of $15 \%$ in the major OECD countries. Energy requirements for new appliances fell by as much as $50 \%$ by 1985 compared with 1973 models. But the improvements in both space-heating and appliance efficiency began to slow after 1985. 
Energy saving in the service sector was mixed. In virtually every country studied, the ratio of fuel used to total floor area or gross domestic product originating from the service sector fell more than $25 \%$, but electricity intensity fell very little or increased. Savings in space heating account for much of the decline in fuel intensity. Increased penetration of electric heating, computers, and greater lighting levels were the main barriers to a real decline in electricity intensity.

This comparison reveals that OECD countries reduced many important energy intensities and saved energy between 1973 and 1987. In the case of manufacturing, the energy savings represented an acceleration of historical trends from the 1950s. In the residential and service sectors, the savings achieved broke with previous trends. In transportation the record was mixed; only in the air travel sector were there clear energy savings. The recent slowdown in the pace of energy savings in automobiles, trucks, and homes is troublesome if industrialized countries are to count on reducing future fossil fuel use to restrain emissions of $\mathrm{CO}_{2}$.

\section{References}

Schipper L, Steiner R, Duerr P, Strom S, An F. Encrgy LIsc in Passe'tiger Transport in OECD Countries: Change's Betzueen 1970 and 1987. Lawrence Berkeley Laboratory Report No. LBL-29830, 1991.

Howarth R, Schipper L, Duerr P. Mamufacturing Oil and En'rgy Llse in Eight OECD Conntries. Lawrence Berkeley Laboratory Report No. LBL-27887, 1990.

Ketoff A, Schipper L. Looking beyond aggregate household energy demand: What really happened to conservation. In: Proceedings of the ACEEE 1990 Summer Study on Energy Efficiency in Buildings, August 26-September 1, 1990. Washington, DC: American Council for an Energy-Efficient Economy, 1990, pp. 9.157-9.183.

Srhipper L, Hawk D. More efficient household electricity use: An international perspective. Entergy Policy (in press, 1991).

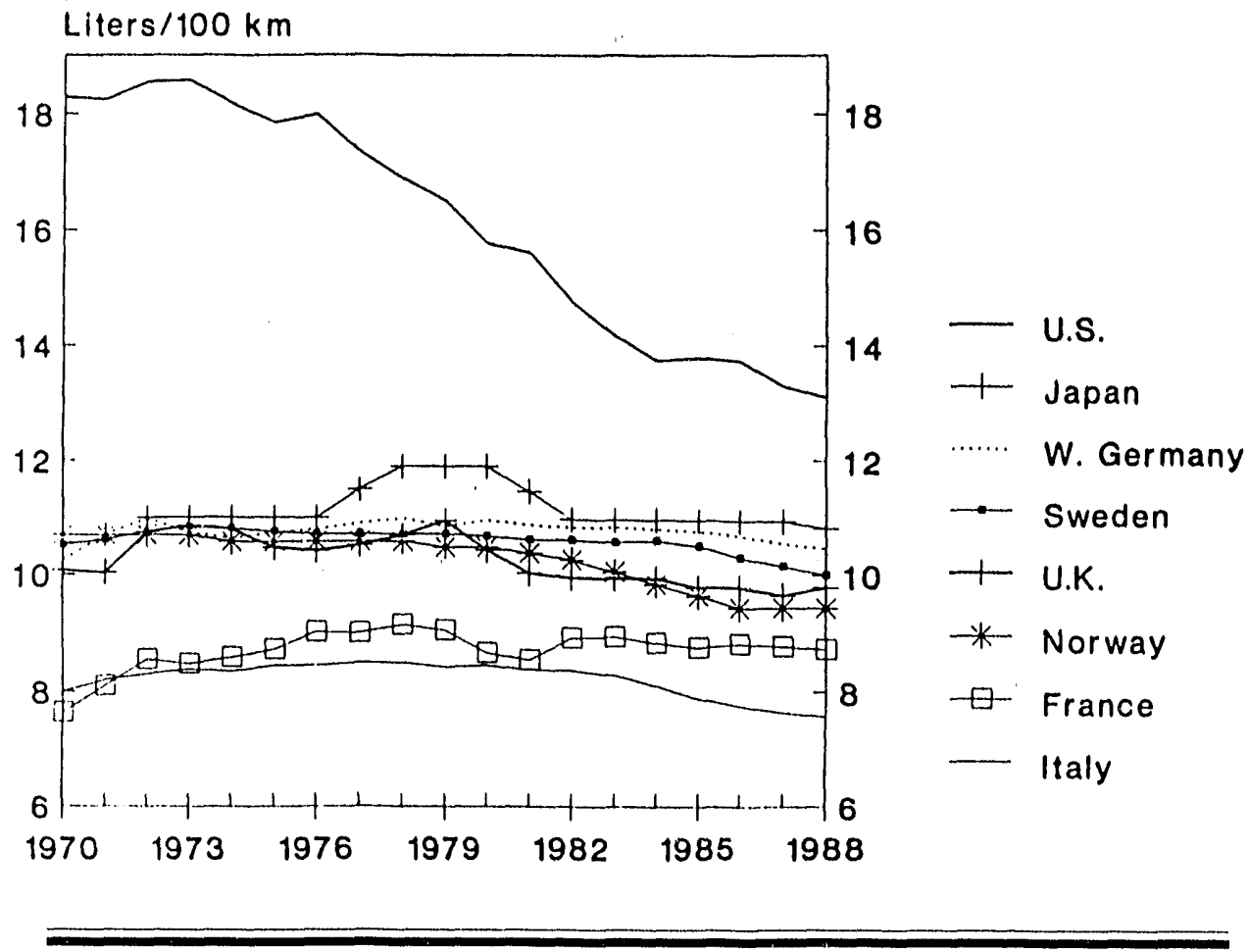

Figure. Automobile fuel economy, on-the-rond fleet averages. Includes diesel cars and, for the United States, personal light trucks. 


\section{Changes in Energy Use, 1973-1987: An Overview for Three Countries}

\author{
L. Schipper, R. Howarth, and S. Meyers
}

For the three largest Organization for Economic Cooperation and Development (OECD) economies, the United States, Japan, and West Germany, we analy zed the impacts of changes in activity levels, structure, and energy intensittes in five sectors between 1973 and 1987, calculating the evolution in sectoral energy use that would have been driven by each factor if the other two had remained fixed over time. For each of these components of change, we also constructed a weighted average to estimate the cumulative impact across sectors. In this analysis, we estimated the impact on primary energy' use.

Increases in sectoral activity placed strong upward pressure on manufacturing energy use in the United States and Japan, but not so much pressure in West Germany. Growth in activity played a major role in passenger transportation and in the services sector in all three countries. Activity in freight transport, measured in ton- $\mathrm{km}$, had a somewhat less strong impact. The smallest impact of activity was in the residential sector, especially in West Germany, where population did not increase at all. Weighting the activity impact in each sector according to the sector's share of energy use in 1973, we find that the cumulative impact of growth in activity (holding structure and energy intensities constant) was to increase energy use by $45 \%$ in Japan, by $34 \%$ in the United States, and by $18 \%$ in West Germany. In each country, the weighted average of activity change was less than the growth in gross domestic product (GDP), which was $73 \%$ in Japan, 40\% in the United States, and 29\% in West Germany.

Changes in the mix of activities or output in each sector (also called "structural change") pushed upward on energy use in most cases except manufacturing. In that sector, reductions in the importance of basic materials industries lowered energy use by $11 \%$ in Japan, $14 \%$ in the United States, and $2 \%$ in West Germany. Increases in the share of passenger travel in automobiles and airplanes raised energy use by $3 \%$ in the United States and by $5 \%$ in West Germany, but by $21 \%$ in Japan. Changes in the modal mix of freight transport increased energy use by $29 \%$ in Japan and by $14 \%$ in West Germany, but by only $2 \%$ in the United States. Structural change had the greatest impact in the residential sector. Increases in home floor area, central heating, and appliance ownership raised energy use by $37 \%$ in the United States, $54 \%$ in West Germany, and $97 \%$ in Japan. In the service sector, on the other hand, the impacts of structural change were relatively small. In aggregate, structural change within the five sectors, given constant activity levels and energy intensities, raised energy use by $7 \%$ in Japan, by $5 \%$ in the United States, and by $15 \%$ in West Germany.

Changing energy intensities had a significant impact in reducing energy use in most sectors. In manufacturing, intensity changes reduced energy ure by $20 \%$ to $30 \%$ in all three countries. In passenger transportation, modal intensity change reduced energy use by $20 \%$ in the United States and by $3 \%$ in Japan, but increased it by $12 \%$ in West Germany. In freight transportation, intensity reduced energy use by $2 \%$ in the
United States, $11 \%$ in Japan, and $16 \%$ in West Germany, In the residential sector, change in intensities reduced energy use by $20-24 \%$ in the United States and West Germany, but increased use by $9 \%$ in Japan. Cumulatively, changing energy intensities, given constant activity and sectoral structure, would have reduced energy use by $20 \%$ in Japan, $21 \%$ in the United States, and $17 \%$ in West Germany.

For Japan and the United States, the declines in weighted intensity are less than the decrease in the energy/GDP ratio, which was $34 \%$ in Japan, and $26 \%$ in the United States. The two declined by about the same proportion in West Germany. These differences exist because changes in the mix of activities within sectors, as well as changes in the relative activity levels of the sectors, had a powerful effect on energy use. In West Germany, such changes in manufacturing were offset by shifts towards greater intensity in transportation and in the residential sector.

We can estimate the savings due to intensity change between 1973 and 1987 in these countries, i.e., the increased amounts of primary energy that would have been used had intensities not decreased. The calculations show that total savings of primary energy were 17.2 exajoules (EJ) in the United States, 3.4 EJ in Japan, and 2.0 EJ in West Germany. Put differently, primary energy use in 1987 would have been $26 \%$ higher in the United States. if intensities had not declined, $23 \%$ higher in Japan, and 21\% higher in West Germany.

\section{References}

Schipper L, Howarth R, Geller H. United States energy use from 1973 to 1987: The impacts of improved efficiency. Annual Review of Energy 1990;15: 455-504.

Schipper L. Energy Demand and Efficiency in Japan: Myths and Realities. Presentation to the U.S. Dept, of Energy, Oct. 1, 1990.

Schipper L, Howarth R. Energy ina Long-Term Perspective: The Case of Germany. Lawrence Berkeley Laboratory Report No. LBL-30468, 1991. 


\section{Improving Appliance Efficiency in Indonesia}

\section{Schipper and S. Meyers}

We studied the patterns of household electricity use in urban Java, Indc nesia, based on results from a 1988 World Bank survey of 2700 households, as well as the market for and characteristics of appliances currently sold in Indonesia. We estimated the degree of cost-effective improvement in appliance energy efficiency that could be achieved, and its impact on future electricity demand. Finally, we studied the barriers to improvement of appliance efficiency and described various policy approaches that the government could take in order to accelerate the adoption of higher-efficiency appliances. While we focused our attention on Indonesia, many of the conclusions apply to other developing countries as well.

To illustrate the potential impact of more efficient appliances on residential electricity use, we developed a scenario of future demand in the year 2008. Our estimate of appliance saturation was based on the levels of saturation found in upper-income households in Java and in mure advanced Asian developing countries. We then applied the assumed levels of saturation to the projected number of households in urban Java in 2008. To make a base case, we assumed no change in the unit electricity consumption (UEC) of any appliance. We then estimated the reductions in unit consumption that could occur by comparing the UEC of existing appliances in Indonesia with those in other countries, notably Japan, West Germany, and the United States, and by examining various technical and economic studies of conservation potentials for home appliances (Figure).
The "best 1988 " scenario assumes that the average appliance in 2008 incorporates the technology used in the most efficient applances available today in the market of industrialized countries. In some cases, such technology is present in the top-of-the-line imported models sold in Indonesin. In this scenario, the percentage reduction relative to the UEC in 1988 is in the 2()-30\% range for most appliances.

The "advanced" technology scenario assumes that the average appliance in 2008 incorporates technology that is beginning to be adopted, or could soon be adopted, by manufacturers in the market industrialized countries. In this scenario, the percentage reduction relative to the UEC in 1988 is in the 30-50\% range for most appliances (and $60 \%$ for refrigeraturs and air conditioners).

Compared to the consumption that would be obtained if the average UECs in 2008 were the same as those of today, which is 26.0 TWh, the results show a savings of 8.0 TWh in 2008 for the "best 1988" scenario, and 13.7 TWh for the "advanced" technology scenario. To put these numbers in perspective, actual residential electricity consumption for all of Java in 1987 was about $4.8 \mathrm{TWh}$.

Growth in the number of households with electricity and in the number of appliances they own will have a significant impact on future electricity demand in Java and in most other parts of the developing world. Improved technology could i educe energy requirements for these appliances and thus restrain the growth in future electricity demand significantly. During the 1991 fiscal year, we will examine more closely this prospect, extending our Indonesian study to other countries in Southeast Asia.

\section{Reference}

Schipper L, Meyers S. Improving appliance efficiency in Indonesia. Energy Policy (in press, June 1991).

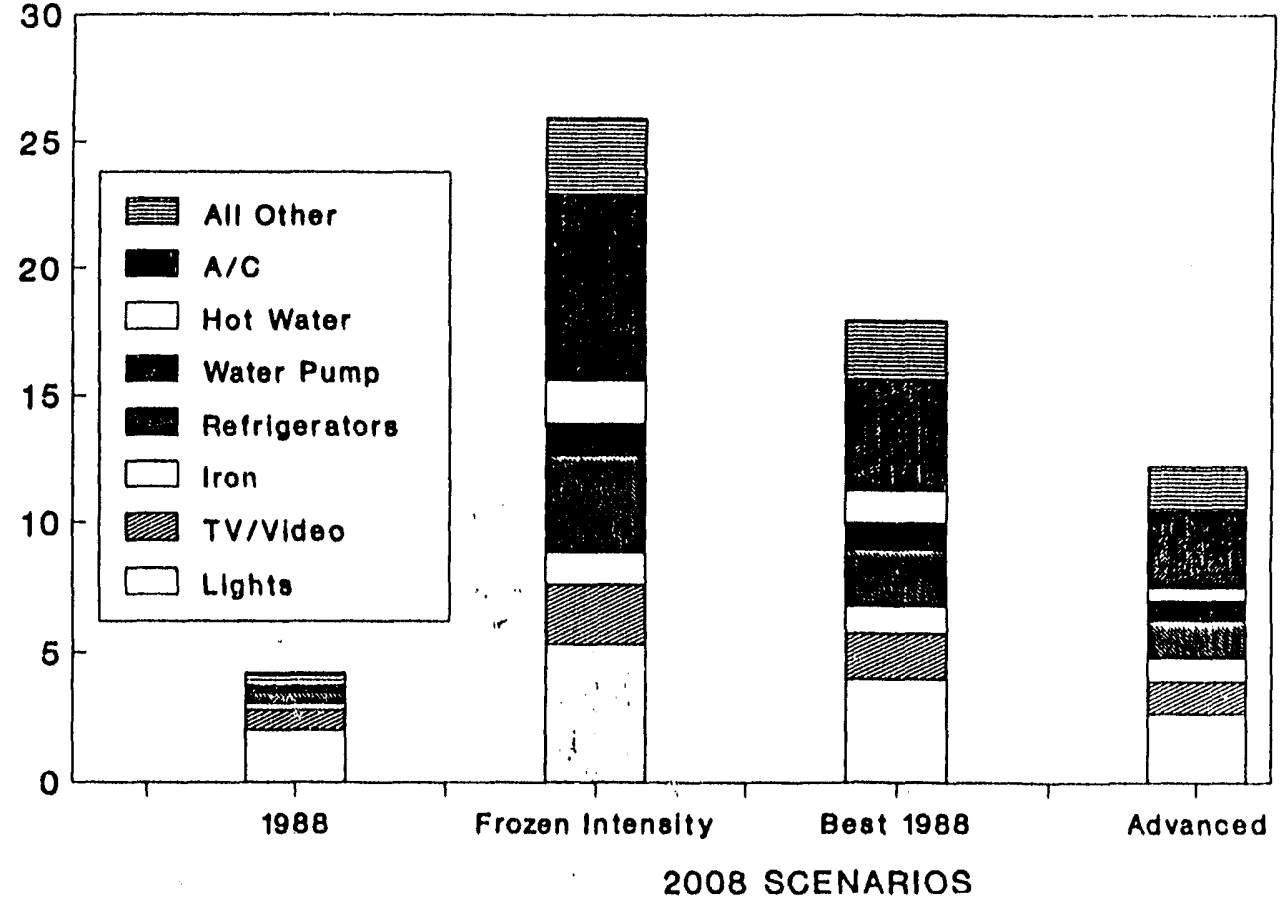

-34 -
Figure. Urban

household electricity use in Java, Indonesia. Patterns in 1988 and three scenarios of future use. 


\section{Energy Efficiency and Household Electric Appliances in Developing Countries}

\author{
S. Meyers, S. Tyler, H. Geller, I. Sathayee, and \\ L. Schipper
}

Residential electricity demand is growing at a rapid rate in many developing countries, contributing to financial problems for electric utilities as well as to negative environmental impacts of electricity generation. Major reasons for the growth are rapid increases in appliance ownership and the relative inefficiency of appliances sold in developing countries.

The purposes of this project are to assess the extent of growth in appliance ownership, to gain a better understanding of the characteristics and energy efficiency of appliances, to assess the potential for and barriers to improved appliance energy efficiency, and to consider strategies for realizing higher energy efficiency in new appliances. We gathered and analyzed information on appliances in a number of countries, including Brazil, Egypt, Indonesia, South Korea, Taiwan, and Thailand.

We found that saturation of several major appliances such as television sets and refrigerators has already grown significantly in upper-income developing countries, and is currently growing fast in many middle-income countries. The size of the typical new refrigerator is small (150-250 liters) compared to new refrigerators in Europe and Japan (300-400 liters).

Most major appliances are assembled by local companies operating in collaboration with companies based in Japan, Europe, or the United States. Designs typically used in developing countries are well behind the state-of-the-art, since companies are very keen to keep appliances affordable to consumers in developing countries.

The energy efficiency of new appliances is difficult to assess due to lack of uniform testing procedures, but it seems that efficiency has improved in at least some countries. In South Korea, which exports large numbers of appliances, data from manufacturers show considerable improvement in energy efficiency since 1980 ) for refrigerators, room air conditioners, and television sets (Figure). In Brazil, where a testing and labeling program for new refrigerators was initiated in 1986, the average test energy use of the most common onedoor size declined from 490 to $435 \mathrm{kWh} / \mathrm{yr}$ between 1986 and 1989; the most efficient Brazilian model in 1989 used only 335 $\mathrm{kWh} / \mathrm{yr}$.

There appears to be a considerable potential to introduce design changes in major appliances that save electricity at much lower additional cost than it costs utilities to provide electricity to residential customers. For refrigerators, increasing insulation thickness and use of higher-efficiency compressors are among the options that are likely, to be costeffective. For air conditioners, use of rotary compressors, larger heat exchangers, and more efficient motors could reduce electricity consumption by at least $20-40 \%$ in many cases. In Brazil, analysis of the costs and energy-savings benefits of a variety of design changes that could be implemented by local manufacturers found an average cost of conserved electricity of about $\$ 0.03 / \mathrm{kWh}$, well below the marginal cost of supply to residential customers of $\$ 0.12$ / kWh.

Despite the economic attractiveness of improving appliance efficiency, implementation of cost-effective design changes is likely to be slow due to lack of consumer knowledge about and interest in energy efficiency and the reluctance of manufacturers to introduce changes that would increase the cost of appliances intended for the mass market. Given the severe problems of the public power sector in

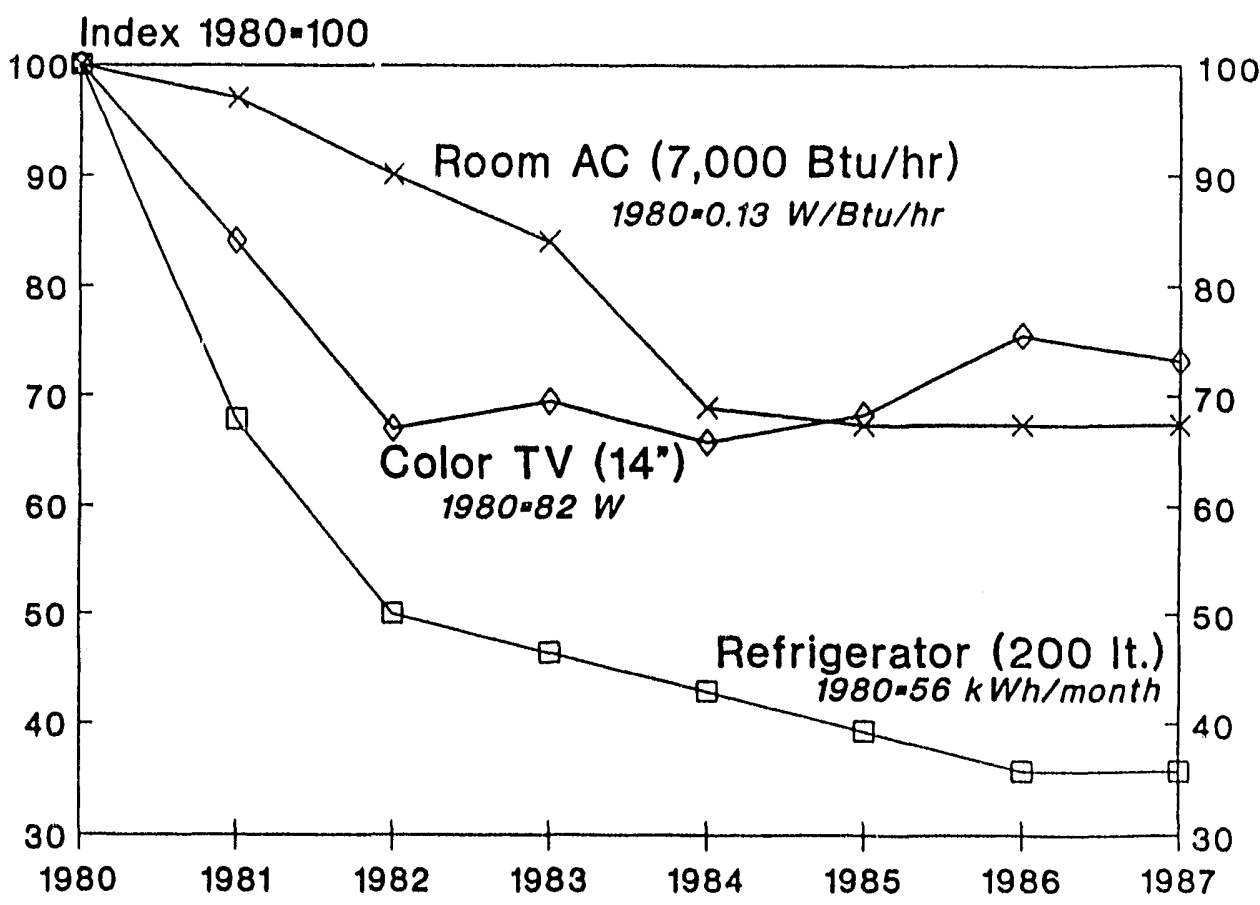

Figure. Energy use of new Korean appliances. 
many countries, government involvement is likely to be necessary to accelerate the market's adoption of design changes. Such involvement could range from minimum efficiency standards to agreements with manufacturers to improve energy efficiency. The latter approach is currently being implemented in Brazil for refrigerators. Gaining a better understanding of current levels of appliance energy efficiency through testing programs is important to develop and implement strategies to improve appliance efficiency. The indusirialized countries also have an important role to play, since many appliance manufacturers in developing countries seek to expand exports to those countries. Design changes made in order to meet standards in the industrialized countries in turn affect the designs used in appliances intended for the domestic market

During the 1991 fiscal year, we intend to continue investigating issues concerning appliance energy efficiency in developing countries. We are undertaking a study of appliance efficiency prospects in Southeast Asia, with a particular emphasis on involving international appliance manufacturers.

\section{Reference}

Meyers S, Tyler S, Geller H, Sathaye J, Schipper, L. Energy Efficiency and Household Electric Applinnces in Developing and Neroly lindustrinlized Comntries. Lawrence Berkeley Laboratory Report No. LB1-29678, 1990.

\section{Oil Use in the Developing Countries: Statistical Analysis and Le: g-Term Scenarios}

\author{
1. Sathaye, S. Stoft, W. Setiawan, and L. Lee
}

From a small base, energy demand in the developing countries is growing rapidly. As the economies of these countries develop, the demand for energy, particularly for oil, will increase. Economic development is accompanied by large changes in the structure of energy use in these countries. The changes in economic structure, demography, and location of households will alter the elasticity of energy use. The use of constant elasticity models is likely to provide incorrect projections of future energy use.

During the 1989 fiscal year, we estimated variable elas-

* Countries studied: Argentina, Brazil, India, Indonesia, Malaysia, Mexico, Pakistan, the Philippines, South Korea, Taiwan, and Venexuela. ticity of energy demand for transportation energy in eleven developing countries from 1970 through 1988.* Demand for various fuel types within the transportation sector was also estimated.

Per capita demand for transportation energy was modeled as a function of income, price, and an unspecified country-specific factor. The country-specific factor is multiplicative and varies by more than a factor of two between India (which has the highest factor) and Solith Korea and Indonesia (which have the iowest factors). These factors tended to remain fairly constant throughout the time period of our study, indicating that they can be used in long-range forecasts.

In modeling the elasticity of energy demand, we found that the poorer countries are generally more elastic with respect to both income and price. In very poor countries, short-run income elasticity is as high as 0.6 and long-run as high as 1.8 . The elasticity with respect to price was found to have less than half the magnitude of the income elasticity. Both elasticities were found to drop dramatically as income increased, but we do not yet have sufficient data to estimate the elasticities of the wealthiest developing countries in our sample (Figure).

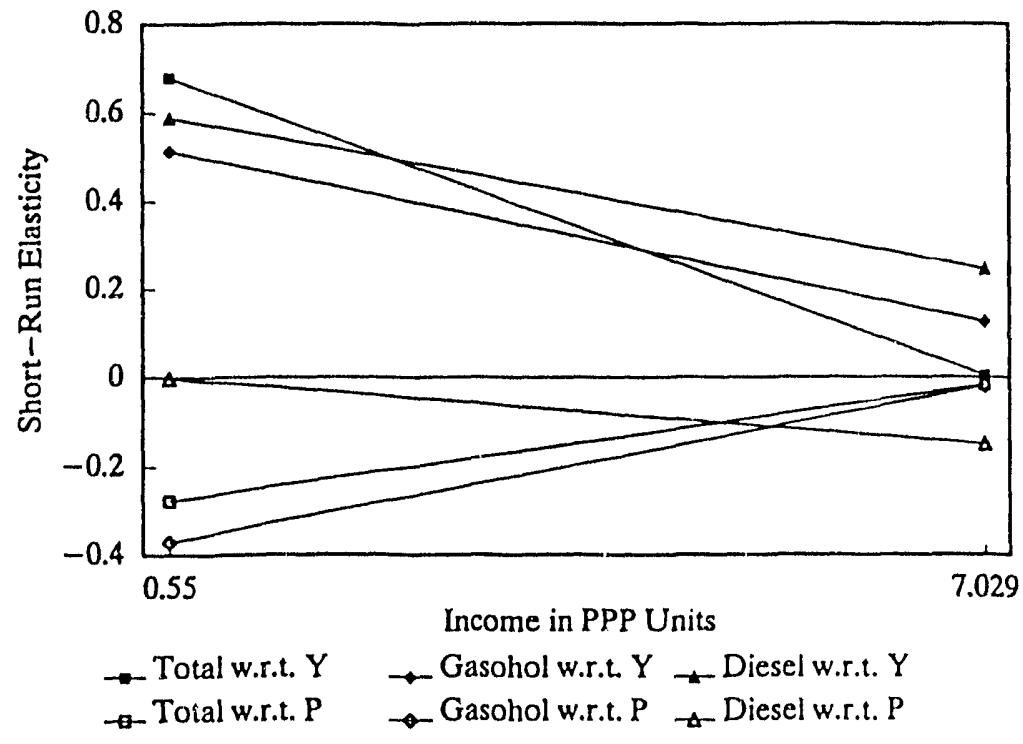

Figure. Short-run elasticities of transport fuels for twelve developing countries. Purchasing-Power Parity (PPP) is a special conversion factor designed to equalize purchasing powers of various countries' currencies. PPP is defined as the number of units of a country's currency required to buy the same amounts of goods and services in the domestic market as one dollar would buy in the United States. (w.r.t. $Y=$ with respect to income; w.r.t. $P=$ with respect to price.) 
Luring the 1990 fiscal year, we have extended this model, developed for the transportation sector, to cover all oil and energy use in these countries. We have also investigated the changes in results from the addition of lower-income industrialized countries to the earlier analysis. The results for overall oil and energy use are consistent with those for the transport sector. The addition of the industrialized countries did not alter the results for either the transport analysis or for the overall oil and energy use analysis.

\section{References}

International Energy Studies Group, LBL. Progress Report: Energy Llse in the Deruloping Conntries: A Statistical Analysis: Focus on Transportation. Report to the U.S. Department of Energy, 1989.

Stoft S, Sathaye J. Chmuging De'mund Elasticitie's and Their Use' in Forecasting the Domand for Ene'ryy in Dereloping Comntrie's. Lawrence Berkeley Laboratory Report No. LBL$3(1517,1990$.

\section{Urban Energy Use: Saturation and Fuel Transition in the Developing Countries}

\author{
1. Sathaye and S. Tyler
}

This project has investigated the transition in household fuel use in cities of the developing countries from traditional biomass fuels to fossil fuels and electricity. Household energy consumption in several cities was surveyed by each of five research teams at institutes in Hong Kong, India, China,

Table. Fuel and Electricity consumption per capita (GJ/year/capita)

\begin{tabular}{|c|c|c|c|c|}
\hline \multirow[b]{2}{*}{ City } & \multirow[b]{2}{*}{ Low } & \multicolumn{3}{|c|}{ Household Income Level } \\
\hline & & Medium & High & Average \\
\hline \multicolumn{5}{|l|}{ Beijing* } \\
\hline Useful Fuel & 1.5 & 1.4 & 1.2 & 1.4 \\
\hline Delivered Fuel & 4.1 & 3.9 & 2.9 & 3.7 \\
\hline Electricity & 0.5 & 0.5 & 0.5 & 0.5 \\
\hline \multicolumn{5}{|l|}{ Hong Kong } \\
\hline Useful Fuel & & 0.7 & 0.7 & 0.7 \\
\hline Delivered Fuel & & 1.6 & 1.6 & 1.6 \\
\hline Electricity & 2.4 & 2.3 & 2.5 & 2.4 \\
\hline \multicolumn{5}{|l|}{ Nanning } \\
\hline Useful Fuel & 1.5 & 1.5 & 1.4 & 1.4 \\
\hline Delivered Fuel & 7.2 & 7.0 & 5.9 & 7.0 \\
\hline Electricity & 0.3 & 0.4 & $(0.4$ & 0.4 \\
\hline \multicolumn{5}{|l|}{ Pune } \\
\hline Useful Fuel & 0.7 & 0.9 & 1.0 & 0.9 \\
\hline Delivered Fuel & 2.1 & 2.4 & 2.5 & 2.3 \\
\hline Electricity & 0.3 & 0.8 & 1.6 & 0.8 \\
\hline \multicolumn{5}{|l|}{ Thailandt } \\
\hline Useful Fuel & 0.7 & 0.8 & 1.1 & 0.8 \\
\hline Delivered Fuel & 2.7 & 2.4 & 2.9 & 2.6 \\
\hline Electricity & 1.5 & 2.2 & 3,6 & 2.4 \\
\hline \multicolumn{5}{|c|}{ * Excludes space heating. } \\
\hline
\end{tabular}

the Philippines, and Thailand. The objective of the research is to relate patterns of fuel use to differences in household characteristics such as income, size, location, and access to fuels. In addition, a limited sample of indoor and outdoor air quality measurements will help show the relative exposures of different types of households to airborne combustion products.

Most of the activities were sponsored by the International Development Research Center in Ottawa, Canada. LBL has been responsible for project development, provision of technical advice and support to the Asia-based research teams, and overall project coordination. LBL organized three workshops in Asia as part of the project and conducted cross-national comparative analysis of survey findings as they became available. The comparative analysis shows that because of the difficulty in easily relighting coal stoves, Chinese households tend to leave them burning (at a low rate) and therefore consume more energy for cooking than those in other Asian cities (Table). On the other hand, because of low ampere wiring, Chinese households use far less electricity than their counterparts despite their high ownership of refrigerators, TV sets, and clothes washers. The use of biomass fuels for cooking, except for the use of charcoal in Thailand, has virtually disappeared in the surveyed cities. Household fuel choice is dictated more by women's income and time available for cooking than other variables.

The rapidly growing ownership of appliances suggests that more attention is needed to improve the efficiency of household appliances, but in order to achieve it, test labs for establishing energy performance of appliances are essential.

The survey findings also included data on transport, air pollution, and appliance electricity consumption. These results will bu reported next year.

\section{Reference}

Sathaye J, Tyler S. Transitions in urban household energy use in Hong Kong, India, China, Thailand, and the Philippines. Anmunal Rervicue of Energy (in press, 1991). 


\section{Long-Term Energy Scenarios for the Developing Countries}

\section{J. Sathaye, A. Ketoff, and N. Goldman}

This project is intended to construct long-term energy scenarios for developing countries. These scenarios will help estimate the emissions of greenhouse gases and the trend toward global climate change. The scenarios will also provide a context in which to implement the most effective energy strategies for reducing $\mathrm{CO}_{2}$ emissions.

The tirst phase of the project began in FY88 and focused on an end-use approach to developing long-term energy demand scenarios for the developing countries.

The second phase of the project was initiated in early FY89, expanding the efforts to establish a network of analysts from institutions in several of the largest energy-consuming developing countries to divelop scenarios of long-term energy use for each country in order to project greenhouse gas emissions. A paper which summarizes the scenarios of $\mathrm{CO}_{2}$ emissions was published this year. The paper concludes that greenhouse gas emissions from the developing countries will grow several-fold in the future and efforts to reduce emissions will only reduce the growth rate (Table). Reducing energy intensity will be the best option for reducing the growth rate of emissions while the opportunity for fuel-switching is limited.

In addition, country-specific reports on long-term energy scenarios were published. These highlight the contribution of energy use to carbon emissions from each country. Surprisingly, the share of emissions from the Gulf Cooperation Council (GCC) countries is large and their growth outstrips that of the other countries.

A third phase of the project was initiated this year. This will focus on the barriers to improving energy efficiency and on the cost of reducing the growth of carbon emissions in India, China, Mexico, and Brazil.

\begin{tabular}{|c|c|c|c|}
\hline \multicolumn{4}{|c|}{$\begin{array}{l}\text { Table. Carbon dioxide emissions by country } \\
\text { (Million tons of carbon) }\end{array}$} \\
\hline & & 2025 & 2025 \\
\hline City & 1985 & High & Low \\
\hline China & 480 & 1700 & 1365 \\
\hline India & 115 & 700 & 615 \\
\hline Mexico & $75^{*}$ & 225 & 155 \\
\hline GCC Countries & 60 & 400 & 330 \\
\hline Brazil & 45 & 140 & 65 \\
\hline Korea & 45 & 170 & 120 \\
\hline Indonesia & 25 & 130 & 105 \\
\hline Venezuela & $25 t$ & 65 & 55 \\
\hline Argentina & 20 & 45 & 30 \\
\hline Nigeria & 10 & 55 & 40 \\
\hline Ghana & 1 & 4 & 3 \\
\hline Sierra Leone & - & 1 & 1 \\
\hline Total & 900 & 3635 & 2880 \\
\hline $\begin{array}{l}\text { *1987 data } \\
+1984 \text { data }\end{array}$ & & & \\
\hline
\end{tabular}

\section{References}

Sathaye J, Ketoff A. CO, Emissions from Major Developing Conntries: Better Unterstanding the Role of Energy in the Long-Term. Vol. I-Summary. Lawrence Berkeley Laboratory Report No. LBL-29507 Rev., 1990.

Ketoff A, Sathaye J, Goldman N, eds. CO, Emissions from Major Developing Conntries: Better Understanding the Roie of Energy in the Long-Term. Vol. II-Argentina, Brazil, Mexico, and Venezuela. Lawrence Berkeley Laboratory Report No. LBL-30059, 1990.

Sathaye J, Goldman N, eds. $\mathrm{CO}_{2}$ Emissions from Major Developing Countries: Better Understanding the Role of Energy in the Long-Term. Vol. III-China, India, Indonesia, S. Korea. Lawrence Berkeley Laboratory Report No. LBL-30060, 1990.

Sathaye J, Goldman N, eds. CO, Emissions from Major Developing Countries: Better Understanding the Role of Energy in the Long-Term. Vol. IV-Ghana and Sierra Leone, GCC Countries, and Nigeria. Lawrence Berkeley Laboratory Report No. LBL-30061, 1990.

Sathaye J, Ketoff $\mathrm{A}$. $\mathrm{CO}_{2}$ emissions from major developing countries: Berter understanding the role of energy in the long term. Encrgy foumal 1991; 12(1):161-196. 


\section{Residential Energy Use and Conservation in Venezuela}

\section{A. Ketoff, O. Masera, and M.J. Figueroa}

We are conducting a study in Venezuela on residential energy use and conservation. The project consists of a survey and an analysis of household energy use in Venezuelan cities covering almost $50 \%$ of the country's urban population. The goal is to provide appropriate recommendations for energy conservation and fuel-switching programs that will reduce household energy demand and increase the residential gas market share in the country (Figure).

Results of the surveys show that basic usages of electricity, lighting, television, and refrigeration are diffused in almost all'households and that clothes washers are found in more than $75 \%$ of urban dwellings. (Air-conditioning is diffused only in few hot climate cities.) Hot water, on the other hand, is available in less than $50 \%$ of the dwellings and appears to be a potential market for natural gas. However, the use of electricity for water heating is rapidly diffusing as a result of low electricity prices and the limited extension of the natural gas grid. Less than $2 \%$ of the households surveyed are using gas water heaters.

Other results indicate that the intensity, i.e., unit consumption, of energy use for refrigeration and hot water is high compared to consumption in other cities of the developing countries (e.g., Brazil and Indonesia), and is even higher than in several European countries. This appears to be a consequence of the quality and size of the appliances available in the country, mostly oversized devices of old, obsolete design.
This study examines viable policy options for increasing the market penetration of natural gas and improving the efficiency of appliances. To maximize the return of the gas grid investment, the national gas utility must increase the acceptability of gas as a fuel for cooking and heating water in higher income homes. Policy action directed toward appliance manufacturers, on the other hand, appears to be the best way to increase appliance efficiency. At the same time, subtle action is necessary to promote efficiency as a "status symbol."

The extremely low prices of energy in Venezuela appear to be the major obstacle to an effective energy conservation policy in that nation. Although there are long-term plans to increase the prices for electricity and gas, energy prices in Venezuela are still among the lowest in the world. A program of rebates for efficient energy-using appliances might be necessary to encourage successful diffusion in an environment of low energy prices.

\section{References}

Ketoff A, Masera O, Figueroa MJ. Residential Energy Use and Conservation in Venezuela: Results and Implications of a Household Survey in Caracas. Lawrence Berkeley Laboratory Report No. LBL-30508, 1990.

Figueroa MJ, Ketoff A, Masera O. Perfil Energetico Residencial de la Ciudad de Caracas. Lawrence Berkeley Laboratory Report No. LBL-30518, 1990.

Ketoff A, Masera O. Household electricity demand in Latin America. In: Proceedings of the ACEEE 1990 Summer Study on Energy Efficiency in Buildings, August 26-September 1, 1990. Washington, DC: American Council for an Energy-Efficient Economy, 1990, pp. 9.143-9.155.

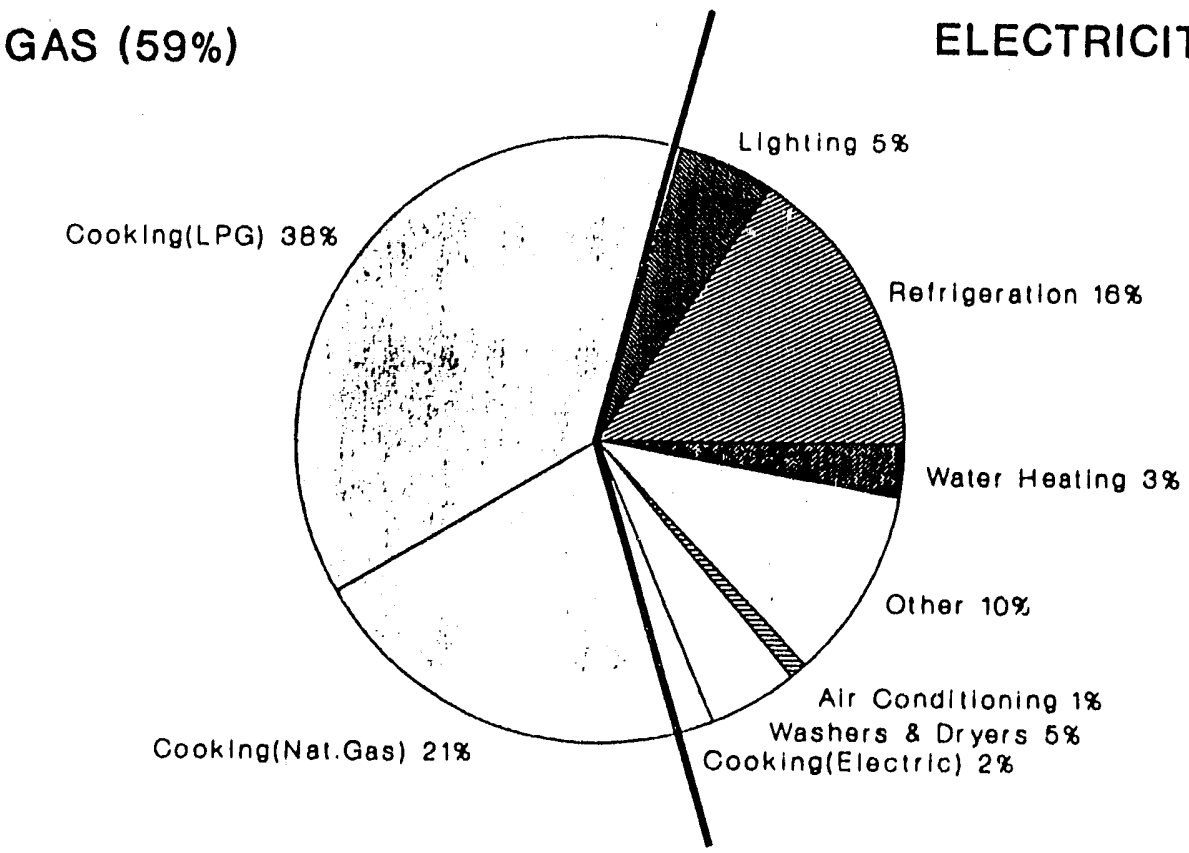

Figure. Energy consumption by end-use in Caracas, 1988.

TOTAL $28 \mathrm{PJ}$

(30.5 GJ/household) 


\section{Tropical Forestry and Global Climate} Change

\author{
W. Makundi, J. Sathaye, and A. Ketoff
}

In the course of an investigation of greenhouse gas emissions from energy use in the developing countries, it became clear that, in many tropical countries, the emissions from the forestry sector may eclipse those from fossil fuel use. Examination of results of various studies revealed that estimates of emissions from deforestation were very imprecise due to uncertainties associated with the constituent variables such as the rate of deforestation, carbon stocks, and the dynamics of the release process. In an attempt to improve the estimates of emissions and sequestration, an international network of scientists from those countries undergoing the most deforestation was organized in 1990, with the initial participation of Brazil, Mexico, Indonesia, China, Thailand, India, and Nigeria.

The Tropical Forestry and Global Climate Change Network provides a collaborative structure for estimating $\mathrm{CO}_{2}$ emissions and sequestration across the tropical forests, using a common methodological and analytical framework. To this end, we developed a spreadsheet-based model that is being used by the mombers in their respective countries (Figure). We have organized a workshop for mid-1991 that will bring together all the researchers to:

- complete the estimates for each country;

- undertake a biome-wide aggregation; -identify those variables of critical uncertainty and examine ways to improve our knowledge of them;

- analyze the emission and sequestration implications of various forest management policies and the possible impact on global climate change;

- search for optimal policies that will incorporate the greenhouse gas issue within the countries' objective of sustainable socioeconomic development.

Future plans include adding other tropical countries to the network, obtaining more reliable data for the critical variables, integrating the forestry sector emissions/sequestration with other anthropogenic sources and greenhouse gas sinks, and evaluating the forestry sector's net contribution to global climate change and its feedback effects on that sector and on the general economy.

\section{References}

Graca G, Ketoff A, Makundi W, Helene M, Robot J, Romm J, Sathaye J. Tropical Forestry and Global Climate Change: Background and Agenda for an International Research Network. Lawrence Berkeley Laboratory Report No. LBL30526, 1990.

Makundi W, Sathaye J, Ketoff A. Copath: A Spreadsheet Model for Estimating Carbon Flows Associated With Tropical Forest Use. Lawrence Berkeley Laboratory Report No. LBL30525,1991

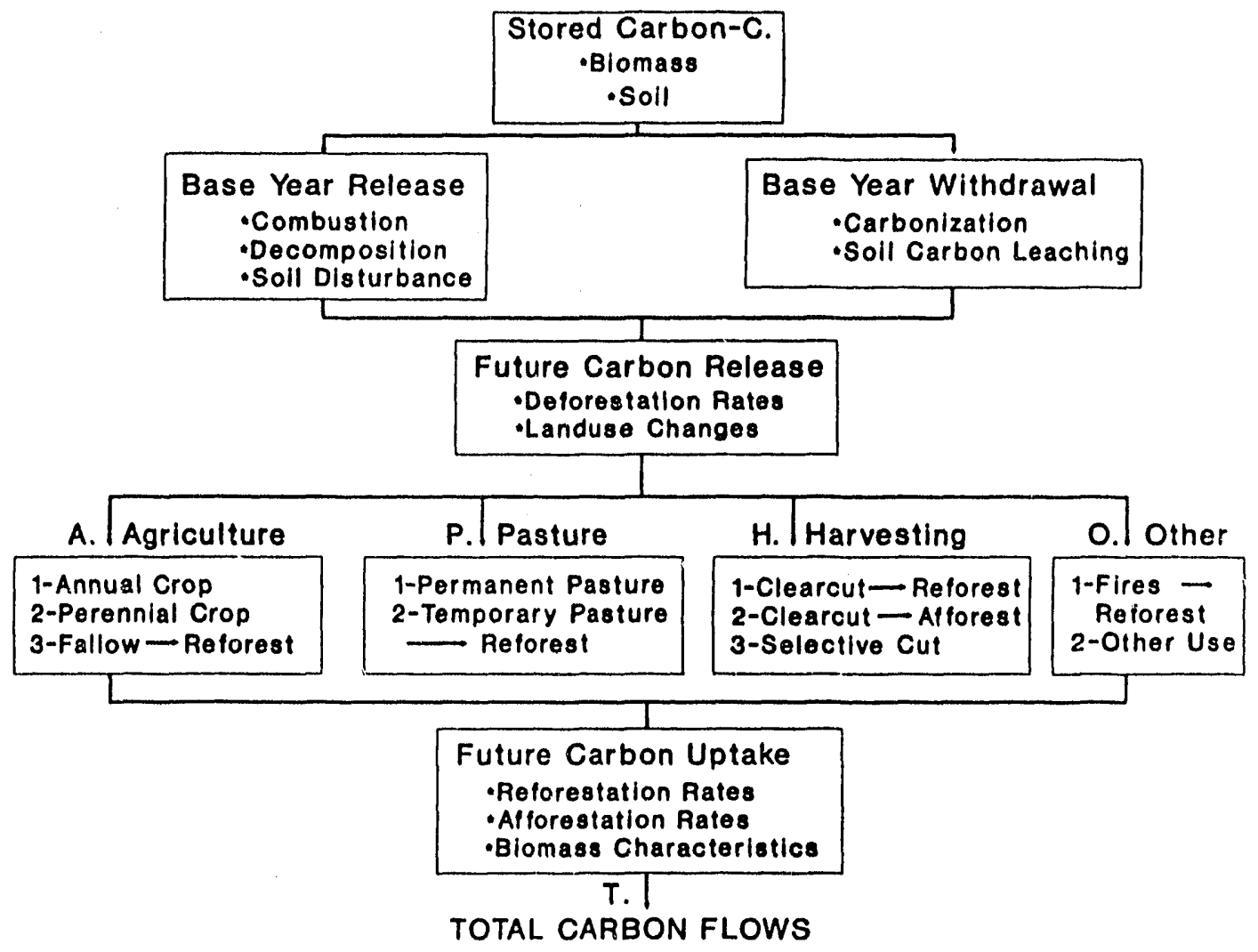

Figure. Copath: a model to estimate current and future carbon flows from forest use. 


\section{Electricity Consumption and Structural Change in the Manufacturing Sector in Developing Countries}

\section{S. Meyers, S. Tyler, and C. Camphell}

Mlanufacturing accounts for $50-60 \%$ of total electricity consumption in most developing countries. As these countries have expanded and modernized their manufacturing sectors, growth in electricity use has been rapid. The purpose of this project was to gain a better understanding of the forces causing change in manufacturing electricity use in developing countries. We collected and analyzed data on historic trends in electricity consumption and economic output in manufacturing industry for nine countries with relatively large industrial sectors. In each case, we sought to examine the role of change in the composition of manufacturing output and change in electricity intensity (electricity use per unit of value-added) of particular industries. While lack of data limited the depth of our analysis, a number of findings were made.

Between 1975 and the late 1980s, there were large increases in aggregate manufacturing electricity intensity in Thailand, Brazil, Argentina, Mexico, and Venezuela, large decreases in Taiwan and China, and little net change in South Korea and India. The evidence suggests that the effect of change in the composition of manufacturing output on aggregate electricity intensity was less important than the effect of change in intensities at the sub-sectoral level. In some cases, change in the share of specific industries within subsectors affected electricity intensity. Development of electricity-intensive steel and aluminum industries contributed to increases in manufacturing electricity intensity in Brazil and Venezuela, as did substitution of electricity for oil in Brazil. The decreases in Taiwan and China were partly due to energy conservation efforts (Figure).

Comparison of aggregate manufacturing electricity use per unit of value-added (converted to U.S. dollars) shows that intensity in the mid-1980s varied by more than a factor of two among six countries. China and India, both of which operate relatively old equipment in their industries, are at the top of the range, while South Korea and Taiwan, both of whom have relatively new equipment, are at the low end. With the exception of India, there is a clear correlation between electricity intensity and the average price of electricity to industry. Comparison of intensity among particular industrial sectors, which gives a better sense of the relative efficiency of countries, also shows a considerable range for most sectors.

\section{Reference}

Meyers S, Tyler S, Campbell C. Electricity Consumption and Structural Change in the Manufacturing Industry in Developing Countries. Lawrence Berkeley Laboratory Report No. LBL-28762, 1990.

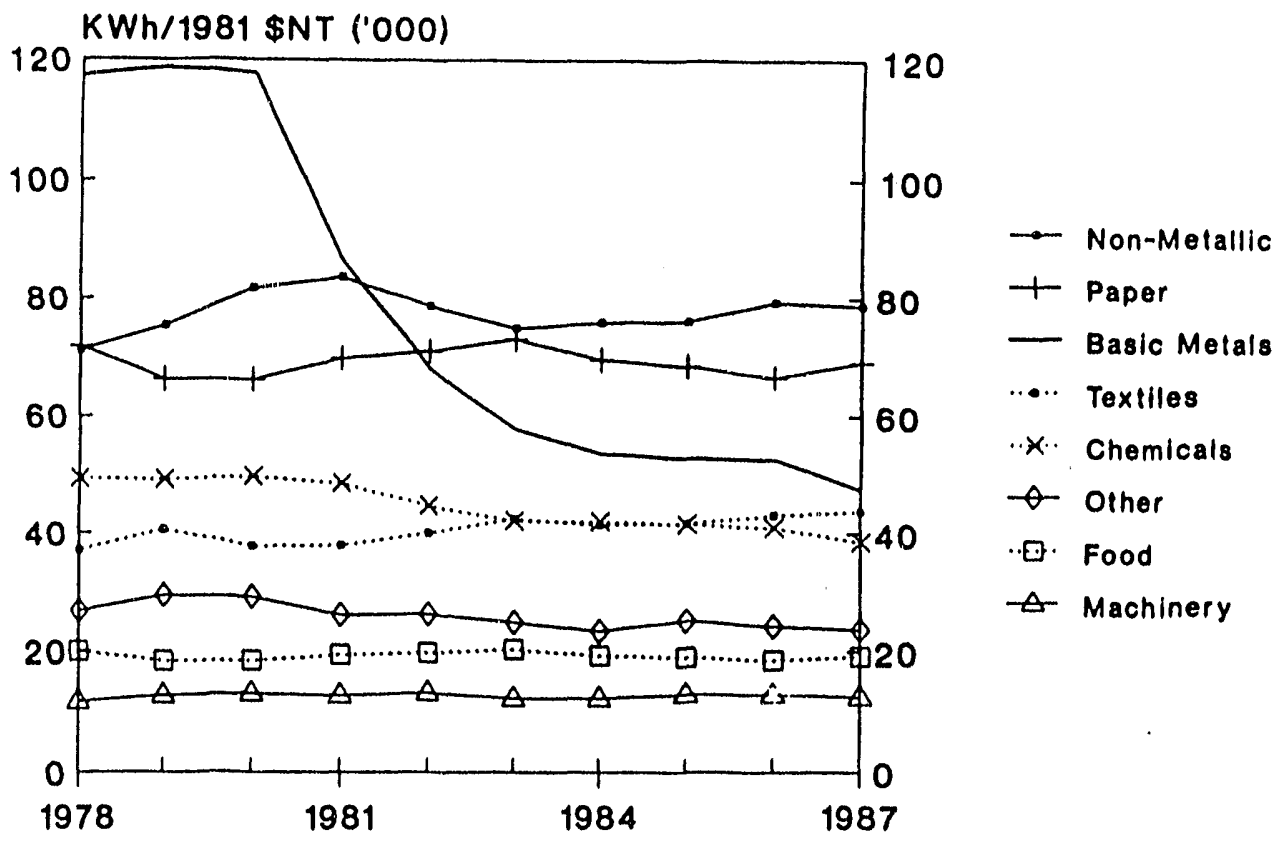

Figure. Electricity intensities by manufacturing subsector for Taiwan. 


\section{Energy-Efficient Transportation in Brazil: Prospects and Barriers}

\section{A. Ketoff}

In this study, we analyze the prospects for and barriers to long-term etficiency improvements in a developing country, taking Brazil as a case study. Brazil has, among developing countries, one of the highest levels of private car ownership and also a well-developed car-manufacturing ind ustry. Additionally, the country's fuel-switching policy, favoring the substitution of sugarcane alcohol for gasoline, makes it an interesting case to analyze in view of future prospects for energy efficiency.

Several factors are contributing to the rapid growth of transport demand in Brazil, the key one being the increasing urbanization of the population. Large cities-twelve have more than one million people and two have more than ten million-require extensive public transport systems to guarantee personal mobility. Additionally, the growth of cities being faster than the development of infrastructures, freight is almost completely transported on wheels.

To face the increasing transport energy demand and the increasing cost of oil imports, Brazil undertook in the late 1970s a major program of fuel substitution. Gasoline was mixed with $22 \%$ ethanol for use in standard cars and hydrated alcohol was used in appropriately converted vehicles. By 1989, half of the energy used for cars was coming from alcohol which was a considerable success for the Proalcool program. More than $30 \%$ of the car fleet was running on alcohol, thanks to the rapid diffusion of a technology developed by local car manufacturers. As alcohol substituted for gasoline in the light vehicles fleet, diesel became the mandatory fuel for heavy trucks and buses, further reducing gasoline demand.
While reducing gasoline imports, fuel substitution has acted, on the other hand, as a barrier to improvements in the fuel efficiency of the Brazilian vehicle fleet. The inconsistent quality of gasoline, varying in alcohol content from 5\% to over 30\% depending on the alcohol supply, has caused improper tuning of the majority of the car fleet. Conscious of the problems created by the low quality of fuels, car manufacturers produced larger engines and avoided introducing more efficient vehicles, as they would require fine tuning to operate properly.

Among the barriers to vehicle efficiency, poor conditions of roads and highways forced the manufacturers to reinforce chassis and suspensions, resulting in increased weight. On the other hand, an historical policy of import quotas has limited the introduction of technological innovation in vehicles, particularly the use of electronic injection. As a result, Brazilian cars are heavier and less powerful than their sister European models. According to two major local manufacturers, the additional cost for larger engines and stronger structures on "Brazilian versions" is around $25 \%$ of that of the original model, while the efficiency is around $20 \%$ lower. The best available Brazilian car has an average performance of $31 \mathrm{mpg}$, while the best model available in the United States reaches $45 \mathrm{mpg}$ (52 mpg in Japan).

Another limit to the efficiency improvement of Brazil's car fleet is the uneven distribution of income in the country. With more and more of its population falling under the poverty level (58\% in 1990), Brazil has a shrinking market for new cars (Figure). Most buyers of new cars are upgrading to larger models. As a consequence, the average performance of new models, which improved by around 10\% between 1983 and 1987 , has remained level since then.

This study concludes that energy efficiency in vehicles will be considerably restrained if major structural reforms are not undertaken in the country. Some of the changes (e.g., regionalization of the alcohol fleet, opening up of technologi-

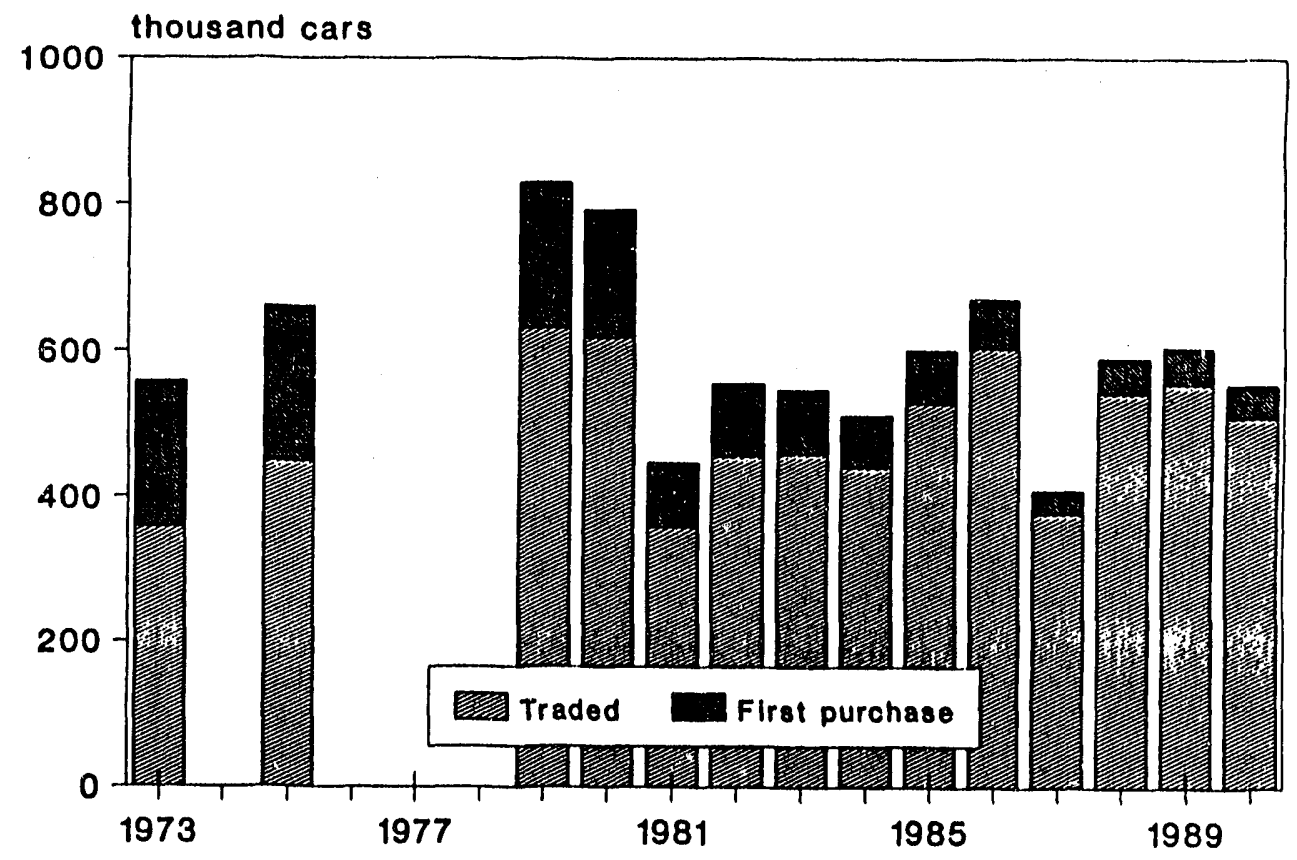

Figure. New car sales by purchaser type; first car vs. traded or second car. 
cal markets) might be relatively simple to pursue. Others (e.g., bringing flexibility into the refining system, improving road quality, cieveloping alternative transport modes) might be very expensive for the country, but are still necessary for the overall development of its economy.

\section{Reference}

Ketoff A. Overcoming Barriers to Energy Efficiency in Transportation: The Case of Brazil. Lawrence Berkeley Laboratory Report No. LBL-30444, 1991.

\section{- Utility Planning and Policy-}

\section{Integrated Resource Planning}

\author{
C.A. Goldman, J.H. Eto, F. Krause, J.F. Busch, \\ M.D. Levine, and A.H. Rosenfeld
}

During the past few years, the scope and nature of resource planning at electric utilities have changed dramatically. Integrated resource planning (IRP) involves the creation of a planning process in which customer energy service needs are met in a cost-efficient manner through consideration of a variety of demand and supply options. In this new planning paradigm, energy efficiency and load management are explicitly considered as alternatives to power plants, environmental factors as well as direct economic costs are considered, public participation is encouraged, and the uncertainties and risks posed by different resource portfolios and external factors are analyzed. Key IRP issues facing utilities and public utilities commissions (PUCs) include:

- Providing financial incentives to utilities for successful implementation of IRPs;

- Incorporating environmental factors in IRPs;

- Bidding for demand and supply options;

- Treating demand-side management (DSM) programs as capacity and energy resources;

- Developing guidelines for preparation and review of utility resource plans.

We will discuss several of these topics in more detail. Current rate-of-return regulation as practiced in most states rewards utilities for short-term sales and discourages optimal use of DSM options. PUCs and utilities have developed various approaches to overcome these disincentives to DSM investments. For example, at least nine states allow DSM investments to be included in the rate base. Several states adjust for DSM-induced revenue losses or effectively decouple utility profits from sales variation. Recently, PUCs in a number of states have approved various types of bonus incentives that reward utility shareholders for exemplary delivery of DSM services, including increased rate of return, bounty, and shared savings. With incentives, utility earnings often depend on the savings from DSM programs, and thus program evaluation assumes increased importance.

The Table lists the major approaches used to incorporate environmental externalities in utility resource planning and selection and in system operation. About one-third of the nation's PUCs have adopted explicit procedures for considering environmental externalities in resource planning. Two general approaches have been used to monetize environmental externalities: direct assessment and valuation of actual environmental damages imposed on society by different generating technologies, and "implied valuation" which relies on the cost of control (or mitigation) of pollutants to estimate the value of pollution reduction. "Set asides" for specified technologies in resource selection processes and limits on emission levels or targets for quantities of pollutants (e.g., lower and maintain $\mathrm{CO}_{2}$ emissions at 1985 levels) have also been proposed as a reasonable response given the uncertainties associated with the monetization of externalities. Under "full-cost" dispatch, a utility would include both direct costs (fuel and variable operations and maintenance) as well as monetized environmental externality costs in their operational dispatch of existing generation facilities.

DSM programs are likely to account for an increasing share of total electric utility energy and capacity options. Utilities in New England, New York, Wisconsin, California, and the Pacifi, Northwest are rapidly expanding their DSM programs, with budgets expected to double or triple within a few years. Additional data are needed in three areas to improve DSM resource planning: baseline data on the efficiency and utilization patterns of end-use systems in the existing stock of equipment and buildings, data on the costs and performance of energy efficiency and load management technologies, and data on customer participation in, and costs of, different types of utility DSM programs.

Future projects will focus on the following areas: IRPS for gas utilities, evaluation of integrated bidding systems and incentive mechanisms that reward utility shareholders for exemplary DSM programs, transmission issues in IRP, utility and regional case studies that assess alternative methods of incorporating environmental externalities into the resource planning process, comparative assessment of utility DSM program experience, transferability of end-use load shape data, and training courses on key IRP issues for PUC staff.

\section{Reference}

Hirst E, Goldman C. Creating the future: Integrated resource planning for electric utilities. Annual Review of Energy $1991 ; 16$. 
Table. Alternative approaches to incorporating environmental externalities.

\begin{tabular}{|lccc|}
\hline & $\begin{array}{c}\text { Resource } \\
\text { planning }\end{array}$ & $\begin{array}{c}\text { Acquisition } \\
\text { and selection }\end{array}$ & $\begin{array}{c}\text { System } \\
\text { operation }\end{array}$ \\
\cline { 2 - 4 } $\begin{array}{l}\text { Characterize and describe } \\
\text { environmental effects }\end{array}$ & $X$ & \\
Ranking and weighting & $X$ & $X$ & $X$ \\
Monetization: & $X$ & $X$ & $X$ \\
Implied valuation (cost of control) & $X$ & $X$ & $X$ \\
Direct assessment and \\
valuation of damages & & $X$ & \\
Resource set-asides & $X$ & \\
Full-cost dispatch & & \\
Emission quantity targets & & & \\
\hline
\end{tabular}

\section{Auctions for Dispatchable Power}

\author{
E. Kahn, S. Stoft, C. Marnay, and D. Berman
}

The independent power industry is expanding and maturing in a number of dimensions. More utilities are acquiring private power resources through competitive bidding and the nature of the projects is becoming more diverse. In FY90 we examined developments in this market by surveying competitive auctions for power contracts and analyzing the economics of dispatchable projects.

Dispatchability is a new feature of the private power market. Under the Public Utilities Regulatory Policy Act (PURPA), utilities are obligated to purchase output from private suppliers at all times. The PURPA obligation limits the operational flexibility of utilities. The competitive bidding mechanism allows utilities to purchase power under long-term contracts that specify more flexible operating procedures. The generic name for this operating flexibility is dispatchability; meaning that the utility can dispatch these resources in a manner similar to the way they utilize their own generators. In a competitive bidding framework utilities can purchase baseload, intermediate, or peaking facilities as their systems require.

Our survey of competitive bidding solicitations and the resulting contracts shows a wide variety of dispatchability features. There are frequently limits on the operational flexibility being offered and purchased. There are also a number of technical issues that arise in evaluating projects which offer dispatchability of different kinds.

One important problem involves the use of the "percentage of avoided cost" method to evaluate dispatchable bids. This method is really a vestige of PURPA rules under which all projects were essentially baseload producers. When projects are dispatched, i.e., operate optimally for different periods of time, then the percentage of avoided cost rule does not identify the best bids. Even in sophisticated bid evaluation systems which associate different avoided costs with dispatchable bids that operate optimally for different periods of time, the percentage rule is biased. We show that the bias works systematically against baseload bids.

Many of the operating restrictions that appear in contracts for dispatchable power require complex computer simulation models in order to evaluate them. The most significant of the restrictions that we identified involved the minimum operating level of the project. All generators operate over a range of output from some minimum level of capacity up to their maximum rating. These minima are typically in the range of $25 \%$ to $40 \%$ of maximum capacity. Several private power contracts, however, specify minimum operating levels of $80 \%$. We found that long-range planning models are unable to identify costs associated with these high minimum operating levels, but that detailed models do find such costs. For representative cases, such high minimum operating loads add about $10 \%$ to the cost of intermediate load gas-fired projects, and about $5 \%$ to the cost of baseload coal projects. These differences are within the range that determines winners and losers in competitive bidding.

Other subjects reviewed in our FY90 work include the role of security deposits in private power contracts and R\&D issues associated with dispatchability. In the 1991 fiscal year, we will examine how various economic risks are allocated in independent power contracts and the use of existing power plant sites to meet new electricity demand.

\section{Reference}

Kahn E, StoftS, Marnay C, Berman D. Contracts for Dispatchable: Power: Economic Implications for the Competitive Bidding Market. Lawrence Berkeley Laboratory Report No. LBL29447, 1990. 


\section{Incentives for Utility Demand-Side Management}

\author{
J. Eto, C. Marnay, D. Schultz, and \\ G.A. Comnes*
}

Under traditional utility ratemaking practice, selling more energy increases profits, while selling less energy decreases them. This practice represents a major institutional barrier to utility acquisition of demand-side resources, which can often produce energy services less expensively than supply-side resources. The National Association of Regulatory Utility Commissioners now formally recognizes this inherent bias in utility regulation and has begun actively promoting regulatory alternatives to stimulate utility participation in demand-side resource markets. In FY90, we examined two particularly promising alternatives to traditional ratemaking practices.

The California Electricity Revenue Adjustment Mechanism or ERAM (adopted in 1982) is a balancing account that holds utility revenues fixed at pre-determined levels, independent of actual sales. Increased sales cannot increase profits, just as decreased sales (one likely effect of successful utility demand-side management programs) cannot reduce them. Differences between revenue forecasts and actual collections are either recovered from or returned to the ratepayers in the next forecast cycle. The accounting procedures are straightforward and we illustrate them with numerical examples taken from recent California utility experience in Marnay and Comnes (1990).

The effect of ERAM is to remove the anti-conservation bias inherent in traditional ratemaking for California utilities. However, ERAM also insulates utility revenues from other fluctuations in sales that are not related to conservation, which means that ERAM may coitfound other regulatory policy objectives, such as encouraging utilities to negotiate rates with large customers that are favorable to other ratepayers.

While ERAM removes the disincentive to utility participation in demand-side markets, it provides no positive incentive. That is, ERAM only means that utility earnings will be made indifferent to fluctuations in sales (some of which may be due to utility demand-side activities). In California, utility spending on demand-side activities, after years of continuous growth from the late 1970s, began to decline in the mid- to late 1980s. These declines led to concerns by California's regulators and environmental groups that California was losing its national lead in demand-side management activities.

In 1989, California's largest utilities took part in a unique set of collaborative discussions with representatives from their regulators, major customer groups, and environmentalists designed to re-kindle utility interest in demand-side activities. What emerged was proposals by California utili- ties to increase their demand-side management efforts dramatically, in return for favorable regulatory treatment. In particular, the citilities proposed that they be permitted to earn profits on these activities in excess of those set by their allowed rate-of-returns and guaranteed by ERAM. The Pacific Gas and Electric Company and the Sain Diego Gas and Electric Company proposed that the profits be based on a formula to share the savings from the utilities' demand-side management activities.

The basis for shared-savings incentives is that utilityacquired demand-side resources cost less than those that are avoided on the supply-side. As a result, the difference between the benefit provided by the avoided supply-side resources and the cost of the demand-side resource can be "shared" between utility ratepayers and shareholders. The issues discussed in the collaborative process meetings, which form the basis of our report (Schultz and Eto, 1990), included how the savings should be measured (engineering estimates versus post-program analyses), which costs should be included (those borne by the participant and the utility or just those borne by the utility), how should the benefits be recovered (whether or not they should be front-loaded), and finally, what should be the penalties for non-performance (how big and how triggered).

As other states develop regulatory mechanisms to stimulate utility participation in demand-side markets, we believe they will benefit from the lessons learned by California with ERAM and shared-savings incentives.

\section{References}

Marnay C, Comnes GA. Ratemnking for Conservation: The Californin ERAM Experience. Lawrence Berkeley Laboratory Report No. LBL-28019, 1990.

Schultz D, Eto J. Designing Shared-Savings Incentive Programs for Encrgy Efficiency: Balancing Carrotsand Sticks, Lawrence Berkeley Laboratory Report No. LBL-29503, 1990.

"The Division of Rate-Payer Advocates, California Public Utilities Commission, San Francisco, CA. 


\section{Integrating Environmental Externalities in Utility Resource Planning}

\author{
F. Kranse, J.F. Busch, S. Cohen, J.H. Eto, C.A. \\ Goldman, and I. Koomey
}

A number of state public utility commissions in the United States have begun to implement or consider monetary adders (charges) for air emissions and other environmental impacts from power plants. These environmental externality adders would be charged for emissions not already avoided by current emission standards. They are to give utilities an incentive to reduce emisstons beyond current requirements, including, in some cases, currently unregulated emissions such as carbon dioxide (monetized adder approach). Alternatively, states could set emission caps or reduction targets similar to those implemented in recent clean air legislation and emission rights could be traded under such caps or targets (quantity constraints or targetbased approach). LBL's externality research projects are part of DOE's Integrated Resource Planning program. The principal objectives of current research are:

- To assess the impact of externality incorporation on electricity bills and rates;

- To compare target-based approaches with monetized approaches in terms of their relative impacts on electricity costs and their effectiveness in bringing about emission reductions;

- To compare monetized adder approaches when applied to new power plants

- To assess the impact on electricity costs of reducing carbon dioxide emissions in the utility sector.

So far, two preliminary reports have been completed:

- A survey of current efforts by state regulatory utility commissions to incorporate environmental exter. nalities into resource selection and utility planning.

- A quantitative comparison of nine proposed or currently applied valuation systems for calculating the externality cost of air emissions.

The survey of state public utility commissions showed that only a small number have implemented externality cost adjustments so far. All existing regulations apply such adjustments at the margin, i.e., to new power plants only. The comparison of current and proposed valuations showed significant differences in how emissions are or would be valued. Also, the adders would have significantly greater impacts on existing plants than on new plants with the best control technologies.

The core analysis on incorporation mechanisms and cost impacts is still ongoing. In this study, the target-based and the monetized adder approach are compared using the New England Power Pool (NEPOOL) as a case study. Specifically, the project examines how the recently enacted Massachusetts adder system would impact NEPOOL emissions and elec- tricity costs if extended to the entire six-state NEPOOL region.

Production cost modeling of the power system over a 2()year period is used to determine the impacts of these adders on ratepilyer bills, as well as the likely reductions in acid rain and earbon dioxide emissions that would result. These cost and emission impacts are then compared to a target-based policy in which a $20 \%$ reduction of carbon dioxide emissions is implemented without adders using established least-cost planning procedures. From there, a range of adders for $\mathrm{CO}_{2}$ is determined that would be sufficient to mobilize the resources needed to achieve the carbon dioxide reduction goal.

Findings to date suggest that a $20 \%$ reduction in carbon dioxide emissions relative to 1990 levels could be technically achieved based on currently available technologies and demand-side and supply-side resources with low-carbon burdens. Demand-side management programs could be increased substantially to reduce load growth. On the supply side, biomass, wind, gas-fired cogeneration plants, gas-fired central stations, and other resources could reduce carbon dioxide emissions per kWh produced.

The project is scheduled to be completed by June, 1991. Follow-up sensitivity analyses will be undertaken in a separate project.

\section{References}

Koomey 1. Comparation Analysis of Monctary Estimates of External Envirommental Costs Associnted zuith Combustion of Fossil Fuds. Lawrence Berkeley Laboratory Report No. LBL-28313, 1990.

Cohen SD, Eto JH, Goldman CA, Beldock J, Crandall G. A Survey of State PUC Activities to lucorporate Enovirommental Externalities into Elactric Utility Phoming and Re'gulation. Lawrence Berkeley Laboratory Report No. LBL-28616, 1990. 


\section{Demand-Side Bidding: Assessing Current Experience}

\author{
C.A. Goldman and J.F. Busch
}

Utllities in Maine, New York, New Jersey, Washington, and Indiana are currently implementing "all-source" bidding processes, which include both supply-side and demand-side management (DSM) options, often at the behest of regulatory commissions. A defining feature of DSM bidding programs is that they involve customers or third-party energy service companies (ESCOs) or customers competing for long-term contracts with utilities which specify amounts of DSM savings to be achieved by a winning participant over a defined time period.

The Table summarizes results from programs in which there are either signed contracts from the solicitation or the final award group has been announced. We also show the capacity need (In MW) requested by the utility in its Requests for Proposal (RFP) and the number of profects and $\mathrm{MWs}$ initially offered by supply and DSM bidders. We grouped these programs into three broad categorles based on the type of solicitation and origin of program: an "all-source" integrated solicitation that includes both supply and demand resources, separate RFIs for demand-side options, and performance contracting programs which involve ESCOs.

Central Maine Power (CMP) was the first utility to implement an all-sources bidding process with its Power Partners program. Proposed DSM projects must have. simple payback time of greater than one year and pass a costeffectiveness test equivalent to the "all-ratepayers" (or total resource cost) test. Solicttations issued by three New Jersey utilities-Orange \& Rockland Uttlitles (ORU), Jersey Central Power \& Light (JCP\&L), and Public Service Electric \& Gas (PSE\&G) - were strongly influenced by a settlement agree-

Table. Supply- and Demand-Side Management (DSM) resources in utllity bidding programs.

\begin{tabular}{|c|c|c|c|c|c|c|c|c|}
\hline \multirow[b]{2}{*}{ Utility } & \multirow[b]{2}{*}{$\begin{array}{l}\text { Amount } \\
\text { Requested }\end{array}$} & \multicolumn{2}{|c|}{ Supply Projects } & \multicolumn{2}{|c|}{ DSM Projects } & \multicolumn{2}{|c|}{ No. of DSM Bids } & \multirow[b]{2}{*}{$\begin{array}{c}\text { Program } \\
\text { Gual } \\
\text { (MW) }\end{array}$} \\
\hline & & $\begin{array}{l}\text { Proposed } \\
\text { (MW) }\end{array}$ & $\begin{array}{c}\text { Winning } \\
\text { Bids } \\
\text { (MW) }\end{array}$ & $\begin{array}{l}\text { Proposed } \\
\text { (MW) }\end{array}$ & $\begin{array}{l}\text { Winning } \\
\text { Bids } \\
\text { (MW) }\end{array}$ & $\begin{array}{l}\text { Proposed } \\
\text { (MW) }\end{array}$ & Winning & \\
\hline \multicolumn{2}{|l|}{$\begin{array}{l}\text { All-Source } \\
\text { Bidding Programs }\end{array}$} & & & & & & & \\
\hline Central Maine \#1 & 100 & 666 & 0 & 35.6 & 16.6 & 13 & 6 & $\sim 65-105$ \\
\hline Central Maine \#2 & $150-300$ & 2338 & 50 & 30.4 & 9.2 & 9 & 2 & $\sim 65-105$ \\
\hline ORU & 200 & 1395 & 181 & 29 & 17.5 & 15 & 11 & $\sim 76$ \\
\hline JCP\&L & 270 & 712 & 235 & 56 & 26 & 8 & 4 & $\sim 200$ \\
\hline PSE\&G & 200 & 654 & 210 & 46.7 & 46.7 & 9 & 9 & $\sim 360$ \\
\hline Puget Power & 100 & 1251 & 127 & 28 & 10 & 8 & 5 & $\sim 100$ \\
\hline PSI & 550 & 1800 & 640 & 78.5 & $10^{\circ}$ & 9 & 2 & $\sim 5$ \\
\hline NiMo & 350 & 7115 & 405 & 162.5 & 36 & 33 & 7 & $\sim 50$ \\
\hline Con Ed & 200 & 2976 & 204 & 11.9 & 10.5 & 4 & 3 & $\sim 50$ \\
\hline \multicolumn{2}{|l|}{$\begin{array}{l}\text { Separate } \\
\text { Auctions }\end{array}$} & & & & & & & \\
\hline Long Island Light & $15-20$ & & & 23 & 10 & 11 & 3 & $\sim 50$ \\
\hline \multicolumn{9}{|l|}{$\begin{array}{l}\text { Performance } \\
\text { Contracting }\end{array}$} \\
\hline $\begin{array}{l}\text { New England: DSM } \\
\text { Elect. System: Supply }\end{array}$ & 1 & 4729 & 204 & & 13.6 & 4 & 3 & $\sim 326$ \\
\hline $\begin{array}{l}\text { Boston: DSM } \\
\text { Edison: Supply }\end{array}$ & 200 & 2800 & 200 & & 35 & & 13 & $\sim 170$ \\
\hline
\end{tabular}


ment negotiated by various interested parties, which proscribes a set of procedures for the state's electric utilities to use in purcitasing energy and capacity from independent power producers and conservation providers. In June 1989, Puget Power issued an RFP seeking $100 \mathrm{MW}$ of electricity from DSM and generation resources by 1993. Puget Power limited its DSM solicitation to commercial and industrial customers. As part of an all-sources integrated resource bidding program, Public Service of Indiana (PSI) issued a Request for Expressions of Interest to customers and third parties interested in proposing DSM projects that would shift demand to off-peak, reduce coincident electricity demand, and conserve energy during peak times. PSI has structured its bidding program so that it maximizes the utility's flexibility in selecting third party firms with whom it wants to develop a long-term partnership. The seven investor-owned utilities in New York are at different stages of implementing pilot bidding programs, based on an order issued by the New York Public Service Commission in June 1988. While the Commission established some common features to be used in bidding systems of all utilities, the utilities were allowed somediscretion and flexibility in designing their solicitations, so that a variety of approaches is being tested.

Typically, there have been four to fifteen DSM bids submitted by ESCOs or individual customers, with one exception-Niagara Mohawk (NiMo). These demand-side bids typically represented about $20-25 \%$ of the utility's requested resource need, ranging from a low of $6 \%$ for Consoltdated Edison (Con Ed) to a high of $46 \%$ for NiMo. Additional players appear to be entering the DSM bidding market as evidenced by the increasing number of firms that are bidding and the aggregate level of demand reductions offered in more recent solicitations. For example, NiMo received 33 DSM bids that proposed $162 \mathrm{MW}$ of demand reductions. However, ESCOs are also being more selective, as illustrated by the relatively small number of bids received by $\mathrm{Con} \mathrm{Ed}$, a comparably sized utility (only four bids which offered 12 MW of demand reductions). Con Ed's threshold and eligibility requirements were much more stringent than those of most other utilities and this appears to have affected the response of potential DSM bidders.

Thus far, ESCOs constitute the vast majority of bids; few individual customers are participating directly in these programs. There are some notable exceptions: CMP received five bids from customers in its December $1987 \mathrm{RFP}$ and NiMo received three customer bids. However, most other utilities have gotten only one to two small bids from individual customers.

Projects proposed by DSM bidders have a relatively strong likelihood of winning (20-100\%, in the nine "all-source" solicitations). While the response by conservation providers has been encouraging, it pales in comparison to the offers made by independent power producers. Typically, the number of MWs offered ranges from three to fifteen times the capacity requested by the utility. With the exception of CMP, utilities have generally selected one or more winining supply projects representing about 90-125\% of the utility's original amount requested. Individual supply-side projects typically have only a $5-15 \%$ chance of being selected.

In the last column of the Table, we show the utility's current estimate of the cumulative load reductions that will occur from existing or planned conservation and lond management programs by the mid-1990s (1.2., 1994-1995), which is the same time-frame that DSM bidders must achieve their savings targets in the current bidding programs. It is useful to compare the MW savings represented by the winning bidders with the overall DSM goals of the utility to gain a perspective on the relative contribution of DSM bidding programs, The amount of DSM savings proposed by winning bidders while significant (e,g, 9 to $47 \mathrm{MW}$ s over a threeto five-year period for the nine integrated bidding programs), typically represents a relatively small part of a utility's overall DSM program (10-15\%). At Con Ed, however, DSM bidding accounts for only about $2 \%$ of the utility's expected DSM resource savings. We belleve that the rather small contribution of DSM bidding programs to overall utility DSM goals is primarily attributable to four factors: 1) bidding programs are not appropriate for all market segments or program types (e.g., new construction); 2) utilities are often skeptical and, in some cases, hostile towards DSM bidding; 3) the ESCO industry is still maturing, and 4) the fact that ESCOs are adopting a cautious approach given the risks associated with guaranteeing the savings and their limited experience with DSM bidding. The relative immaturity of the ESCO industry means that the quantities bid under DSM bidding programs will be relatively small and will not reflect the full market potential of DSM.

Future work will focus on analyzing the costs and benefits of DSM bidding programs, as more information becomes avallable on actual impacts.

\section{Reference}

Goldman CA, Wolcott D. Demand-Side Bidding: Assessing Current Experience. In: Proceedings of tho ACEEE 1990) Summer Study on Energy Efficiency in Buildings, Algust 26-September 1, 1990. Washington, DC: American Council for an Energy-Efficient Economy (Vol. 16, in press, 1990). 


\section{Projects described in this report were supported by the following sources:}

- Assistant Secretary for Conservation and Renewable Energy, U.S. Department of Energy: Office of Buildings and Community Systems, Building Systems Division Office of Buildings Energy Research, Building Equipment Division Office of Building Energy Research, Building Systems and Materials Division Deputy Assistant Secretary for Building Technologies, Office of Codes and Standards

- Deputy Assistant Secretary for Coal Technology, U.S. Department of Energy

- Office of Policy, Planning and Analysis, Office of Environmental Analysis, U.S. Department of Energy

- U.S. Environmental Protection Agency Office of Policy, Planning, and Evaluation

Office of Policy Analysis, Division of Global Climate Change

- U.S. Agency for International Development

- Bonnev alle Power Administration

- California Institute for Energy Efficiency

- Gas Research Institute, Residential/Commercial Technology Analysis Division, under GRI Contract No. 5086-800-1318

- Electric Power Research Institute

- University-wide Energy Resources Group of the University of California, Berkeley

- Los Angeles Department of Water and Power

- American Council for an Energy Efficient Economy

- California Energy Commission

- AB Volvo

- Exxon USA

- Nissan North America

- Stockholm Environment Institute

- World Bank

- International Development Research Center, Ottawa, Canada

- Venezuelan Ministry of Energy and Mines

- PDVSA, the national Venezuelan oil company

This support was provided through the U.S. Department of Energy under Contract No. DE-AC03-76SF00098. 
DATE FILMED $4 / 16 / 92$ 
